\title{
Desenvolvimento e CaRacterizaÇão Físico-Química de UM Sistema PARA LiberaçÃo InTRACANAL de EPIGALOCATEQUinA-3-Galato E SEU EFEITO NA COR DOS Dentes.
}

\author{
Dissertação apresentada à Faculdade de Odontologia de \\ Ribeirão Preto da Universidade de São Paulo para \\ obtenção do título de Mestre em Ciências. Programa: \\ Odontopediatria \\ Área de Concentração: Odontopediatria \\ Orientadora: Profa. Dra. Andiara De Rossi
}




\section{AUTORIZAÇÃo PARA REPRODUÇÃo}

Autorizo a reprodução e/ou divulgação total ou parcial da presente obra, por qualquer meio convencional ou eletrônico, desde que citada a fonte.

\section{Ficha Catalográfica}

Ferreira, Danielly Cunha Araújo

Desenvolvimento e caracterização físico-química de um sistema para liberação intracanal de Epigalocatequina-3-galato e seu efeito na cor dos dentes. Ribeirão Preto, 2013.

99p. : il. ; $30 \mathrm{~cm}$

Dissertação de Mestrado, apresentada à Faculdade de Odontologia de Ribeirão Preto/USP - Área de Concentração: Odontopediatria.

Orientador: De Rossi, Andiara

1. Epigalocatequina-3-galato 2. Análise físico-química 3. Medicação intracanal 4. Alteração de cor dental 
Ferreira DCA. Desenvolvimento e caracterização físico-química de um sistema para liberação intracanal de Epigalocatequina-3-galato e seu efeito na cor dos dentes.

Dissertação apresentada à Faculdade de Odontologia de Ribeirão Preto da Universidade de São Paulo, para obtenção do Título de Mestre em Ciências. Área de Concentração: Odontopediatria.

Data da defesa:

1

\section{BANCA EXAMINADORA}

Prof. Dr.

Julgamento Assinatura

Prof. Dr.

Julgamento Assinatura

Prof. Dr.

Julgamento Assinatura 



\section{Danielly Cunha Araújo Ferreira}

Dados Curriculares

Nascimento 05 de outubro de 1986 - Uberlândia/MG

Filiação Evandro Araújo Ferreira (in memorian)

Marta da Cunha

2004-2008 Curso de Graduação

Faculdade de Odontologia da Universidade Federal de Uberlândia - FOUFU

2009-2011 Curso de Especialização em Odontopediatria

Faculdade de Odontologia da Universidade Federal de Uberlândia - FOUFU Monografia intitulada "Técnicas de gerenciamento comportamental em Odontopediatria: atitudes dos pais de crianças com e sem necessidades especiais"

2011-2012 Curso de Aperfeiçoamento no Atendimento Odontológico à Pacientes Especiais

Faculdade de Odontologia de Ribeirão Preto da Universidade de São Paulo FORP/USP

2011-2013 Curso de Pós-Graduação em Odontopediatria, nível de Mestrado

Faculdade de Odontologia de Ribeirão Preto da Universidade de São Paulo FORP/USP - Dissertação intitulada "Desenvolvimento e caracterização físicoquímica de um sistema para liberação intracanal da Epigalocatequina-3galato e seu efeito na cor dos dentes." (Bolsa CNPQ) 

A Deus, pela minha vida e saúde com que me permitiu chegar até aqui. Obrigado por Ser minha fortaleza, pelo seu amor incondicional, pelo carinho, pelo cuidado comigo e minha família.

Tua constante presença com certeza foi o grande apoio que me fez chegar atéo fim. Muito Obrigada pela conquista!

A Nossa Senhora, por estar à minha frente me guiando e iluminando meus caminhos. Por ser presença constante em minha vida, nunca desviar Vosso olhar benigno e me proteger e fortalecer nos meus momentos de ansiedade e insegurança. 

A minha mãe Marta da Cunha, pelo amor incondicional e pela admirável arte de educar. Obrigada por me ensinar os princípios da ética, respeito e responsabilidade. Agradeço pela educação que me foi dada e pelos "nãos" recebidos que com certeza hoje me fazem uma pessoa melhor. Obrigada mãe por investir em mim e por não acreditar que seria difícil toda essa trajetória, pois você conseguiu. Agradeço por respeitar minhas decisões e me orientar nos momentos de confusão. Mamãe, obrigada pelo amor, segurança, apoio e compreensão que encontro em você, pois você é meu porto seguro em momentos de dificuldades.

\section{Esta conquista também é sua!}

Aos meus queridos avós Ambrosina Araújo Ferreira, Lourdes Jacinta da Cunha e Synval Amaro da Cunha, sem vocês essa conquista não seria possível! Obrigada pelo amor, apoio, incentivo e amizade incondicional. Obrigada por me incentivar a sempre continuar aprimorando meus conhecimentos. Amo vocês!

Ao meu namorado, Vinicius Rodrigues de Oliveira, meu companheiro de sempre. Obrigada pelo apoio e companheirismo durante essa trajetória. Obrigada pela compreensão nos momentos de ausência e agradeço por acreditar na minha capacidade. Amo você!

A todos os familiares e amigos que sempre torceram por mim e me deram carinho! 

À minha orientadora Prof'. Dr'. Andiara De Rossi, agradeço pela paciência com que me transmitiu seus ensinamentos e por compartilhar comigo suas experiências pessoais e profissionais. Andi, obrigada por ter sido mais que uma orientadora, você é uma grande amiga com quem pude compartilhar minha vida e aprender muito. Agradeço pelos conselhos dados nos momentos oportunos e pela compreensão com que soube contornar as minhas limitações, não permitindo que isso se tornasse um obstáculo em minha vida profissional. Expresso meu sincero agradecimento e meu profundo respeito, que sempre serão pouco diante do muito que me ofereceu. Agradeço pelas palavras, tempo e atenção dedicados a mim e pela orientação na minha formação profissional. Agradeço pela confiança com que acreditou em mim, para o desenvolvimento deste trabalho e por não medir esforços para me ajudar durante esta trajetória. Agradeço por Deus ter colocado você no meu caminho!

\section{Obrigada por ter acreditado em mim!}

A Profa. Dra. Léa Assed Bezerra da Silva, pela oportunidade de me permitir fazer parte deste Departamento e por ter me acolhido de forma tão especial. Agradeço por todos os ensinamentos transmitidos e por ser uma inspiração para minha carreira profissional, pois com certeza a sua determinação, objetividade e segurança nas tomadas de decisões, serão sempre um grande exemplo a seguir. Obrigada por acreditar na minha capacidade, por me tratar com tanto carinho e atenção e pelo incentivo constante ao aprendizado e à Pesquisa. Serei eternamente grata por tudo o que me proporcionou.

Ao Prof. Dr. Paulo Nelson-Filho, pela forma carinhosa que tanto me acolheu. Agradeço pela atenção em transmitir todo seu conhecimento. Obrigada pelos conselhos e pela colaboração no desenvolvimento deste trabalho. Agradeço pelo exemplo de ética, profissionalismo e dedicação ao ensino. 
A Profa. Dra. Raquel Assed Bezerra da Silva, obrigada pelo apoio e incentivo que sempre me oferece. Agradeço pela atenção e presteza que sempre me recebeu nos momentos de dúvidas e inseguranças. Agradeço pela sua colaboração e atenção na realização deste trabalho.

A Profa. Dra. Alexandra Mussolino de Queiroz, agradeço pela forma carinhosa com que sempre me acolheu e a todos que estão a sua volta. Obrigada por me ensinar de forma tão paciente a arte de aprender. Danda, obrigada pela dedicação e participação na minha vida profissional, pois você sempre estava junto para me orientar, me corrigir e me ensinar e por tudo que você fez por mim durante esta trajetória, te agradeço imensamente.

Ao Prof. Dr. Roberto Santana da Silva, pela forma peculiar que me ajudou a desenvolver este trabalho. De forma tão paciente me passou todos as diretrizes para que este trabalho fosse desenvolvido de forma clara e objetiva. Agradeço pela sua dedicação, apoio e atenção, que sempre me recebe nos momentos de dificuldades, desde o início, que foram fundamentais para a realização deste trabalho.

A Prof". Dro. Juliana Cristina Biazotto de Moraes, agradeço, pois sem você este trabalho não teria sido possível. Muito obrigada pela forma carinhosa, paciente, educada e alegre com que sempre me recebeu em seu laboratório. Agradeço por ter me transmitido todos os ensinamentos para a realização deste trabalho. Se não fosse você com sua insistência e determinação e me ajudar nessa trajetória, esse trabalho não teria acontecido. Obrigada por me ensinar a caminhar os primeiros passos nesse universo que era tão novo para mim.

A Prof". Dra. Alessandra Maia de Castro Prado e Prof". Dra. Fabiana Sodré de Oliveira, agradeço pela minha formação. Pelo carinho, atenção, respeito e presteza com que sempre me receberam durante a Graduação e Especialização. Obrigada por me incentivarem a sempre continuar aprimorando meus estudos e estarem sempre a disposição para me ajudar e colaborar no meu aprendizado e crescimento. Adoro vocês! 
À Faculdade de Odontologia de Ribeirão Preto da Universidade de São Paulo, na pessoa do atual diretor Prof. Dr. Valdemar Mallet da Rocha Barros e da ViceDiretora Prof ${ }^{a}$. Dra ${ }^{a}$. Léa Assed Bezerra da Silva.

A Coordenação do Curso de Pós-Graduação em Odontopediatria da Faculdade de Odontologia de Ribeirão Preto da Universidade de São Paulo, na pessoa da Coordenadora Prof ${ }^{a}$. Dr ${ }^{a}$. Léa Assed Bezerra da Silva e da Vice-Coordenadora Prof ${ }^{a}$. Dr ${ }^{a}$. Raquel Assed Bezerra da Silva.

À Prof ${ }^{a}$. Or ${ }^{a}$. Sada Assed, pelos princípios de determinação, amor à vida e dedicação ao Ensino.

A Prof ${ }^{a}$. Dra . Aldevina Campos de Freitas, grande exemplo de dedicação, paciência, determinação e amor à profissão. Professora, muito obrigada pelos conhecimentos teóricos e clínicos transmitidos durante esta trajetória.

Ao Prof. Dr. Mário Roberto Leonardo, exemplo de simpatia, respeito, humildade e amor ao próximo. Meu sincero agradecimento por todos os seus preciosos ensinamentos que serão sempre lembrados por mim.

A Prof ${ }^{a}$. Dra. Maria Cristina Borsatto, ótima companheira para todas as horas. Exemplo de bom-humor e alegria. Cris, obrigada pelas conversas e pela disponibilidade em ajudar e ensinar.

Aos Professores da Disciplina de Ortodontia da Faculdade de Odontologia de Ribeirão Preto da Universidade de São Paulo, Prof. Dr. Adílson Thomazinho, Prof. Dr. Fábio Lourenço Romano, Prof. Dr. José Tarcísio Lima Ferreira, Prof ${ }^{a}$. Dra. Maria 
Bernadete Sasso Stuani e Profa. Dra. Mírian Aiko Nakane Matsumoto, pela agradável convivência, pelas conversas atenciosas e pelos conhecimentos transmitidos.

A Profa. Dra. Maria da Conceição Pereira Saraiva, professora da Disciplina de Epidemiologia, pela atenção e pela disponibilidade em ajudar sempre.

Aos funcionários do Departamento de Clínica Infantil da Faculdade de Odontologia de Ribeirão Preto:

Dr. Francisco Wanderley Garcia de Paula e Silva, muito obrigada por sempre me ajudar e por ter sempre uma palavra de incentivo. Obrigada pelas orientações nas clínicas e por estar sempre disponível a colaborar com nossa educação e aprendizagem. Agradeço pela convivência agradável, e por dividir suas experiências e conhecimentos.

Dra. Carolina Paes Torres Mantovani, obrigada pela forma tão atenciosa e alegre em me acolher, pela disposição em ajudar sempre. Sua bondade, alegria e simpatia tornam os dias mais agradáveis.

Marco Antônio dos Santos, obrigada pela convivência, pela colaboração nos trabalhos que desenvolvi ao logo desse período no departamento.

Nilza Letícia Magalhães, minha amiga, obrigada pela participação em trabalhos desenvolvidos durante esse período. Obrigada por dividir suas experiências comigo e por estar sempre disposta a ajudar. Nilza a sua alegria é contagiante e isso proporciona um ambiente de trabalho extremamente agradável. Te agradeço pelas conversas e pelos desabafos, muito obrigada por me ajudar nesse período que não foi nada fácil. Você minha eterna amiga!

Fátima Aparecida Jacinto, pela companhia no laboratório, pelas ajudas oferecidas e pelo apoio de sempre. 
Filomena Leli Placciti, obrigada pela alegre convivência, pela forma simpática e carinhosa que sempre nos recebe diariamente.

Matheus Morelli Zanela, obrigada pela paciência, atenção e disponibilidade. Agradeço pelo convívio agradável e pelo carinho.

Micheli Cristina Leite Rovanholo, pela dedicação e apoio durante todo o curso. Mi, obrigada pelo carinho, atenção e paciência com que sempre me dispensou.

\section{Benedita Viana Rodrigues, Fátima Aparecida Rizoli e Renata Aparecida} Fernandes, pela atenção e apoio na Clínica de Pacientes Especiais. Agradeço pela forma amiga, simpática e alegre que sempre me acolhem.

Aos meus amigos e colegas de turma do Mestrado, por compartilhar momentos maravilhosos, por dividir experiências e dificuldades, pelo companheirismo e amizade.

Aos alunos do Programa de Pós-Graduação em Odontopediatria da Faculdade de Odontologia de Ribeirão Preto da Universidade de São Paulo, pela agradável convivência, pelas conversas divertidas e pelos momentos compartilhados.

À minha amiga Karina Alessandra Michelão Grecca Pieroni, uma grande amiga que Deus colocou no meu caminho. Obrigada por sua amizade verdadeira, pelo seu carinho, por me incentivar e ajudar sempre. Obrigada pelos ótimos conselhos, pelas infinitas conversas, pelas nossas trapalhadas e risadas e, principalmente, por me dar forças nos momentos de dificuldade. Ka, minha "mãe" muito obrigada por tudo, você é especial para mim.

Aos funcionários do Biotério Antônio Sérgio Aparecido Mesca, Aline Aparecida Ferraresi Tiballi, pela gentileza e simpatia com que me receberam 
diariamente. Obrigada por terem sido tão prestativos e atenciosos e pelo cuidado no tratamento dos animais.

Aos funcionários da Clínica I da Faculdade de Odontologia de Ribeirão Preto da Universidade de São Paulo, José Aparecido Neves do Nascimento, Vera do Nascimento Scandelai e Karina Dadalt Quaglio, obrigada pela prontidão em me atender, pela alegre convivência, pelo apoio e carinho.

Aos funcionários da Seção de Pós-Graduação da Faculdade de Odontologia de Ribeirão Preto da Universidade de São Paulo, Isabel Cristina Galino Sola, Regiane Cristina Moi Sacilloto e Leandro Marin Silva, pela atenção, pelo carinho e por estarem sempre à disposição.

À secretária do Curso de Especialização em Ortodontia, Rosemary Alves de Sá, pela elaboração do fluxograma. Rose, obrigada pela disponibilidade, atenção e pelo auxilio constante.

Ao CNPQ (Conselho Nacional de Desenvolvimento Científico e Tecnológico), pela bolsa concedida em 2011. 


\section{RESUMO}

Ferreira, DCA. Desenvolvimento e caracterização físico-química de um sistema para liberação intracanal de Epigalocatequina-3-galato e seu efeito na cor dos dentes. Ribeirão Preto, 2013. 99p. [Dissertação de Mestrado]. Ribeirão Preto: Faculdade de Odontologia de Ribeirão Preto da Universidade de São Paulo; 2013.

O chá-verde apresenta efeitos terapêuticos na saúde geral, principalmente em função da epigalocatequina-3-galato (EGCG), componente com comprovada ação antioxidante, antiinflamatória, antimicrobiana, inativadora de endotoxina bacteriana e mineralizadora. Nesse sentido, a EGCG poderia apresentar papel promissor como medicação intracanal, durante o tratamento endodôntico de dentes portadores de necrose pulpar e lesão periapical. Assim, o objetivo deste estudo foi desenvolver um sistema de liberação tópica de EGCG, para uso no interior do sistema de canais radiculares, caracterizar suas propriedades físico-químicas bem como avaliar a possível alteração de cor dental após sua aplicação no interior dos canais radiculares de dentes decíduos e permanentes. Inicialmente, foi realizada a caracterização físico-química da EGCG por meio de espectrofotometria em Ultravioleta/Visível (UV/Vis), fluorescência e titulação potenciométrica. A seguir, foi desenvolvida uma formulação para liberação tópica prolongada de EGCG, utilizando um veículo viscoso (PEG 400). O comportamento espectral desse novo sistema de liberação de EGCG foi avaliado em função do tempo $(1,2,3,4,5,6,24$ e 27 horas) e na presença de dentes (decíduos e permanentes). Para a análise da possível alteração de cor dental, foram utilizados 20 dentes decíduos e 20 dentes permanentes, uniradiculares, recém-extraídos, provenientes do Banco de Dentes da FORP-USP. A cor da coroa dos dentes foi determinada antes (dia 0) e 21, 42 e 56 dias após a aplicação intracanal de EGCG, veiculada em água ou PEG 400, com auxílio do espectrofotômetro digital VITA Easyshade. De acordo com os resultados físico-químicos, o espectro de absorção da EGCG na região do UV/Vis apresentou um pico máximo em 274 nm e na fluorescência um pico máximo de absorção em 393 nm. A EGCG apresentou estabilidade em função do tempo e em meio ácido, tendo comportamento espectral alterado em contato com dentes decíduos e permanentes. Em meio básico o espectro de absorção da EGCG em luz UV/Vis foi alterado para $323 \mathrm{~nm}$. O sistema de liberação tópica intracanal de EGCG não alterou suas propriedades físico-químicas, mantendo os valores de absorção em UV/Vis $(278 \mathrm{~nm})$ e fluorescência $(377 \mathrm{~nm})$, sua estabilidade em função do tempo e não alterou seu comportamento espectral em contato com dentes decíduos e permanentes. A aplicação do sistema proposto de liberação tópica da EGCG, no interior dos canais radiculares de dentes decíduos e permanentes, não causou alteração de cor dental 
significativa, após o período de 21, 42 e 56 dias. Com base nas metodologias e nos resultados obtidos no presente estudo pode-se concluir que a EGCG apresenta fluorescência e estabilidade em função do tempo e em meio ácido, enquanto em meio básico e na presença de elementos dentais seu comportamento espectral sofre alteração. O sistema desenvolvido para liberação controlada da EGCG manteve suas propriedades físico-químicas, apresentou estabilidade em função do tempo e não foi alterou seu comportamento espectral na presença dos elementos dentais. Ainda, a aplicação intracanal deste sistema não causou alteração de cor da coroa dental.

Palavras-chaves: epigalocatequina-3-galato; análise físico-química; medicação intracanal; alteração de cor dental. 


\section{AbSTRACT}

Ferreira, DCA. Development and characterization of physic-chemical properties of a system for intracanal release of epigallocatechin-3-gallate and its effects on the colour of the teeth. Ribeirão Preto, 2013. 99p. [Dissertação de Mestrado]. Ribeirão Preto: Faculdade de Odontologia de Ribeirão Preto da Universidade de São Paulo; 2013.

Green tea has therapeutic effects on general health, mainly due to epigallocatechin-3-gallate (EGCG), a component with proven antioxidant, anti-inflammatory, antimicrobial, inactivating bacterial endotoxin and mineralization action. In this sense, EGCG could present promising role as an intracanal medication during endodontic treatment of teeth presenting pulp necrosis and periapical lesion. Thus, the objective of this study was to develop a system for topical delivery of EGCG, for use inside the root canal system, characterize their physical and chemical properties as well as to evaluate the possible color change after its application in root canals of deciduous and permanent teeth. Initially, was performed physicochemical characterization of EGCG by spectrophotometry Ultraviolet/Visible (UV/Vis), fluorescence, and potentiometric titulation. Next, a formulation for topical extended release of EGCG using a viscous vehicle (PEG 400) was developed. The spectral characteristic of this new delivery system of EGCG was assessed in function of the medium (acidic, basic or neutral), the time $(1,2,3,4,5,6,24$ and 27 hours) and in the presence of teeth (deciduous and permanent). To the analysis of possible tooth color changes, 20 primary teeth and 20 permanent teeth, single-rooted, freshly extracted, from the Bank of Teeth FORP-USP, were used. The color of the tooth crown was determined before (day 0) and 21, 42 and 56 days after intracanal application of EGCG diluted in water or PEG 400, using a digital VITA Easyshade spectrophotometer. According to results the physicochemical spectrum of absorption of the EGCG showed maximum absorption peak at $274 \mathrm{~nm}$ in the UV/Vis and at $393 \mathrm{~nm}$ in the fluorescence. The EGCG presented stability as a function of time and in acid medium, and its spectral behavior was changed in contact with deciduous and permanent teeth. In basic medium the EGCG absorption spectrum in UV/Vis was changed to $323 \mathrm{~nm}$. The topical delivery system of EGCG intracanal did not change its physicochemical properties, maintaining the values of absorption in UV/Vis $(278 \mathrm{~nm})$ and fluorescence $(377 \mathrm{~nm})$, its stability as a function of time, and does not change its spectral contact with deciduous and permanent teeth. The application of the proposed system for topical delivery of EGCG in the root canals of deciduous and permanent teeth, did not cause significant tooth color change after the period of 21, 42 and 56 days. Based on the methodologies and the results obtained in this study it can be concluded that EGCG presents fluorescence and stability as a function 
of time and in an acidic medium, whereas in basic medium and in the presence of dental elements its spectral behavior is changed. The system developed for EGCG controlled release maintains its physicochemical properties, presents stability with time and does not change its spectral behavior in the presence of dental elements. Yet, the intracanal application of this system did not change the color of the teeth's crown.

Key-words: epigallocatechin gallate; physic-chemical analysis; intracanal dressing; dental colour change. 


\section{SumÁRIO}

INTRODUÇÃO
PROPOSIÇÃO
MATERIAL E MÉTODOS
RESULTADOS
DISCUSSÃO
CONCLUSÃO
REFERÊNCIAS
ANEXOS



Introdução 



\section{INTRODUÇÃO}

Desde a pré-história as plantas têm sido utilizadas como produtos terapêuticos nas formas de cataplasmas, infusão, macerado filtrado, tinturas, unguentos, pomadas, xarope, cápsulas ou in natura. O chá, bebida de origem vegetal muito utilizada na forma de infusão (Mukhtar e Ahmad, 1999), apresenta diversos compostos biologicamente ativos, tais como, flavonoides, catequinas, polifenois, vitaminas e sais minerais, que podem contribuir na prevenção e no tratamento de várias doenças (Trevisanato e Kim, 2000; Basu e Lucas, 2007; Rao e Pagidas, 2010; Senger et al., 2010; Cai et al., 2013).

O chá-verde, originário da planta Camellia sinensis, é uma das bebidas mais populares em todo o mundo e tem recebido atenção especial por apresentar comprovados efeitos na saúde geral (Chung et al., 2001; Pianetti et al., 2002, Chung et al., 2003; Dreger et al., 2007; Lee et al. 2009; Hodgson e Croft, 2010; Prabhakar et al., 2010; Rao e Pagidas, 2010; Yang e Wang, 2010; Subramaniam et al., 2012; Jung et al., 2012; Cai et al., 2013). Seus principais componentes químicos são os flavonoides e as catequinas, que correspondem a aproximadamente $26,7 \%$ do seu conteúdo (Schmitz et al., 2005; Soler et al., 2012). Dentre as catequinas mais encontradas, $11 \%$ são epigalocatequina-3-galato (EGCG), 10\% epigalocatequina (EGC), 2\% galato-3-epicatequina (ECG), 2,5\% epicatequina (EC) e 15\% são polifenois não identificados (Schmitz et al., 2005). Recentemente, a EGCG vem sendo estudada na literatura por ser o componente mais bioativo do chá-verde, apresentando ação antioxidante (Cook e Samman, 1996; Yang et al., 1998; Anghileri e Thouvenot, 2000), anti-inflamatória (Nagle et al., 2006), anti-hipertensiva (Basu e Lucas, 2007), antimicrobiana (Ikigai et al., 1993; Stapleton e Taylor, 2002, Blanco et al., 2003; Rocaro et al., 2004; Prabhakar et al., 2010; Subramaniam et al., 2012; Jung et al., 2012; Cai et al., 2013) e anticarcinogênica (Lee et al. 2009; Yang e Wang, 2010; Kang et al., 2010; Rao e Pagidas, 2010). Estas propriedades conferem à EGCG comprovado efeito terapêutico em diferentes tipos de câncer, degenerações neuronais e doenças cardiovasculares (Chung et al., 2001; Pianetti et al., 2002, Chung et al., 2003; Dreger et al., 2007; Hodgson e Croft, 2010, Itoh et al., 2012; Khan e Mukhtar, 2013; Kokubo et al., 2013).

Na Odontologia o uso terapêutico dos derivados do chá-verde vem sendo proposto na redução da erosão e abrasão dentária (Magalhães et al., 2009), em solução para bochechos (Hirasawa et al., 2006, Jenabian et al., 2012) ou em dentifrícios (Maruyama et al., 2011), principalmente em função de seu elevado espectro de ação contra bactérias Gram-positivas e Gram-negativas, atuando inclusive contra $S$. mutans e $S$. sobrinus por impedir a aderência bacteriana ao dente e inibir a glucosil transferase e a amilase bacteriana (Hamilton-Miller, 
2001; Subramaniam et al., 2012; Jung et al., 2012; Cai et al., 2013). Ainda, por ser biocompatível, a EGCG também foi proposta como meio para a conservação de dentes avulsionados após traumatismos, mantendo a vitalidade das células do ligamento periodontal (Hwang et al., 2011; Jung et al., 2011). Por apresentar efetiva ação antimicrobiana contra $P$. gengivalis (Jung et al., 2012; Cai et al., 2013) e E. faecalis, a EGCG também foi proposta como solução irrigadora dos canais radiculares (Prabhakar et al., 2010). Sugere-se que Bactérias Gram-positivas sejam mais susceptíveis à ação antimicrobiana da EGCG que bactérias Gram-negativas (Yoda et al., 2004). O mecanismo de ação da EGCG nas bactérias Gram-positivas envolve danos na parede celular, causados pela sua ligação direta na camada de peptideoglicano, ao passo o dano na parede celular das bactérias Gram-negativas é induzido pela produção de peróxido de hidrogênio (Cui et al., 2012).

Estudos epidemiológicos revelam que o chá-verde também pode trazer benefícios para a saúde dos tecidos mineralizados, aumentando a densidade mineral óssea (Hegarty et al., 2000; Vestergaard et al., 2001; Choi et al., 2003) e reduzindo os riscos de osteoporose ou fratura (Kanis et al., 2000). Diversos estudos realizados in vitro e in vivo revelam que os benefícios ao tecido ósseo são decorrentes da ação da EGCG na inibição da osteoclastogênese (Lin et al., 2008; Lee et al., 2010; Oka et al., 2012) ou na indução da morte celular de osteoclastos por apoptose (Yun et al., 2007). No entanto, a grande maioria dos estudos acerca das propriedades do chá-verde é realizada na área médica, sendo encontrados apenas dois estudos de seus efeitos potenciais na redução da reabsorção óssea alveolar e periapical. Na Periodontia, o consumo de água contendo EGCG ou sua injeção local no ligamento periodontal reduziu significativamente a perda óssea alveolar experimentalmente induzida por meio da injeção de lipopolissacarídeos (LPS) em camundongos (Nakamura et al., 2010). Na Endodontia, o único estudo disponível revelou que a administração sistêmica (intraperitoneal) de EGCG em ratos resultou em acentuada redução na extensão e na severidade de lesões periapicais associadas a dentes portadores de necrose pulpar (Lee et al., 2009). Diante do exposto, verifica-se que as propriedades biológicas da EGCG poderiam ser utilizadas como coadjuvante no tratamento de canais radiculares de dentes com necrose pulpar e lesão periapical, pois este representa um desafio para o profissional. Seu índice de sucesso clínico, radiográfico, microbiológico e histológico é bastante inferior, em torno de 70\%, quando comparado ao tratamento de dentes portadores de necrose, porém sem lesão periapical, os quais apresentam taxa de sucesso de $90-95 \%$ (Sjögren et al., 1997; Ferreira, 2011; Leonardo, 2012). 
O objetivo principal do tratamento endodôntico é a eliminação da infecção microbiana do sistema de canais radiculares e região periapical, pois estes constituem o agente etiológico principal da doença periapical (Kakehashi et al., 1965; Tronstad, 1992; Kandaswamy e Venkateshbabu, 2010; Kovac e Kovac, 2011; Siqueira et al., 2011; Ján e Daniel, 2012). Sabe-se que o preparo biomecânico do canal radicular não é suficiente para eliminação da infecção, pois ela está disseminada em todo o sistema de canais radiculares, região apical e periapical (Andolfatto et al., 2012; Özok et al., 2012). Assim, as falhas no tratamento vêm sendo principalmente associadas à persistência de microrganismos e seus subprodutos, dentro e fora do canal radicular (Nair et al., 1990; Nair et al., 1999; Siqueira et al., 2011), que resultam na manutenção da lesão inflamatória e da reabsorção tecidual, impedindo o processo de reparação. Isso tem eliciado à busca de novas técnicas e materiais, que sejam biocompatíveis e que promovam efetiva eliminação da microbiota envolvida na lesão periapical, inativação da endotoxina bacteriana, paralização da reabsorção e indução da formação de tecido mineralizado (Leonardo et al., 2002, De Rossi et al., 2005; Leonardo et al., 2006, Siqueira et al., 2007; Victorino et al., 2010, Silva et al., 2010). No entanto, apesar dos recentes avanços fitoterápicos e biotecnológicos, até o momento nenhuma medicação é considerada ideal para o tratamento da doença periapical.

Atualmente os avanços trazidos pela nanotecnologia, no que se refere à tecnologia utilizada para manipular estruturas pequenas e torná-las mais reativas, têm proporcionado o desenvolvimento de novos fármacos. A tecnologia de liberação controlada de substâncias para uso terapêutico oferece inúmeras vantagens quando comparados aos sistemas de aplicação convencionais, por apresentar liberação progressiva e controlada de fármacos com direcionamento a alvos específicos, diminuição significativa da toxicidade e maior tempo de permanência, além de proteção contra mecanismos de instabilidade e decomposição (inativação prematura), reduzindo ou eliminando possíveis reações inflamatórias locais (Mufamadi et al., 2011). Os sistemas convencionais de liberação de drogas são conhecidos por fornecer uma liberação imediata do fármaco, sem controle da quantidade e concentração e tempo de permanência no local, já os sistemas de liberação controlada de drogas oferece controle desses fatores incluindo o local de ação (Keraliya et al., 2012). O sistema de entrega de drogas é geralmente baseado nas propriedades físico-químicas e farmacocinéticas da droga. Sistemas de entrega convencionais sofrem limitações de sincronização mínima entre o tempo necessário para as concentrações plasmáticas terapêuticas eficazes da droga e do perfil de liberação da droga real revelado pela forma de dosagem (Sood et al., 2013). No entanto, para se propor uma medicação intracanal que 
promova liberação controlada da droga é necessário primeiro conhecer as propriedades fotofísicas e fotoquímicas da substância.

A terapia endodôntica não deve se concentrar apenas nos aspectos biológicos, funcionais e técnicos, mas também nas questões estéticas (Krastl et al., 2013). Atualmente, o aumento das exigências estéticas dos pacientes torna importante a avaliação de possíveis mudanças de cor do dente em decorrência de tratamentos odontológicos. Vários materiais colocados em contato com a dentina, durante o tratamento endodôntico, tem o potencial de causar alteração de cor dental e prejudicar o resultado estético de dente tratado (Plotino et al., 2009; Meincke et al., 2012; Krastl et al., 2013). Sabe-se que os fatores ambientais como produtos dietéticos e químicos podem causar alterações na cor do dente, de acordo com a frequência e período de exposição (Moreira et al., 2012). A alteração de cor é resultado de interação física e química entre os tecidos dentais e o agente causador da pigmentação, o qual pode ser intrínseco ou extrínseco (Téo et al., 2010). Visto que estas variáveis são determinantes na alteração de cor dental, é de extrema importância que substâncias químicas, utilizadas como curativo antimicrobiano durante o tratamento endodôntico sejam avaliadas quanto ao potencial de alterar a cor do elemento dental, inclusive o hidróxido de cálcio (Kim et al., 2000; Kim et al., 2000; Tinaz et al., 2008). Considerando que o chá é uma bebida com potencial de causar alteração de cor extrínseca em elementos dentários (Attin et al., 2003) torna-se necessária a avaliação da possível alteração de cor causada em dentes decíduos e permanentes após a aplicação da EGCG.

Diante do exposto, verifica-se que as propriedades anti-inflamatórias, antimicrobianas, mineralizadora, inibidora da reabsorção óssea e inativadora do LPS bacteriano, presentes na EGCG, que já desempenham ação comprovada na prevenção e tratamento de diferentes doenças crônicas, também poderiam desempenhar importante papel no tratamento da doença periapical quando aplicadas topicamente no sistema de canais radiculares. Ainda sua utilização poderia ser proposta por meio de uma formulação que promova liberação prolongada de substâncias, e que a mantenha sua forma ativa ou que potencialize sua eficácia, não causando alteração de cor dental. 
Proposição 



\section{Proposição}

\section{Objetivo geral:}

O objetivo deste estudo foi caracterizar as propriedades físico-químicas da EGCG, desenvolver um sistema de liberação tópica, para uso no interior dos canais radiculares, e avaliar a possível alteração de cor dental após sua aplicação em dentes decíduos e permanentes.

\section{Objetivos especificos:}

- Caracterizar o espectro de absorbância da EGCG na região da luz ultravioleta visível e da fluorescência;

- Determinar o pKa da EGCG em função do pH;

- Avaliar a estabilidade da EGCG em função do tempo, em função do meio (ácido, básico ou neutro) e em contato com dentes decíduos e permanentes;

- Desenvolver um sistema para a liberação prolongada de EGCG no interior dos canais radiculares;

- Caracterizar o espectro de absorbância do sistema proposto para a liberação de EGCG na região da luz ultravioleta visível e da fluorescência;

- Verificar se a estabilidade da EGCG em função do tempo e na presença do dente é alterada nesse sistema de liberação;

- Avaliar o efeito do sistema de liberação intracanal de EGCG, na cor de dentes decíduos e permanentes anteriores. 



\section{Material e Métodos}





\section{Material e Métodos}

Previamente à sua execução, o presente estudo foi submetido à apreciação pelo Comitê de Ética em Pesquisa Envolvendo Seres Humanos da Faculdade de Odontologia de Ribeirão Preto da Universidade de São Paulo, tendo sido aprovado (processo no 2011.1.1450.58.4 - Anexo A).

\section{Reagentes e Soluções}

Foi utilizada a EGCG (E41430; Sigma-Aldrich, St. Louis, MO, EUA), derivada do chá verde, disponível em partículas de $5 \mu \mathrm{m}$, apresentadas no estado sólido. Sua estrutura química $\left(\mathrm{C}_{22} \mathrm{H}_{18} \mathrm{O}_{11}\right)$ está ilustrada na Figura 1.

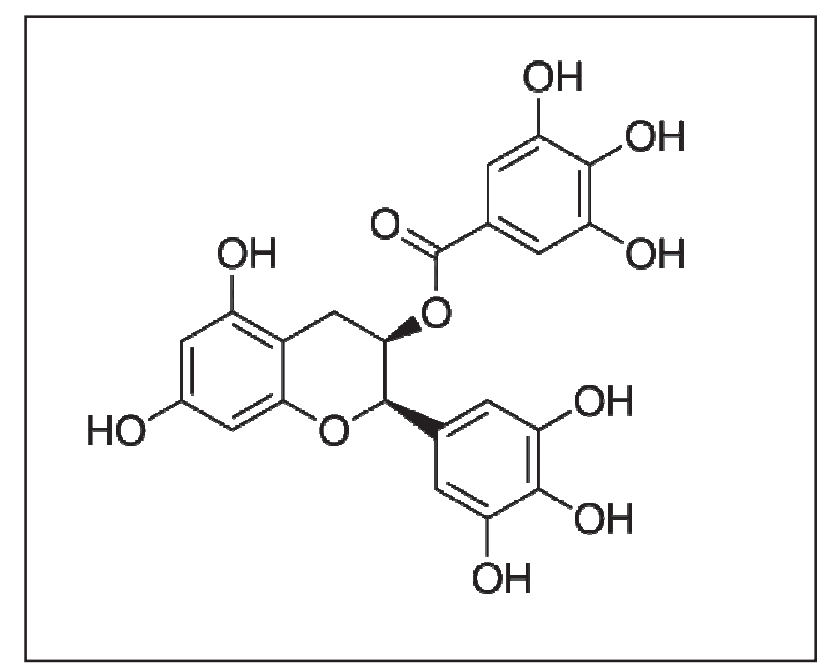

Figura 1. Estrutura química da EGCG $\left(\mathrm{C}_{22} \mathrm{H}_{18} \mathrm{O}_{11}\right)$, massa molecular $458,37 \mathrm{~g} / \mathrm{mol}$.

Para a caracterização físico-química inicial, a EGCG foi manipulada em solução aquosa, de acordo com instruções do fabricante (Anexo B), utilizando água destilada e deionizada proveniente da osmose reversa. A concentração utilizada da EGCG foi calculada baseando-se no valor de $\varepsilon$ que é igual a 11920 pela fórmula $a=\varepsilon . b . c$, onde $a=$ absorbância, $\varepsilon=$ coeficiente de absortividade molar, $b=$ caminho ótico e $c=$ concentração em $\mathrm{mol} / \mathrm{L}$, sendo diretamente proporcional à absorbância.

O sistema proposto para a aplicação tópica da EGCG incluiu sua manipulação em um veículo viscoso, o polietilenoglicol 400 (PEG 400 - Galena Química e Farmacêutica Ltda., Campinas, SP, Brasil), que fornece consistência adequada para sua manutenção por períodos prolongados no interior dos canais radiculares (Ballal et al., 2010; Murad et al., 2008). O 
preparo da EGCG veiculada em PEG 400 incluiu agitação em cuba ultrassônica, para forçar a solubilização. Para a posterior aplicação desse sistema no interior dos canais radiculares, a formulação foi acondicionada em tubetes anestésicos, previamente esterilizados e mantidos em temperatura ambiente.

Todos os materiais foram manipulados e avaliados na temperatura ambiente $\left(37^{\circ} \mathrm{C}\right)$. A massa das substâncias foi determinada em balança elétrica de precisão (Modelo AL500; Marte Balanças, Equipamentos e Aparelhos de Precisão Ltda., SP, Brasil) e o volume determinado com auxílio de micropipetas e béqueres de vidro.

$\mathrm{O} \mathrm{pH}$ das soluções foi determinado com auxílio de pHmetro digital (Digimed modelo DM-20; Digicrom Analítica Ltda, São Paulo, SP, Brasil). Para o ajuste do pH foram utilizadas soluções de ácido clorídrico (HCL, 1 mol/L, 99-100\% de pureza, Sigma-Aldrich Brasil Ltda., São Paulo, SP, Brasil), hidróxido de amônio $\left(\mathrm{NH}_{4} \mathrm{OH}, \mathrm{pH}=10,28-30 \%\right.$ de pureza, SigmaAldrich Brasil Ltda.), hidróxido de cálcio $\left(\mathrm{Ca}(\mathrm{OH})_{2}, \mathrm{pH}=13,99 \%\right.$ de pureza, Jand Química Ind. e Com. de Produtos Químicos Ltda., Brasil) ou cloreto de cálcio $\left(\mathrm{CaCl}_{2}, \mathrm{pH}=7,99 \%\right.$ de pureza, Sigma-Aldrich Brasil Ltda.).

\section{Análise Físico-química}

As análises físico-químicas foram realizadas no Laboratório de Ciências Farmacêuticas, da Faculdade de Ciências Farmacêuticas de Ribeirão Preto da Universidade de São Paulo (FCFRP-USP), com a colaboração dos Profs. Drs. Roberto Santana da Silva e Juliana Cristina Biazzotto de Moares.

A EGCG foi caracterizada por meio de (a) espectroscopia de absorção na região do ultravioleta-visível, realizada em meio neutro, ácido e básico; (b) estabilidade em função do tempo, em meio ácido e em contato com o dente; (c) espectroscopia de fluorescência e (d) titulação potenciométrica (Figura 2).

O sistema proposto para a liberação tópica de EGCG foi caracterizado por meio de (a) espectroscopia de absorção na região do ultravioleta-visível; (b) estabilidade em função do tempo e em contato com o dente e (c) espectroscopia de fluorescência (Figura 3). 


\section{CARACTERIZAÇÃO DA EGCG}

ESPECTRO DE ABSORÇÃO

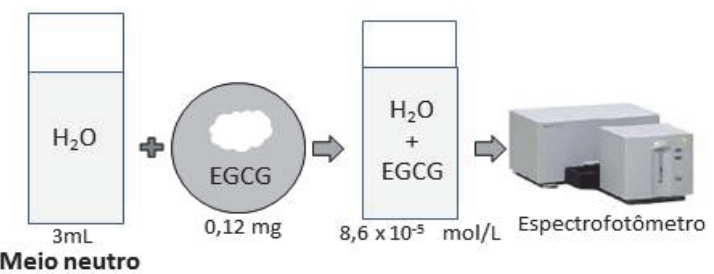

Meio neutro

\section{ESTABILIDADE}
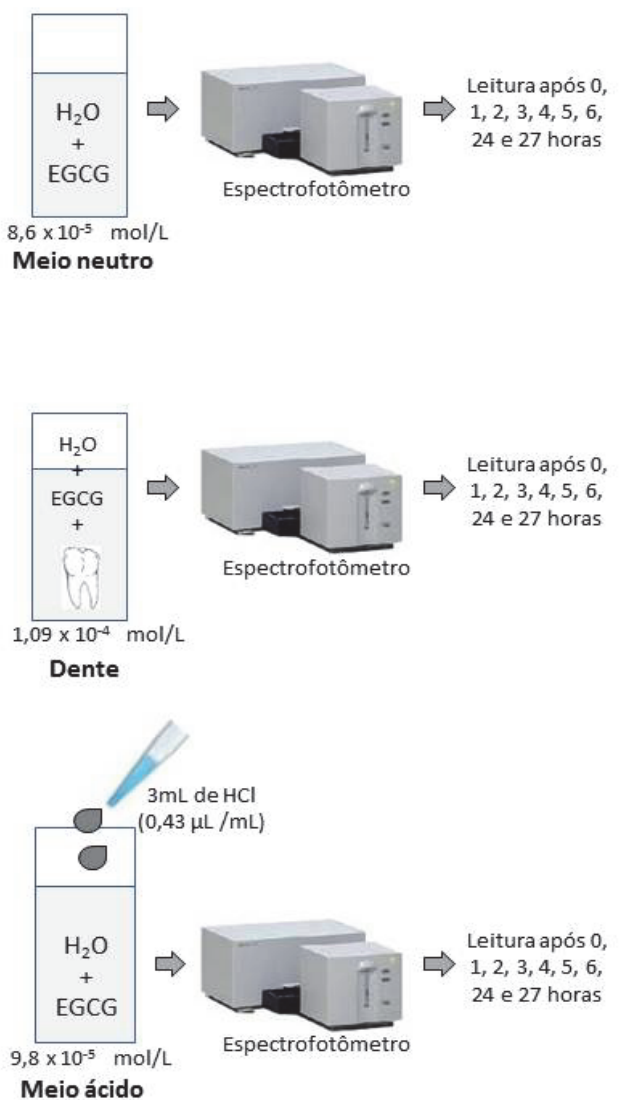

\section{ESPECTRO DE FLUORESCÊNCIA}

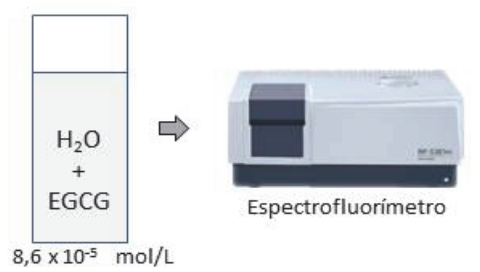

\section{TITULAÇÃo POTENCIOMÉTRICA}

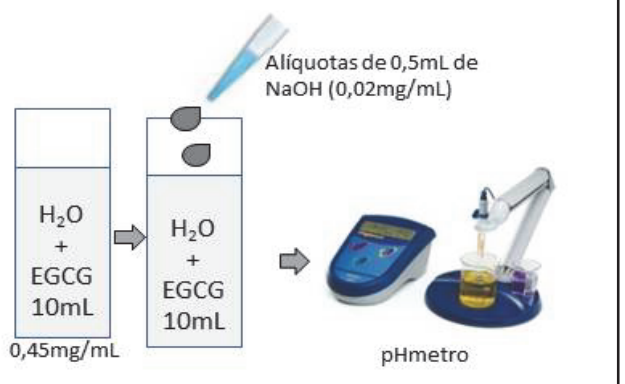

Figura 2. Esquema representativo das metodologias empregadas na análise físico-química da EGCG (veiculada a água). 


\title{
CARACTERIZAÇÃO DA FORMULAÇÃO DESENVOLVIDA PARA LIBERAÇÃO DA EGCG
}

\author{
ESPECTRO DE ABSORÇÃO
}

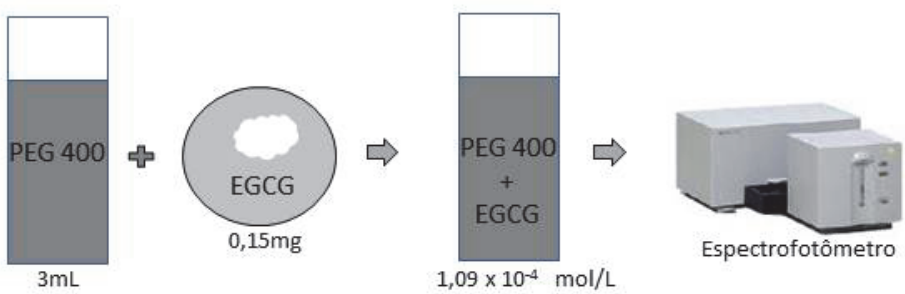

\section{ESTABILIDADE}

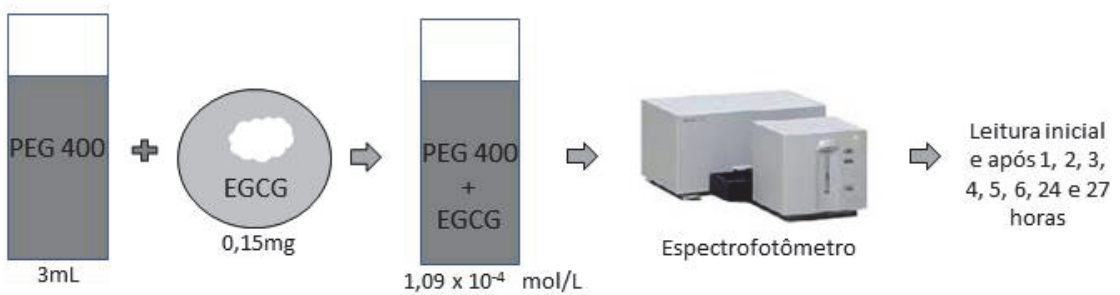

\section{ESTABILIDADE EM CONTATO COM DENTE}

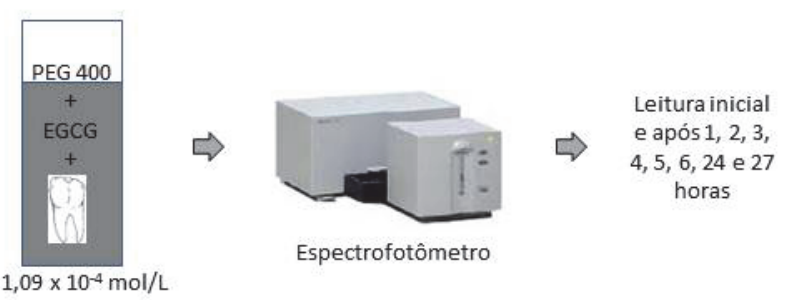

\section{ESPECTRO DE FLUORESCÊNCIA}
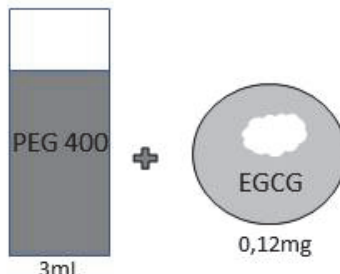

$\Rightarrow$

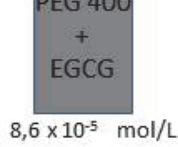

$\Rightarrow$

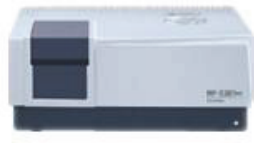

Espectrofluorímetro

$8,6 \times 10^{-5} \mathrm{~mol} / \mathrm{L}$

Figura 3. Esquema representativo das metodologias empregadas na análise físicoquímica da EGCG em formulação desenvolvida para liberação de EGCG (veiculada em PEG 400). 


\section{Espectroscopia de absorção na região do Ultravioleta-Visível}

As medidas espectrofotométricas foram obtidas em um espectrofotômetro UV-Vis Agilent 8453 (Agilent Technologies Deutschland GmbH, Alemanha), acoplado a um sistema de computador e analizados com o software Origin 6.0 (Microcal-TM -OriginR versão 6.0; Microcal Software Inc., USA) (Figura 4).

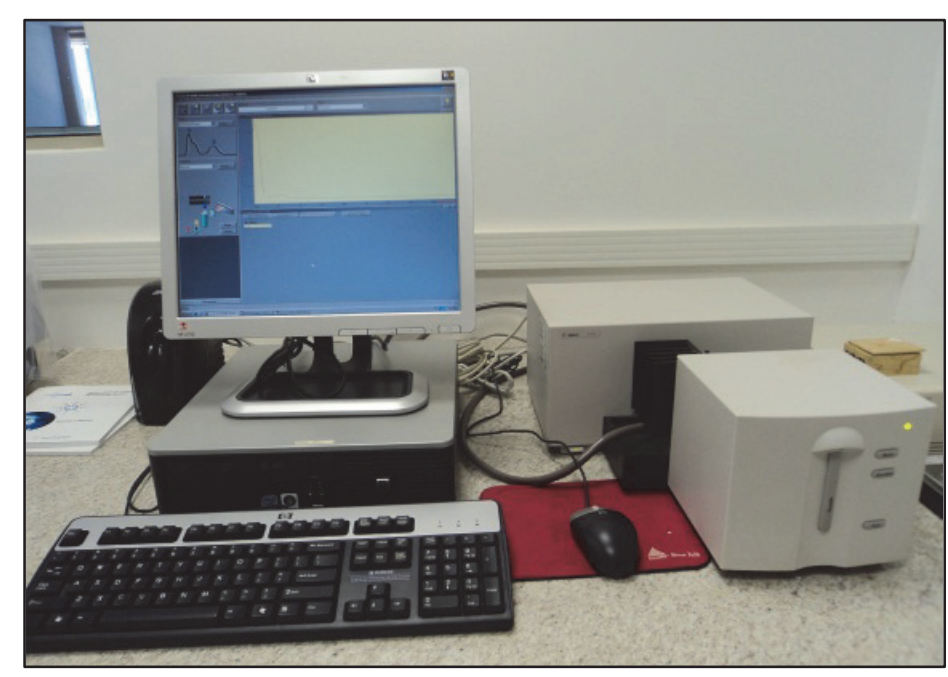

Figura 4. Espectrofotômetro Agilient acoplado ao sistema computadorizado

Para a leitura no espectrofotômetro, as soluções foram colocadas em uma cubeta de quartzo, com caminho óptico de $1 \mathrm{~cm}$ e 2 lados polidos, num volume total de $3 \mathrm{~mL}$. Os espectros foram determinados na faixa de 200 a $400 \mathrm{~nm}$ (luz ultravioleta) e de 400 a 800nm (luz visível). A calibração do equipamento foi realizada antes de cada leitura, em cubeta contendo apenas o solvente (branco). Os espectros foram obtidos a partir da média de três leituras para cada amostra.

A estabilidade da EGCG foi avaliada em função do tempo (0, 1, 2, 3, 4, 5, 6, 24 e 27hs), do meio (neutro, ácido e básico) e da presença de dentes decíduos ou permanentes na solução. Para este estudo, um dente molar humano hígido, decíduo e um permanente, recém-extraído, apresentando raízes íntegras, foram submetidos à abertura coronária realizada pela face oclusal, e imersos nas soluções de EGCG. A abertura foi realizada para aumentar a superfície de contato da substância com o cálcio presente no dente. 


\section{Espectroscopia de Fluorescência}

A espectroscopia de fluorescência foi realizada em um espectrofluorímetro RF-5301 PC Shimadzu (Shimadzu Corporation, Chiyoda-ku, Tokyo, Japão), equipado com uma lâmpada de xenônio de 150 W (Figura 5).

Para a leitura no espectrofluorímetro, as soluções foram colocadas em uma cubeta de quartzo, com caminho óptico de $1 \mathrm{~cm}$ e 4 lados polidos, e submetidas à fendas de excitação (fex) e emissão (fem) variando de 1,5 a $10 \mathrm{~nm}$. Os espectros foram obtidos a partir da média de três espectros para cada amostra. O comprimento de onda de excitação $(\lambda E X)$ inicial foi de 325 a $329 \mathrm{~nm}$, com 1 minuto de excitação em temperatura a $25^{\circ} \mathrm{C}$. A temperatura foi mantida $\pm 2^{\circ} \mathrm{C}$.

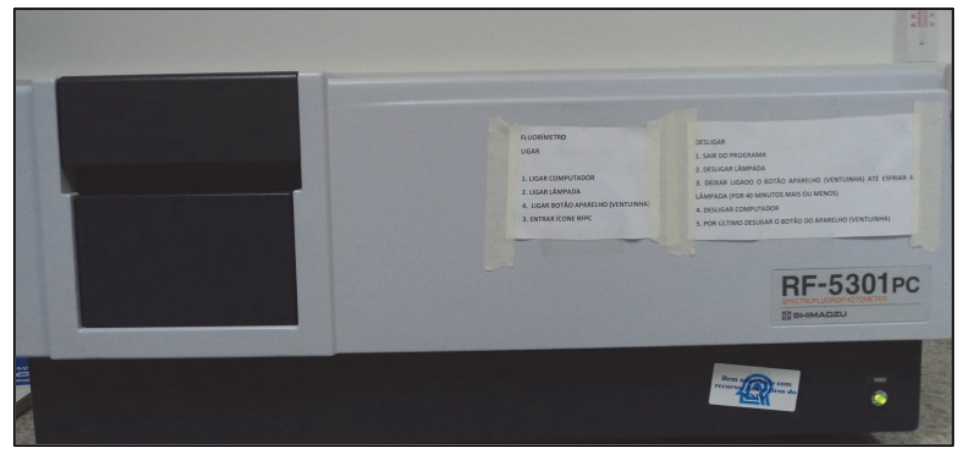

Figura 5. Espectrofluorímetro

\section{Titulação Potenciométrica}

A titulação potenciométrica foi realizada para caracterização do pKa da substância nas formas protonada e desprotonada. As medidas de $\mathrm{pH}$ foram realizadas utilizando-se o pHmetro Digimed DM-20 (Digicrom Analítica Ltda., São Paulo, Brasil) (Figura 6).

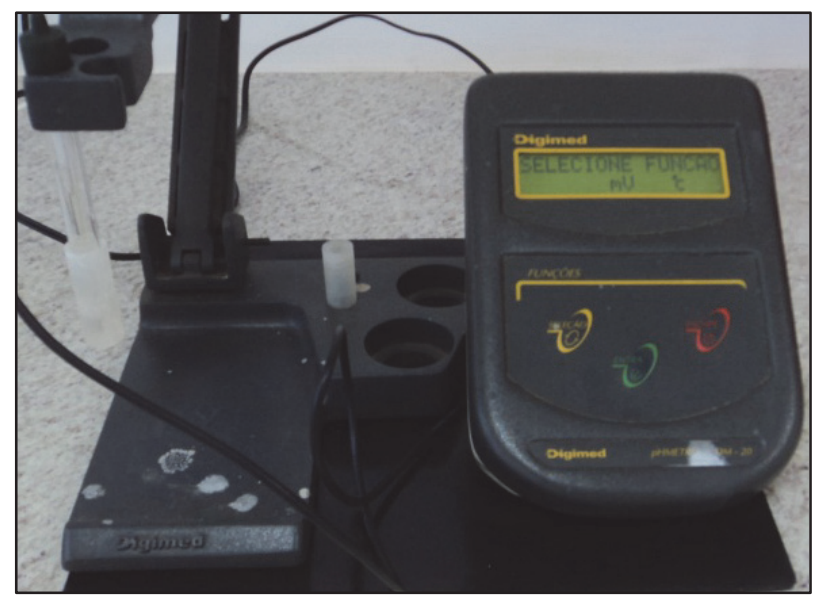

Figura 6. Aparelho pHmetro 
Para esse experimento foram preparados $25 \mathrm{~mL}$ da solução aquosa de EGCG $(1,0$ $\mathrm{mM})$ e $100 \mathrm{~mL}$ de solução de hidróxido de sódio $(1,0 \mathrm{mM})$ em cloreto de potássio $0,1 \mathrm{M}$. Colocou-se em uma bureta, $25 \mathrm{~mL}$ de solução de hidróxido de sódio e $10 \mathrm{~mL}$ da solução de EGCG em um béquer. As medidas foram efetuadas a cada adição de alíquotas de 0,5 $\mathrm{mL}$ da solução de hidróxido de sódio sobre a solução de EGCG, sob agitação. Ao total foram adicionados 20 mL de solução de hidróxido de sódio à solução de EGCG.

\section{Análise da Cor dos Dentes}

A cor da coroa dos dentes foi determinada com auxílio do espectrofotômetro digital VITA Easyshade (Wilcos Brasil Indústria e Comércio Ltda, SP, Brasil) (Figura 7) no Laboratório do Departamento de Materiais Dentários e Prótese, por gentileza da Profa. Dra. Fernanda de Carvalho Panzeri Pires-de-Souza.

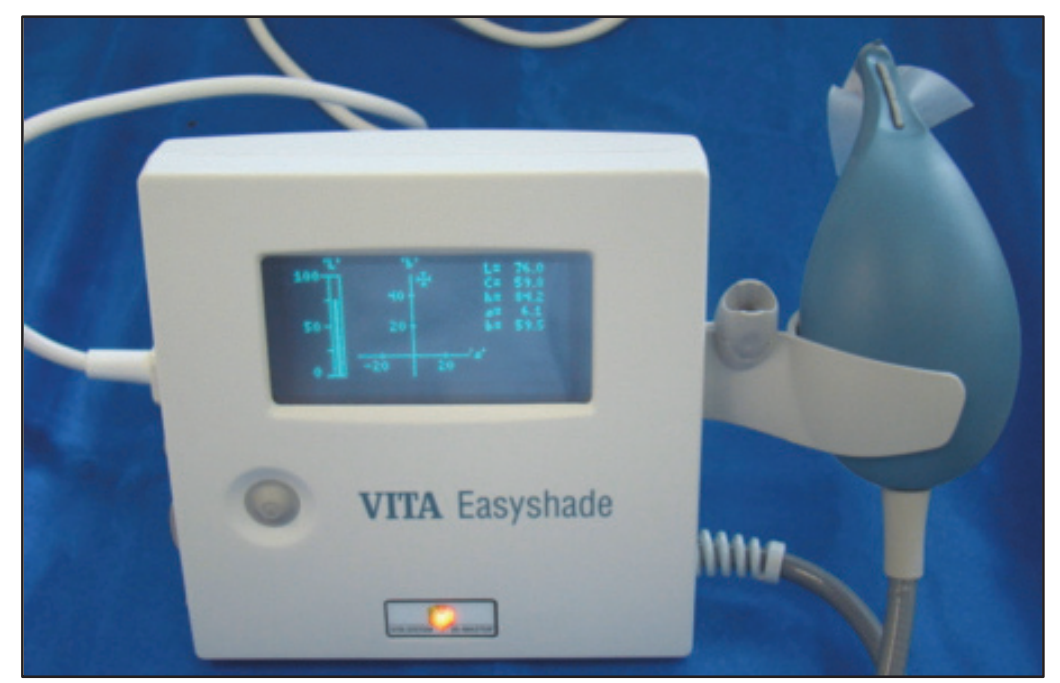

Figura 7. Aparelho VITA Easyshade

O padrão de observação, simulado pelo colorímetro espectofotométrico, seguiu o sistema CIELAB recomendado pela CIE (Comission Internationale de I'Éclairage). Este consiste de dois eixos $a *$ e b*, que possuem ângulos retos e representam a dimensão de matiz e saturação das cores verde-vermelha e azul-amarela, respectivamente. 0 terceiro eixo, $L^{*}$, representa a luminosidade (branco-preto) e é perpendicular ao plano $\mathrm{a}^{*} \mathrm{~b}^{*}$. Com este sistema as cores foram determinadas nas coordenadas $L^{*}, a^{*}, b^{*}$ (Figura 8). 


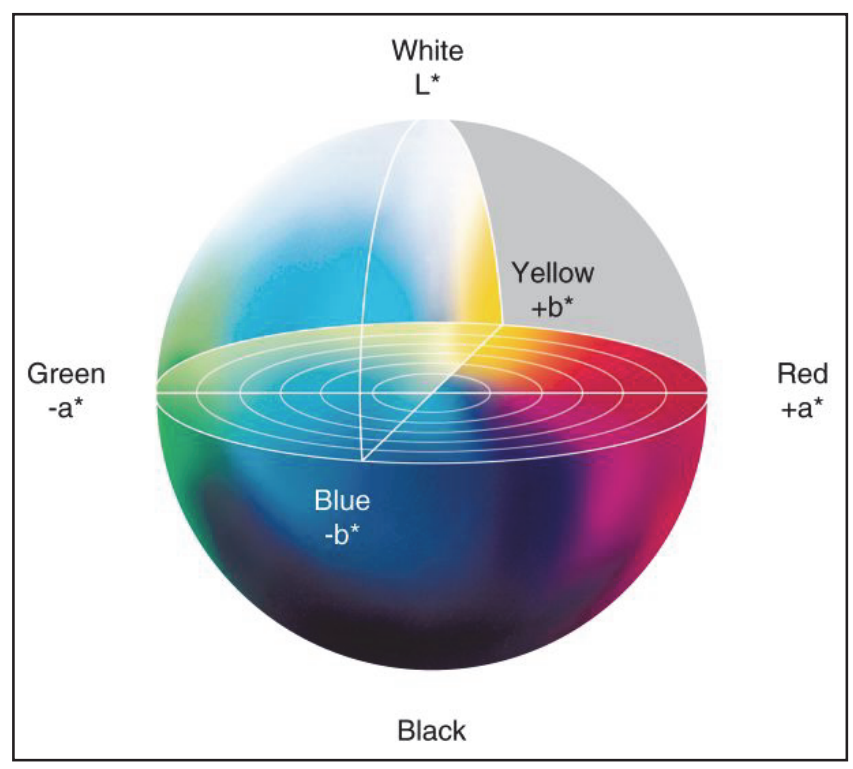

Figura 8. Sistema de coordenadas de cores de CIE L*a*b*(Fonte:disenoypreimpresionmozadr.wo rdpress.com)

As leituras iniciais de cor foram realizadas após abertura coronária e selamento com cimento de ionômero de vidro e as leituras finais aos 21, 42 e 56 dias após a aplicação da EGCG no interior dos canais radiculares, na presença do selamento provisório com CIV. No intervalo entre as leituras os dentes foram mantidos em estufa, com separadores individuais imersos em água destilada na temperatura de $37^{\circ} \mathrm{C}$. As medições foram efetuadas no mesmo ambiente, por um único operador, previamente calibrado. Para cada leitura os dentes foram secos com papel absorvente e colocados em um fundo branco padrão. Os dentes tiveram sua cor avaliada no terço médio da coroa, estando o feixe de luz do aparelho sempre direcionado na mesma região da coroa, permitindo que houvesse uma padronização da realização das leituras sempre na mesma região da coroa. Os valores absolutos de $L^{*}, a^{*}$ $e b^{*}$ foram obtidos a partir de três leituras de cada amostra e em cada período, e o valor médio entre essas três leituras foi considerado.

A partir dos dos valores absolutos foram determinadas as alterações de cor (cor final - cor inicial) de cada eixo, sendo expressas como $\Delta \mathrm{L}, \Delta \mathrm{a}$ e $\Delta \mathrm{b}$, respectivamente (Shi et al., 2012). A estabilidade de cor dos dentes $(\Delta E)$ também foi determinada pela diferença entre as coordenadas obtidas das amostras antes e após a aplicação intracanal da EGCG. O $\triangle E$ foi calculado a partir da fórmula (Attin et al., 2003; Pires-de-Souza et al., 2011; Moreira et al., 2012; Sabatini et al., 2012): 
$\Delta \mathrm{E}=\left[\left(\Delta \mathrm{L}^{*}\right)^{2}+(\Delta \mathrm{a} *)^{2}+\left(\Delta \mathrm{b}^{*}\right)^{2}\right]^{1 / 2}$

Onde:

$\Delta \mathrm{E}^{*}=$ alteração de cor

$\Delta L^{*}=$ diferença do eixo $L^{*}$

$\Delta \mathrm{a}^{*}=$ diferença do eixo $\mathrm{a}^{*}$

$\Delta \mathrm{b}^{*}=$ diferença do eixo $\mathrm{b}^{*}$

\section{Preparo dos dentes decíduos}

Foram selecionados 20 dentes decíduos anteriores superiores e inferiores, extraídos, de humanos, hígidos, com raízes íntegras ou com até $1 / 3$ de rizólise. As superfícies radiculares dos dentes foram cuidadosamente limpas com curetas periodontais e, em seguida, armazenadas em solução de azida de sódio diluída em água destilada, na proporção de 1:4, até o momento da utilização.

Os dentes foram submetidos ao tratamento endodôntico convencional (Figura 9), incluindo a abertura coronária utilizando pontas diamantadas esféricas n 1012 (KG Sorensen Indústria e Comércio, São Paulo, SP, Brasil) em turbina de alta rotação, sob refrigeração. A abertura coronária foi complementada com o uso de ponta diamantada 3083 (KG Sorensen Indústria e Comércio). Uma lima tipo $\mathrm{K} \mathrm{n}^{\circ} 15$ (Dentsply Maillefer, Suiça) foi introduzida no canal radicular até a abertura do forame, para determinação do "Comprimento Real do Dente" (CRD), sendo o "Comprimento Real de Trabalho" (CRT) estabelecido a 1,0 mm aquém da abertura do forame ou do limite do bisel de rizólise. $O$ cursor de borracha foi posicionado tendo como referência a borda incisal da coroa dentária. A medida entre a ponta do instrumento e o cursor foi anotada em ficha sendo esta considerada o CRD. Os dentes foram armazenados em recipientes separados contendo água destilada.

O preparo biomecânico foi realizado utilizando, sequencialmente, limas tipo $\mathrm{K} \mathrm{n}^{\circ} 20$, 25, 30 e 35 no CRT, associadas à copiosa irrigação, aspiração e inundação com hipoclorito de sódio a 0,5\% (Fármacia Daterra, Ribeirão Preto, SP, Brasil), acondicionados em tubetes de anestésicos previamente esterilizados e mantidos em recipiente fechado ao abrigo da luz por no máximo 15 dias. Essa solução foi introduzida no canal radicular por meio de seringa 
Carpule provida de agulha descartável 27 G longa (BecKton Dickinson Ind. Cirúrgicos Ltda., Juíz de Fora, MG, Brasil), limitada por cursor de borracha, de acordo com o CRT, sendo efetuada a cada troca de instrumento com $3,6 \mathrm{~mL}$ de solução. Em seguida, os canais radiculares foram secos por meio de aspiração e preenchidos com uma solução de ácido etilenodiaminotetracético (EDTA) a 14,3\%, tamponado em pH 7,4 (Odahcam; Herpo Produtos Dentários Ltda., RJ, Brasil), por 3 minutos. A seguir, foi realizada a irrigação com solução de hipoclorito de sódio a 0,5\%, aspiração e secagem utilizando cones de papel absorvente (Tanari Industrial, Manacapuru, AM, Brasil).

\section{Preparo dos dentes permanentes}

Foram selecionados 20 dentes permanentes anteriores superiores e inferiores, extraídos, de humanos, hígidos, com raízes completamente formadas, íntegras e retas. As superfícies radiculares dos dentes foram cuidadosamente limpas com curetas periodontais e, em seguida, armazenados em solução de azida de sódio diluída em água destilada, na proporção de 1:4, até o momento da utilização.

Os dentes foram submetidos ao tratamento endodôntico convencional (Figura 10), incluindo a abertura coronária utilizando pontas diamantadas esféricas n 1012 (KG Sorensen Indústria e Comércio) em turbina de alta rotação, sob refrigeração. A abertura coronária foi complementada com o uso de ponta diamantada 3083 (KG Sorensen Indústria e Comércio).

O CRD foi determinado, introduzindo-se uma lima tipo $\mathrm{K} \mathrm{n} \mathrm{n}^{\circ} 15$ (Dentsply Maillefer) até a abertura do forame apical. O cursor de borracha foi posicionado tendo como referência a borda incisal da coroa dentária. A medida entre a ponta do instrumento e o cursor foi anotada em ficha sendo considerado o CRD. Os dentes foram armazenados em recipientes separados contendo água destilada.

A padronização do diâmetro do forame foi realizada utilizando-se limas tipo $\mathrm{K}$ (Dentsply Maillefer), sequencialmente, da lima tipo $K$ de $n^{\circ} 15$, até a lima no 30, o qual foi considerada como "Instrumento Apical Foraminal" (IAF), seguida por copiosa irrigação, aspiração e inundação com hipoclorito de sódio a 0,5\% (Fármacia Daterra), acondicionados em tubetes de anestésicos previamente esterilizados e mantidos em recipiente fechado ao abrigo da luz por no máximo 15 dias. Essa solução foi introduzida no canal radicular por meio de seringa Carpule provida de agulha descartável 27 G longa (Beckton Dickinson Ind. 
Cirúrgicos), limitada por cursor de borracha, de acordo com o CRT, sendo efetuada a cada troca de instrumento com 3,6mL de solução.

A confecção do batente apical foi estabelecida a 1,0mm aquém do CRD, sendo este considerado o CRT. Para a realização do batente apical foram utilizadas limas tipo K no 35, 40, 45 e 50, sendo a lima tipo K de no 50 considerada como "Instrumento Memória" (IM). Após o uso de cada instrumento, foi realizada a irrigação, aspiração e inundação com solução de hipoclorito de sódio a 0,5\%.

O preparo biomecânico dos canais radiculares foi realizado empregando-se a técnica escalonada com recuo progressivo programado. O escalonamento foi efetuado utilizando-se as limas tipo $\mathrm{K} \mathrm{n}^{\circ} 55,60$ e 70 nos quais foi reduzido $1,0 \mathrm{~mm}$ a cada troca de instrumento. Após a utilização de cada lima no escalonamento, o IM foi introduzido nos canais obedecendo o CRT, e ao final do preparo o IAF foi repassado até o CRD. Durante todo o procedimento de preparo biomecânico, o canal radicular foi irrigado, aspirado e novamente inundado com solução de hipoclorito de sódio a 0,5\%, acondicionada em tubetes de anestésicos esterilizados, utilizando-se para isso uma seringa Carpule e agulhas $27 \mathrm{G}$ longa, limitada por cursor de borracha, de acordo com o CRT.

Ao término do preparo biomecânico os canais radiculares foram secos por meio de aspiração e complementados com o uso de cones de papel absorvente (Tanari Industrial), e inundados com uma solução de ácido etilenodiaminotetracético a 14,3\%, tamponado em pH 7,4 (Odahcam), por 3 minutos. A seguir, os canais foram irrigados copiosamente com solução de hipoclorito de sódio a 0,5\% e novamente secos por aspiração e uso de cones de papel absorvente. 


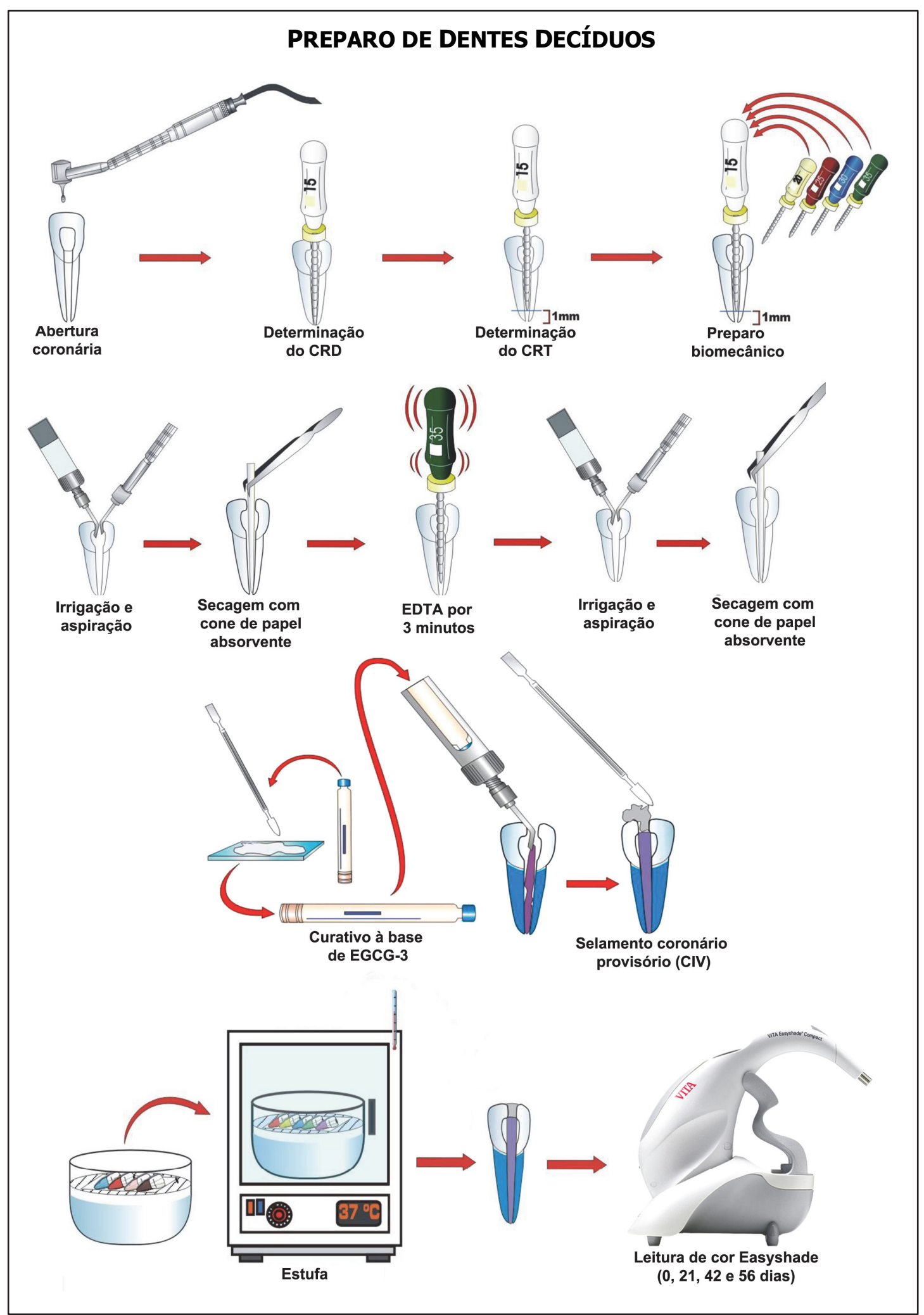

Figura 9. Fluxograma representativo dos procedimentos realizados na análise da alteração, de cor, após aplicação intracanal em dentes decíduos. 


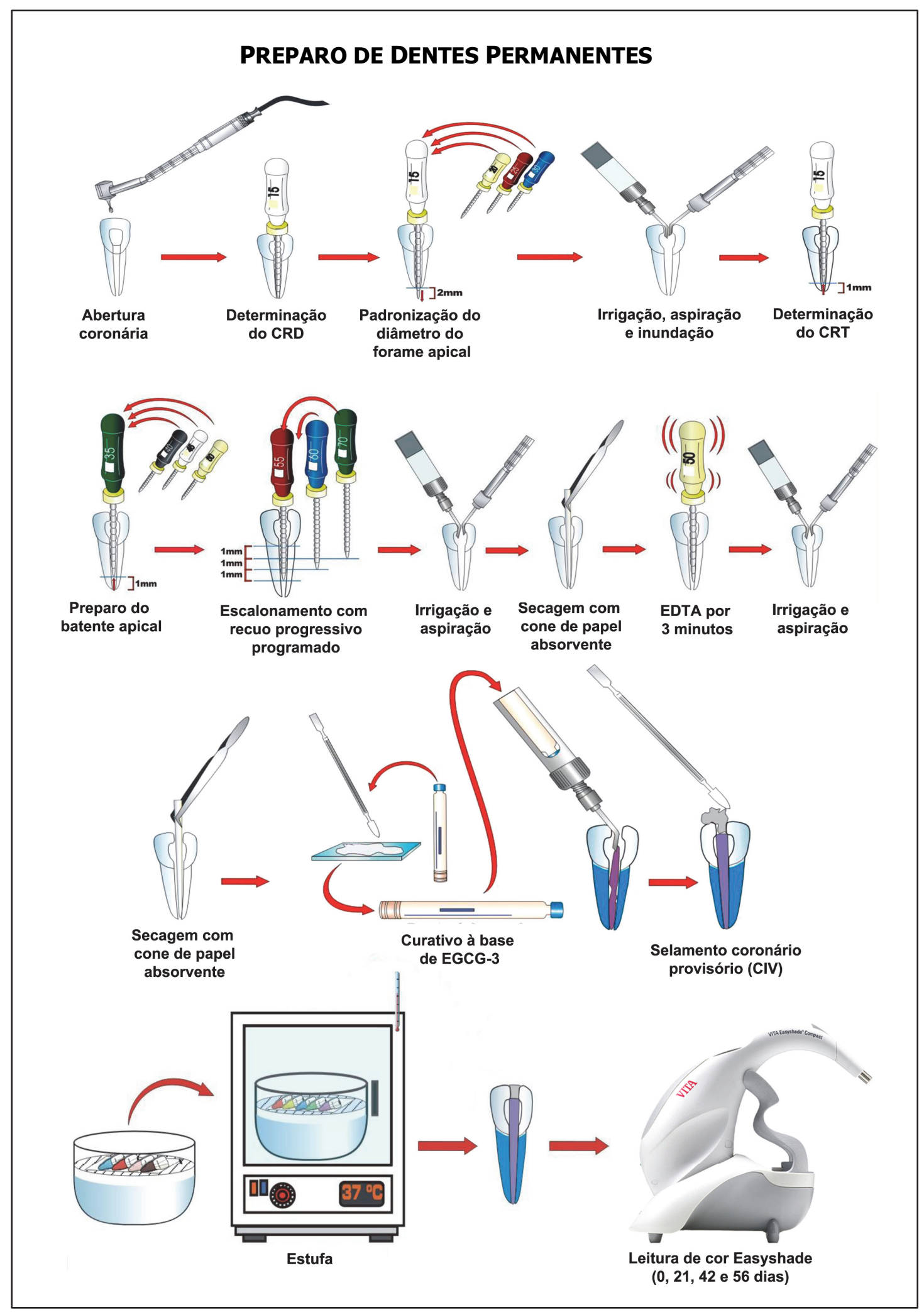

Figura 10. Fluxograma representativo dos procedimentos realizados na análise da alteração de cor, após aplicação intracanal em dentes permanentes. 


\section{Divisão dos grupos experimentais}

Os 20 dentes decíduos e 20 dentes permanentes foram aleatoriamente divididos em 4 grupos de 10 dentes cada, cujos canais radiculares foram preenchidos com os materiais listados na Tabela 1.

Tabela 1 - Grupos experimentais, material utilizado e números de espécimes.

\begin{tabular}{ccc}
\hline Grupos & Material & Números de Espécimes \\
\hline Grupo 1 & EGCG-3 + $\mathrm{H}_{2} \mathrm{O}$ (Dente Decíduo) & 10 \\
Grupo 2 & EGCG-3 + PEG 400 (Dente Decíduo) & 10 \\
Grupo 3 & EGCG-3 + $\mathrm{H}_{2} \mathrm{O}$ (Dente Permanente) & 10 \\
Grupo 4 & EGCG-3 + PEG 400 (Dente Permanente) & 10 \\
\hline
\end{tabular}

\section{Preenchimento dos canais radiculares}

Todos os espécimes (dentes decíduos e permanentes) tiveram seus ápices vedados por cola (Superbonder Henkel Ltda., São Paulo, Brasil), evitando seu escoamento para o interior o canal radicular e para evitar que o curativo pudesse extravasar através forame apical.

Após o completo vedamento dos canais os curativos foram colocados no interior dos canais radiculares, com auxilio de seringa Carpule e agulha $27 \mathrm{G}$ longa. Após verificar o completo preenchimento dos canais radiculares pelo curativo, os dentes receberam selamento coronário com cimento de ionômero de vidro Vidrion R (S.S. White Artigos Dentários Ltda., Rio de Janeiro, RJ, Brasil). Os dentes foram armazenados separadamente durante todos os períodos experimentais e mantidos em estufa na temperatura de $37^{\circ} \mathrm{C}$.

\section{Análise estatística}

Os resultados de alteração de cor, referentes aos valores absolutos de $L^{*}$, a* e b* foram submetidos a análise estatística. Inicialmente foi aplicado o teste de KolmogorovSmirnov para verificar se os dados apresentam distribuição normal. A seguir, foi realizada a análise de variância (ANOVA), seguida do pós-teste de Tukey (95\% de confiança). Os dados foram analisados usando-se o programa estatístico Graph Pad Prism 4 (Graph Pad Software Inc, San Diego, CA, EUA). 


\section{Resultados}





\section{Resultados}

\section{Caracterização Físico-química}

\section{EGCG}

O espectro de absorbância da EGCG, veiculada em água, em pH neutro, apresentou um pico máximo em 274 nm na região do UV/Vis (Figura 11).

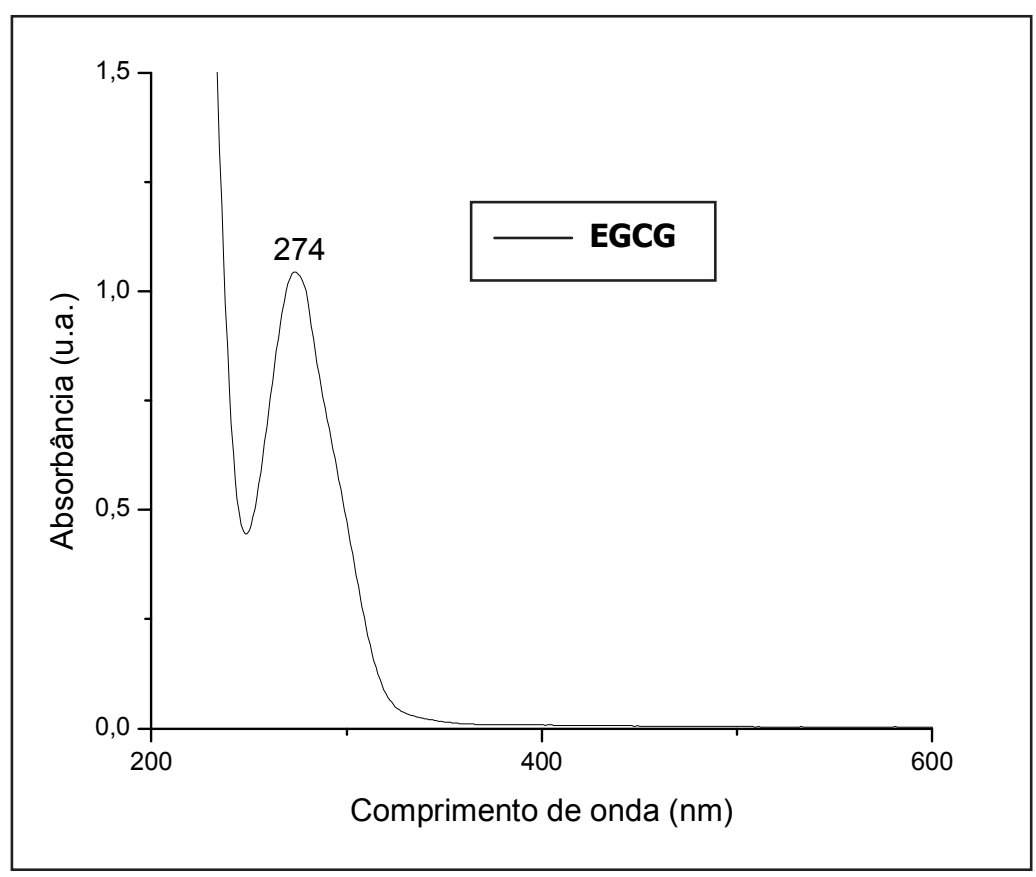

Figura 11. Espectro de absorção UV/Vis da EGCG em solução aquosa com concentração da $E G C G=8,6 \times 10^{-5} \mathrm{~mol} / \mathrm{L} ; \mathrm{pH}=6,2 ; \lambda=$ 274 nm; absorbância= 1u.a.

A EGCG veiculada em água, em pH neutro, também apresentou estabilidade em função do tempo, mantendo seu pico máximo de absorbância na região do UV/Vis em 274 nm, após os períodos de 1, 3, 4, 5, 6, 24 e 27 horas (Figura 12). 


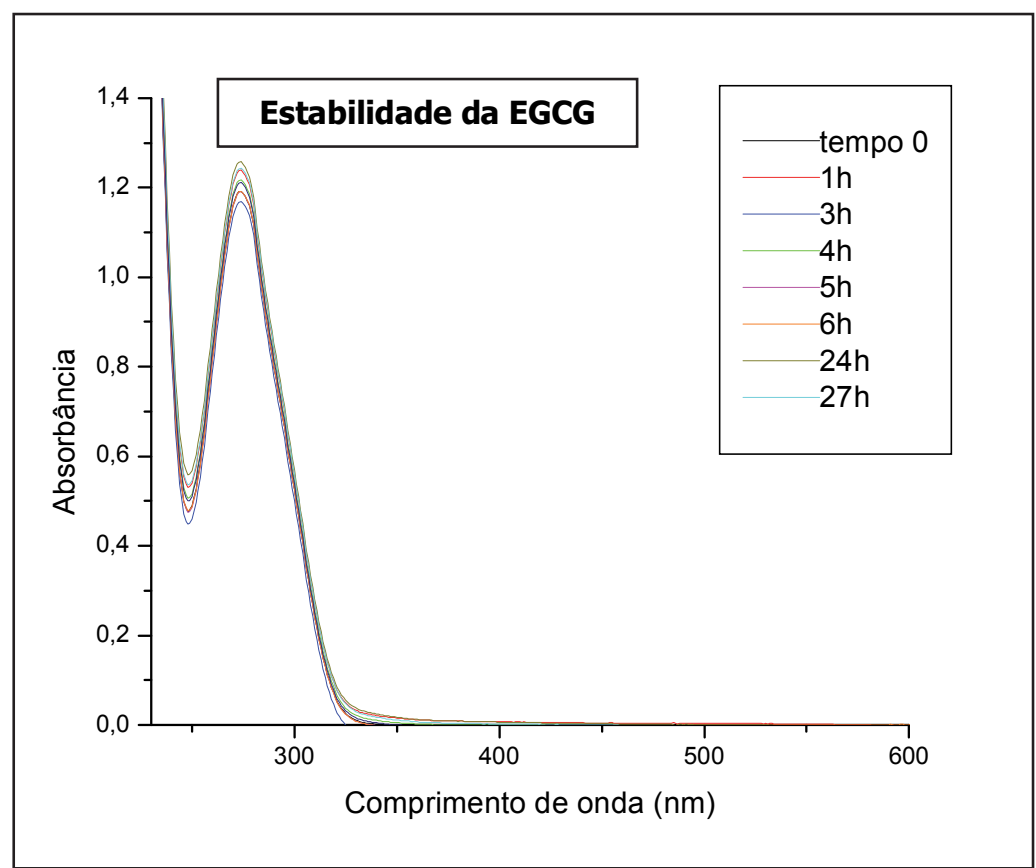

Figura 12. Estabilidade da EGCG em solução aquosa, avaliada por meio do espectro de absorção em espectroscopia de UV/Vis, em função do tempo $(0,1,3,4,5,6,24$ e 27 horas $)$. Concentração da EGCG $=8,6 \times 10^{-5} \mathrm{~mol} / \mathrm{L} ; \mathrm{pH}=6,2 ; \lambda=274$ nm; absorbância= 1u.a.

Em meio ácido o comportamento espectral da EGCG, veiculada em água, não foi alterado, sendo mantido o pico máximo de absorbância na região do UV/Vis em 274 nm (Figura 13).

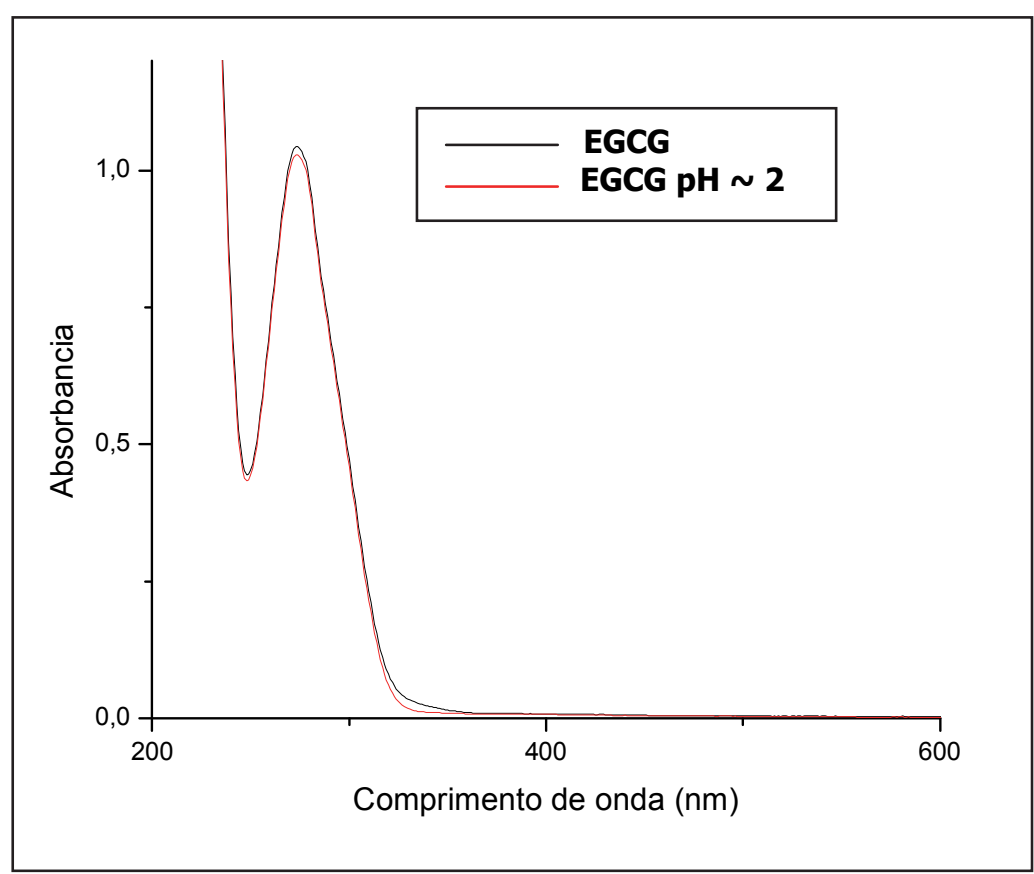

Figura 13. Espectro de absorção UV/Vis da EGCG em solução aquosa neutra e ácida $(\mathrm{pH}=2)$. Concentração da $\mathrm{EGCG}=8,6 \times 10^{-}$ ${ }^{5} \mathrm{~mol} / \mathrm{L} ; \mathrm{pH}=2,0 ; \lambda=274 \mathrm{~nm} ;$ absorbância= $1 \mathrm{u} . \mathrm{a} ; \mathrm{HCl}=$ $1 \mathrm{~mol} / \mathrm{L}$. 
A estabilidade da EGCG, veiculada em água, não foi alterada em meio ácido ( $\mathrm{pH} 4,5)$, sendo mantido o pico máximo de absorbância na região do UV/Vis em 274 nm após os períodos de 1, 2, 3, 4, 5, 6, 24 e 27 horas (Figura 14).

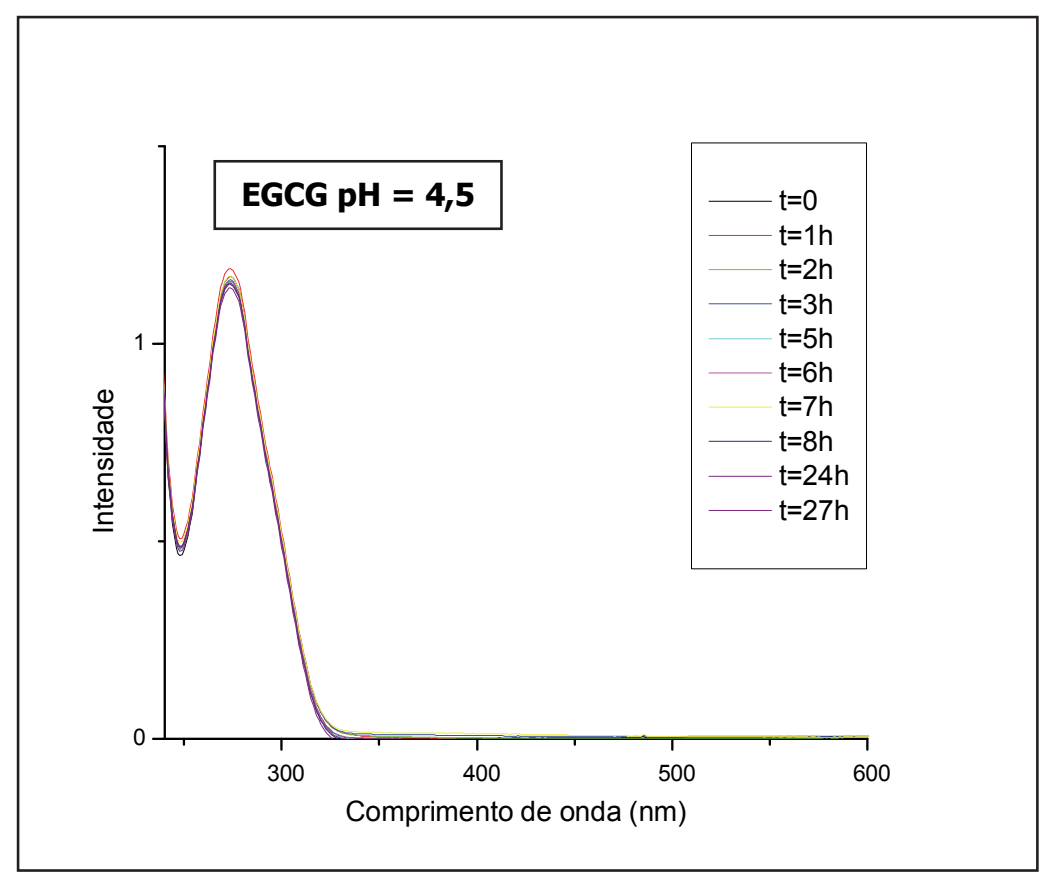

Figura 14. Estudo da estabilidade da EGCG em solução aquosa pH 4,5, no período de 27 horas, por meio de espectroscopia de UV/Vis. Concentração da EGCG $=9,8 \times 10^{-5} \mathrm{~mol} / \mathrm{L} ; \lambda=274$ nm; absorbância = 1u.a.

Em meio básico o comportamento espectral da EGCG, veiculada em água, foi alterado, sendo observado o pico máximo de absorbância na região do UV/Vis em 323 nm (Figura 15). 


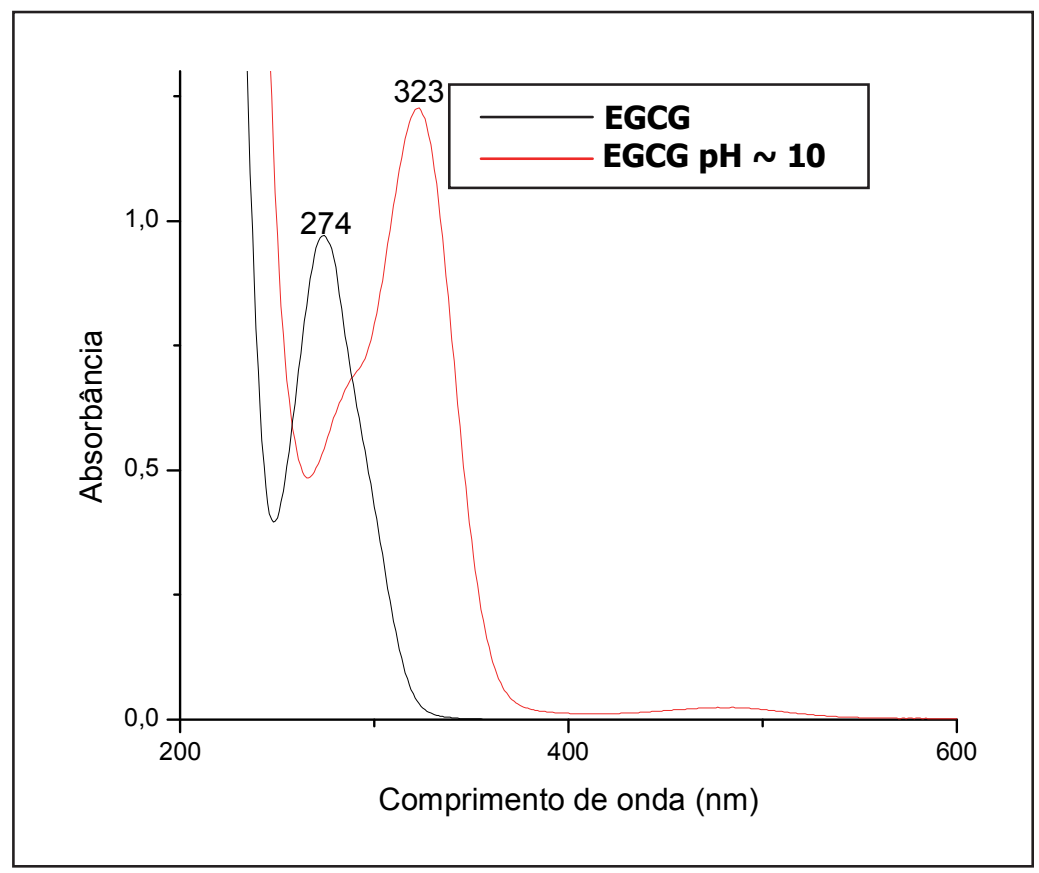

Figura 15. Espectro de absorção UV/Vis da EGCG em solução aquosa neutra e solução de $\mathrm{NH}_{4} \mathrm{OH}(\mathrm{pH}=10)$. Concentração da $E G C G=8,1 \times 10^{-5} \mathrm{~mol} / \mathrm{L} ; \mathrm{pH}=10,0 ; \lambda=274 \mathrm{~nm}$ e $323 \mathrm{~nm}$; absorbância > 1u.a.

Após a tentativa de neutralização da solução de EGCG, veiculada em água em pH básico, observou-se um pico máximo de absorbância na região do UV/Vis em 278 nm e um pico menor em 322 nm, não retornando para suas características originais (Figura 16).

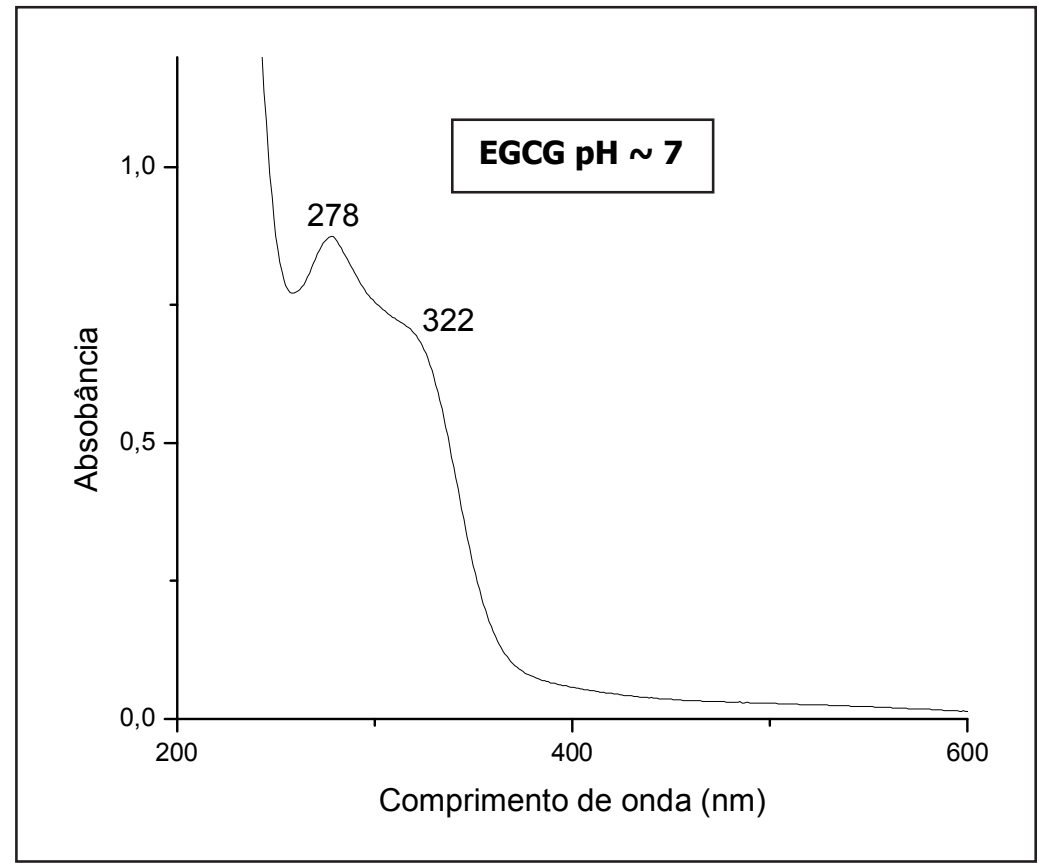

Figura 16. Espectro de absorção UV/Vis da EGCG após adição de $\mathrm{HCl}$ à solução de $\mathrm{NH}_{4} \mathrm{OH}$. Concentração da $\mathrm{EGCG}=8,1 \times 10^{-5} \mathrm{~mol} / \mathrm{L}$; $\mathrm{pH}=7,0 ; \lambda$ entre 278 e 322 nm; absorbância < 1u.a. 
A EGCG em meio básico com adição de hidróxido de cálcio $\mathrm{Ca}(\mathrm{OH})_{2}$, apresentou um pico máximo de absorbância na região do UV/Vis em $322 \mathrm{~nm}$ e após a neutralização houve o desaparecimento da banda de absorção em $323 \mathrm{~nm}$ e uma tentativa de retorno ao pico em 274 nm. Após adição da segunda alíquota de $\mathrm{Ca}(\mathrm{OH})_{2}$, houve escurecimento da solução, mas nenhuma mudança significativa foi observada nos picos de absorção (Figura 17).

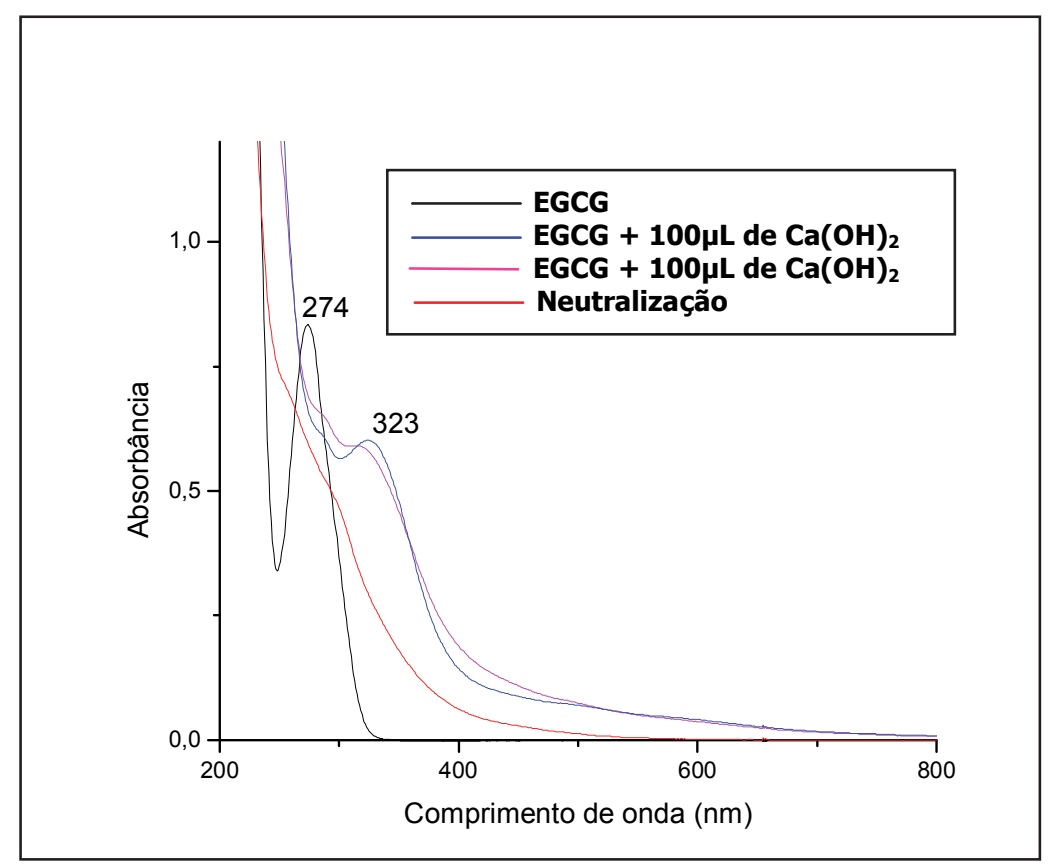

Figura 17. Espectro de absorção UV/Vis da EGCG em meio neutro e após adição $200 \mu \mathrm{L}$ de $\mathrm{Ca}(\mathrm{OH})_{2}$. Neutralização da EGCG com adição de $\mathrm{HCl}$ (1mol/L). Concentração da EGCG= $7,0 \times 10^{-5} \mathrm{~mol} / \mathrm{L} ; \mathrm{pH}=7,0$ e 10,$0 ; \lambda=274$ e $323 \mathrm{~nm} ;$ absorbância < 1u.a.

Na interação da EGCG com $\mathrm{CaCl}_{2}$ observou-se uma diminuição do pico de absorção em 274 nm e o aparecimento de um novo pico em 322 nm, com formação de um ponto isosbéstico em $292 \mathrm{~nm}$. A absorbância teve seu valor sequencialmente reduzido, sendo inferior a 1,0 u.a. e, após a formação do ponto isosbéstico houve um aumento do valor da absorbância para 1,0 u.a. Na neutralização, o comprimento de onda da EGCG retornou ao estado original de 274 nm (Figuras 18 e 19). 


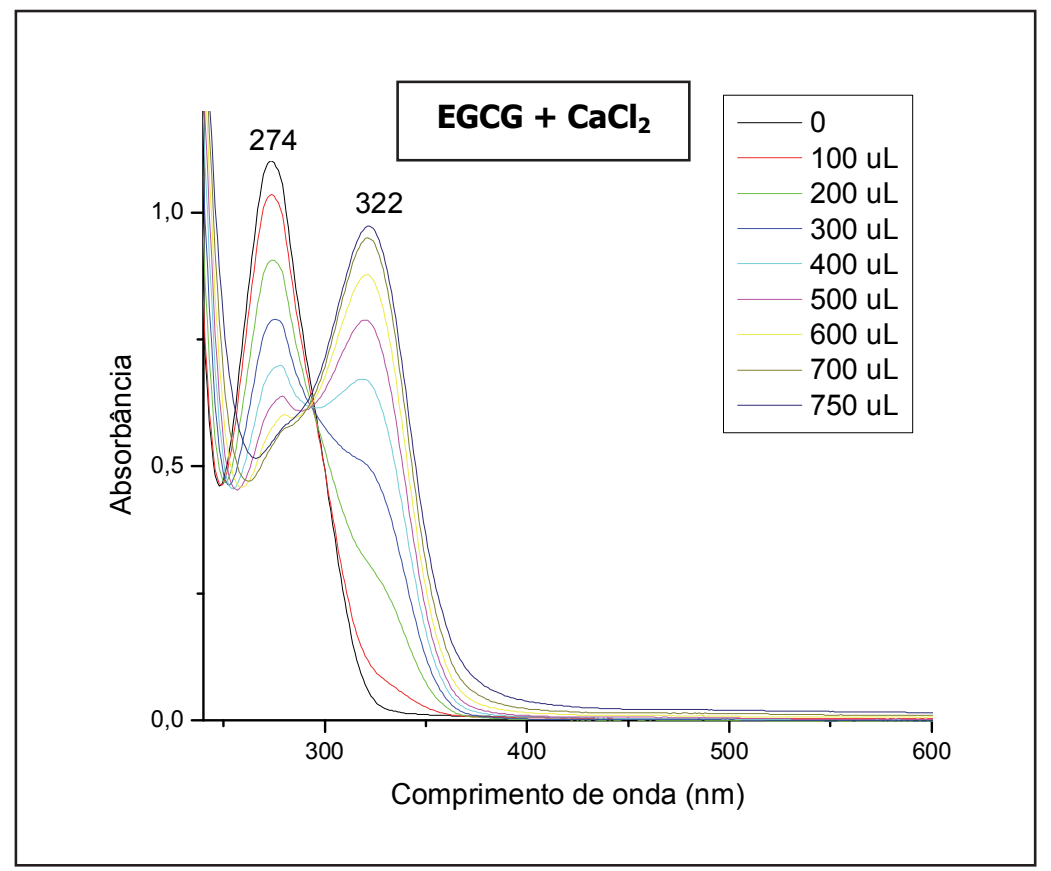

Figura 18. Variação no espectro de absorção UV/Vis da EGCG após adição de $\mathrm{CaCl}_{2}$, à uma solução neutra de EGCG com concentração da EGCG $=9,2 \times 10^{-5} \mathrm{~mol} / \mathrm{L} ; \mathrm{pH}=7,0 ; \lambda=274$ $\mathrm{nm}$; absorbância $=1$ u.a. Após a adição da solução de $\mathrm{CaCl}_{2}$ $\mathrm{pH}=7,0 ; \lambda=322 \mathrm{~nm}$; absorbância= 1u.a. Ponto isosbético em 292nm.

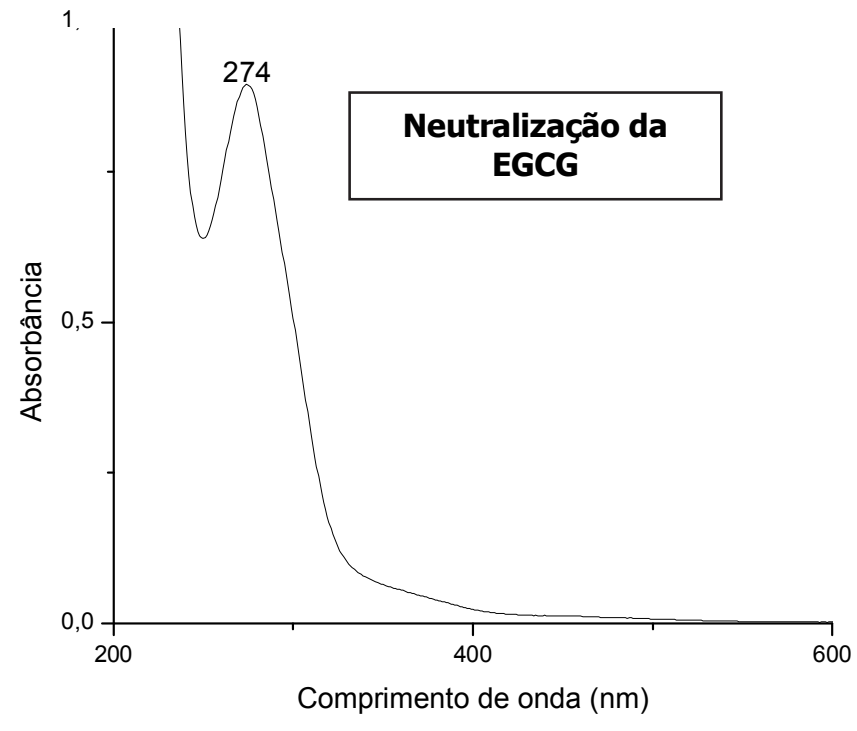

Figura 19. Espectro de absorção UV/Vis da EGCG e $\mathrm{CaCl}_{2}$ após neutralização da solução com adição de $\mathrm{HCl}$ (1mol/L). Concentração da EGCG=9,2X10-5 $\mathrm{mol} / \mathrm{L} ; \mathrm{pH}=7,0 ; \lambda=274$ nm; absorbância= 1u.a.

A EGCG, veiculada em água, em contato com a superfície dental de dentes decíduos manteve sua estabilidade em função do tempo, apresentando apenas uma diminuição 
significativa da absorbância da banda em 274 nm, durante os períodos de 1, 3, 4, 5, 6, 24 e 27 horas. Após 1 hora de imersão dos dentes, seu espectro apresentou uma pequena banda em 322 nm, mais pronunciada para o dente decíduo (Figuras 20 e 21).

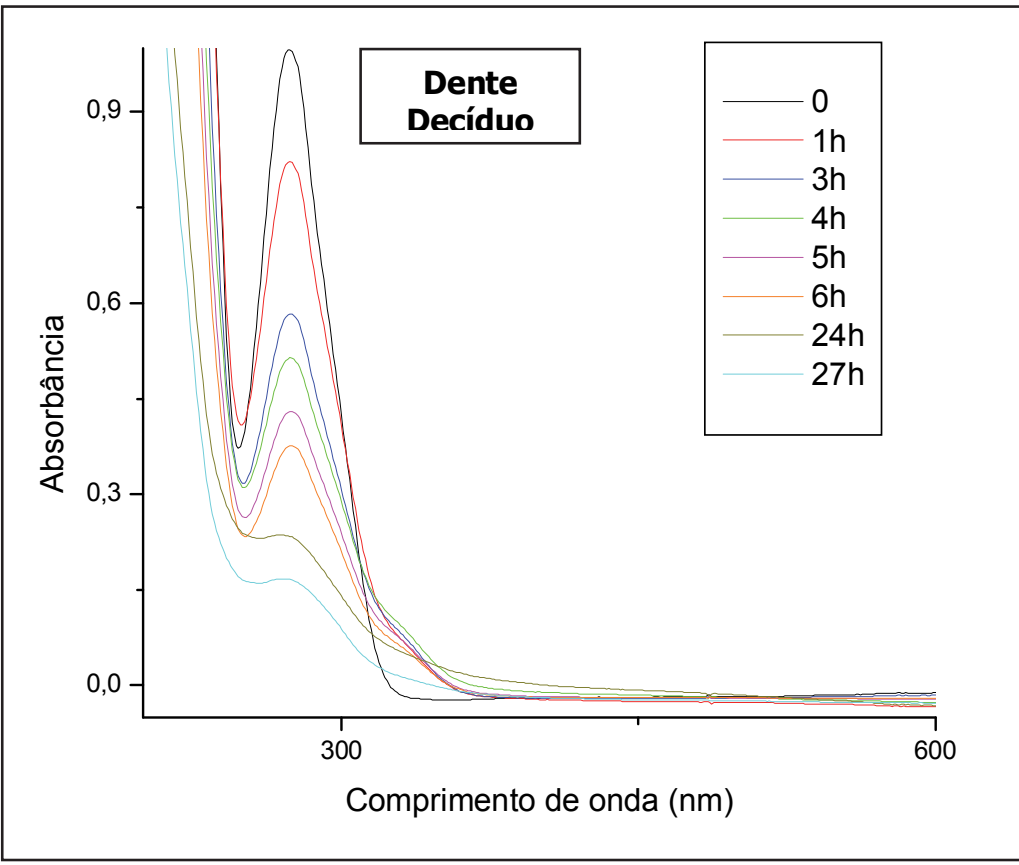

Figura 20. Estudo da estabilidade da EGCG, em solução aquosa, na presença de dente decíduo, no período de 27 horas, por meio de espectroscopia UV/Vis. Concentração da EGCG= $1,09 \times 10^{-4} \mathrm{~mol} / \mathrm{L} ; \mathrm{pH}=7,0 ; \lambda=274$ nm; absorbância< 1 u.a.

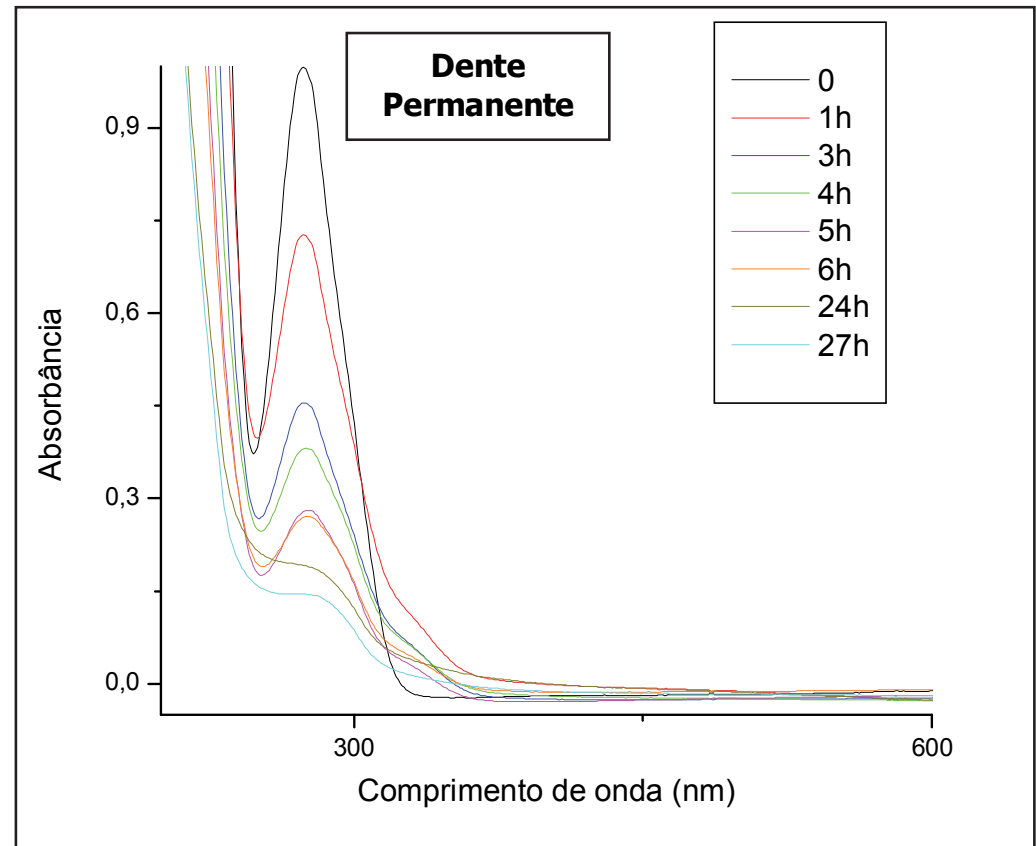

Figura 21. Estudo da estabilidade da EGCG, em solução aquosa, na presença de dente decíduo, no período de 27 horas, por meio de espectroscopia de UV/Vis. Concentração da EGCG= $1,09 \times 10^{-4} \mathrm{~mol} / \mathrm{L} ; \mathrm{pH}=7,0 ; \lambda=274$ nm; absorbância< 1 u.a. 
A constante de velocidade de decomposição k da EGCG em solução aquosa, em contato com os dentes decíduo e permanente, está apresentada no gráfico abaixo (Figura 22A e B); onde A é a absorbância em 274 nm versus tempo nas primeiras 6 horas

Os valores obtidos para a constante de velocidade de decomposição (k) da EGCG-3 em solução aquosa foi de 0,00259, quando em contato com o dente decíduo, de 0,00358, em contato com o dente permanente.

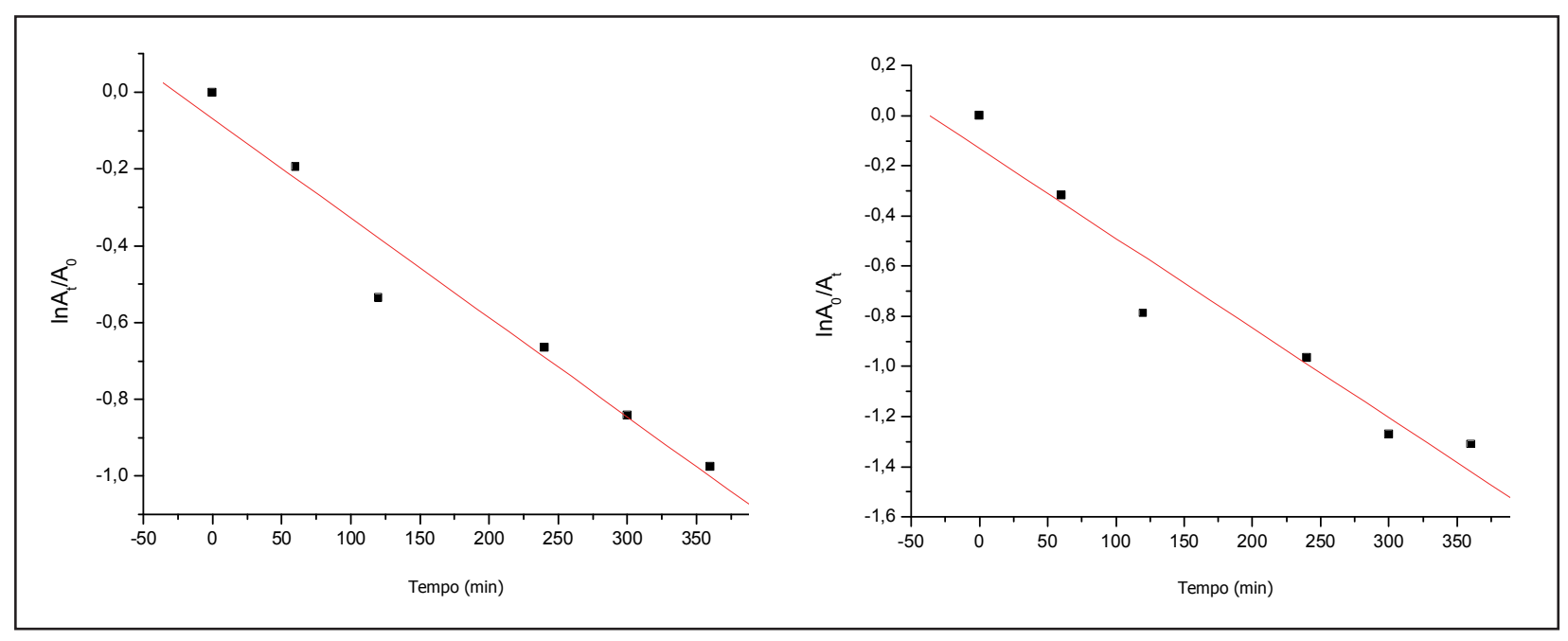

Figura 22. Gráfico InAt/A0 (onde A é a absorbância em $274 \mathrm{~nm}$ ) do logaritmo das absorbâncias em função do tempo para a EGCG em solução aquosa em contato com o dente decíduo (A) e permanente (B).

No estudo de fluorescência da EGCG, a substância apresenou espectro de emissão em 393 nm e espectro de excitação em 325 nm (Figuras 23 e 24). 


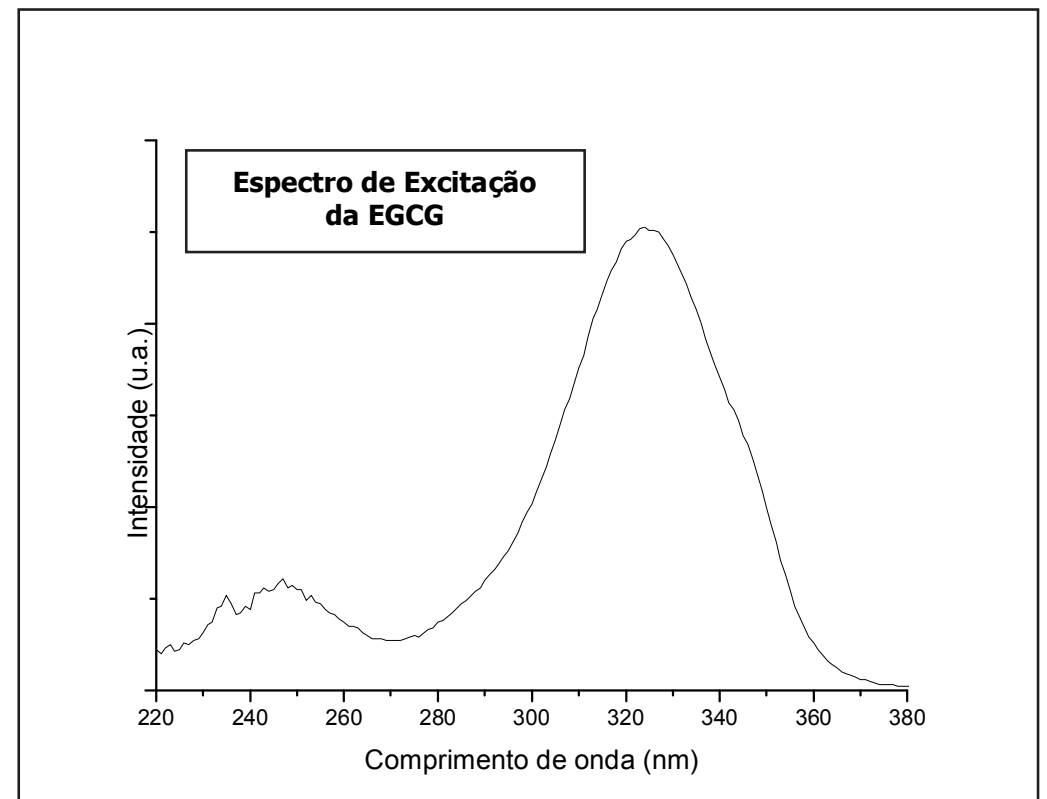

Figura 23. Espectro de excitação da EGCG, em solução aquosa, por meio de espectroscopia de fluorescência. Concentração da EGCG= $8,6 \times 10^{-5} \mathrm{~mol} / \mathrm{L} ; \mathrm{pH}=7,0 ; \lambda e m=393 \mathrm{~nm}$, fendas $5,10 \mathrm{~nm}$; absorbância< 1u.a.

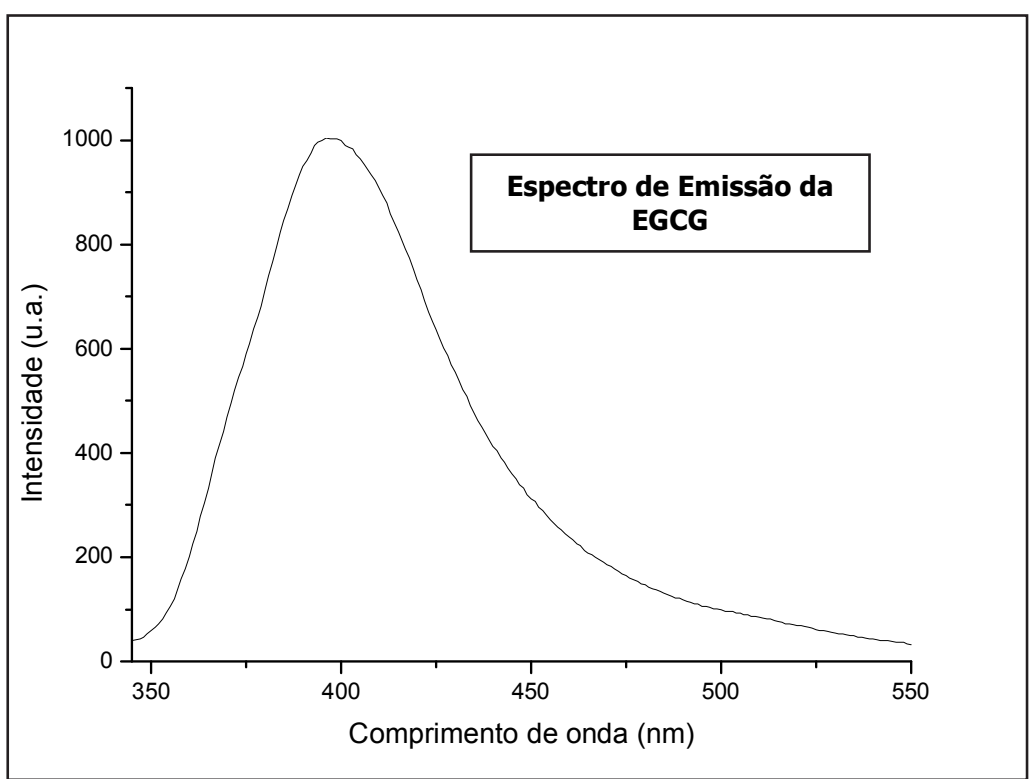

Figura 24. Espectro de emissão da EGCG, em solução aquosa. Concentração da $\mathrm{EGCG}=8,6 \times 10^{-5} \mathrm{~mol} / \mathrm{L} ; \mathrm{pH}=7,0 ; \lambda$ em $=$ $393 \mathrm{~nm}$, fendas 5, $10 \mathrm{~nm}$; absorbância< 1u.a.

No estudo de titulação potenciométrica, que avaliou o efeito do pH sobre a EGCG, verificou-se que o ponto de equivalência se deu aproximadamente em $\mathrm{pH}$ 10, onde sugerese sua saturação (Figura 25). 


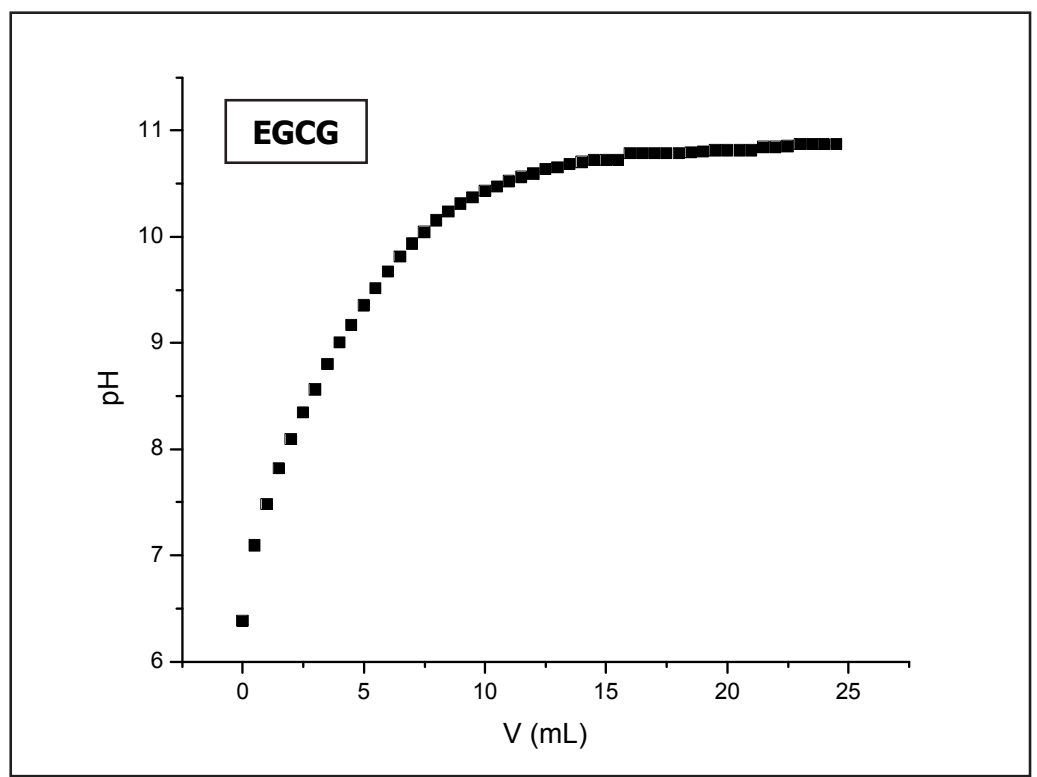

Figura 25. Titulação potenciométrica da EGCG $(0,45 \mathrm{mg} / \mathrm{mL})$ com hidróxido de sódio $(0,02 \mathrm{mg} / \mathrm{mL})$ em $\mathrm{KCl} \mathrm{0,1} \mathrm{M}$.

\section{Espectroscopia de absorção, estabilidade e fluorescência do sistema de liberação tópica de EGCG}

O espectro de absorção da EGCG pode ser observado em um comprimento de onda em $278 \mathrm{~nm}$ e na sua estabilidade em função do tempo verificou-se apenas uma pequena diminuição da absorbância. Na presença de elementos dentais a estabilidade da EGCG foi mantida em um comprimento de onda de $278 \mathrm{~nm}$, porém nas 6 primeiras horas houve um aumento significativo da intensidade da absorbância, decaindo um pouco após esse período e não houve alteração de cor da solução (Figuras 26 a 28). 


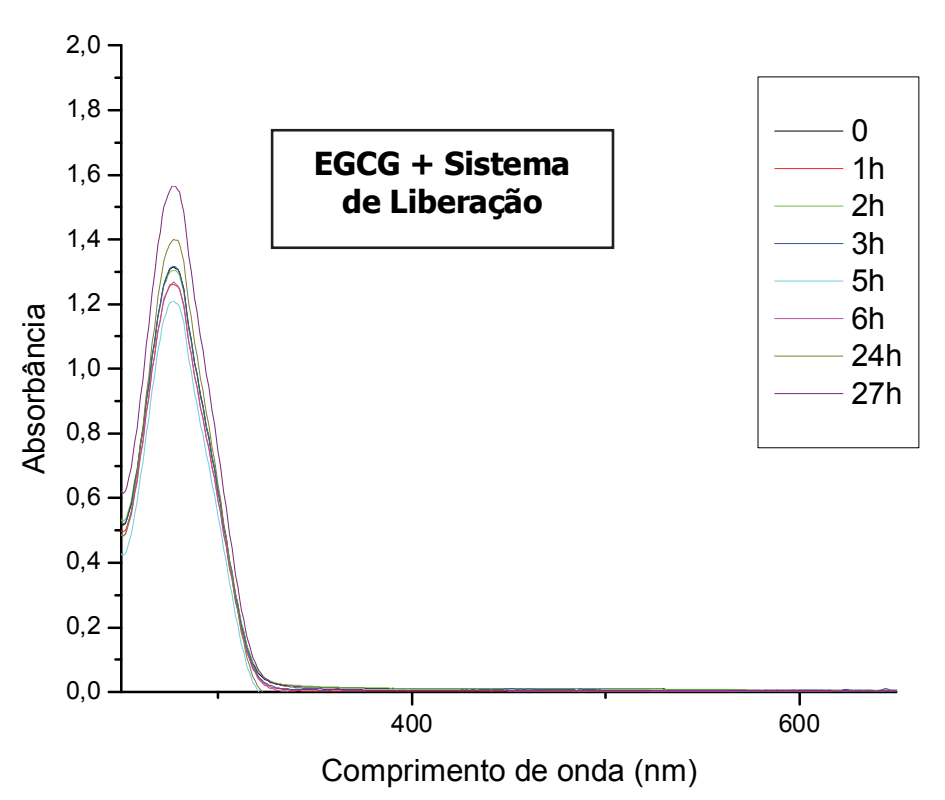

Figura 26. Estabilidade do sistema de liberação de EGCG, avaliada por meio do espectro de absorção em espectroscopia de UV/Vis, em função do tempo (0, 1, 3, 4, 5, 6, 24 e 27 horas). Concentração da EGCG $=1,09 \times 10^{-4} \mathrm{~mol} / \mathrm{L} ; \lambda=278 \mathrm{~nm}$; absorbância> 1u.a.

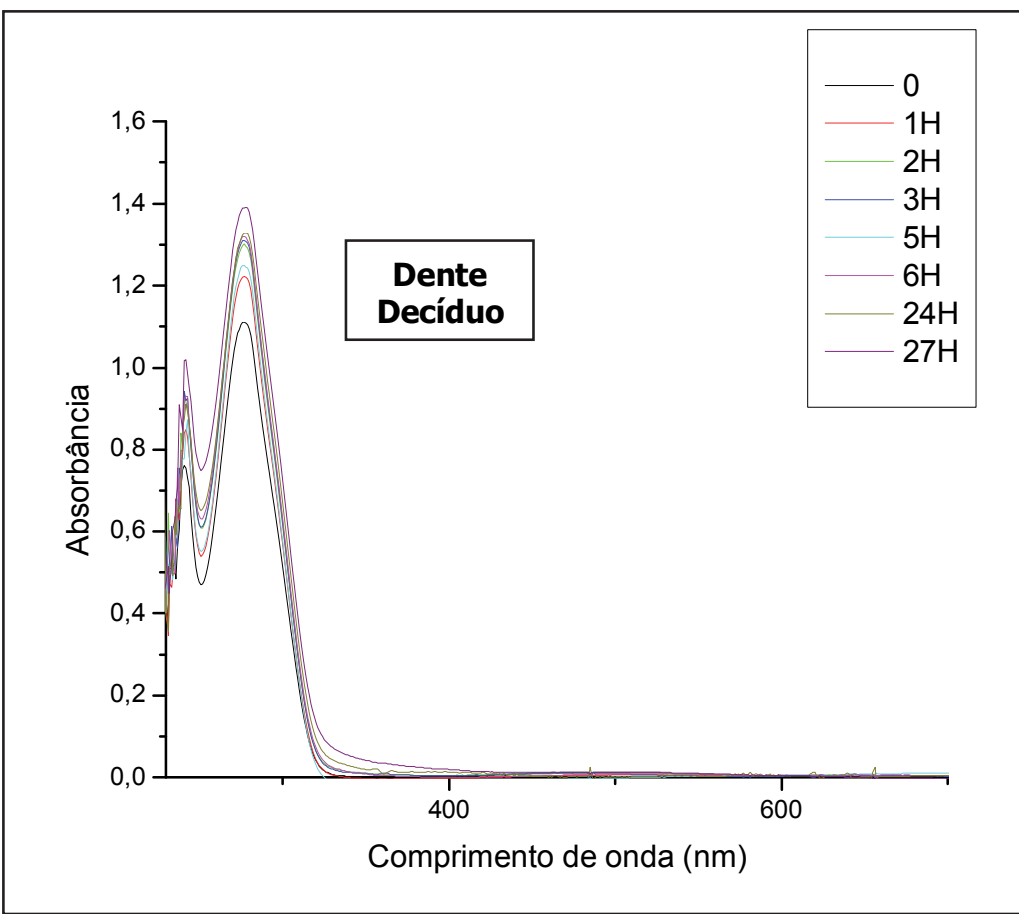

Figura 27. Estudo da estabilidade do sistema de liberação de EGCG na presença de dente decíduo, no período de 27 horas, por meio de espectroscopia de UV/Vis. Concentração da EGCG=

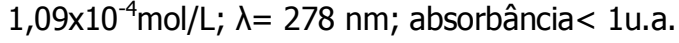




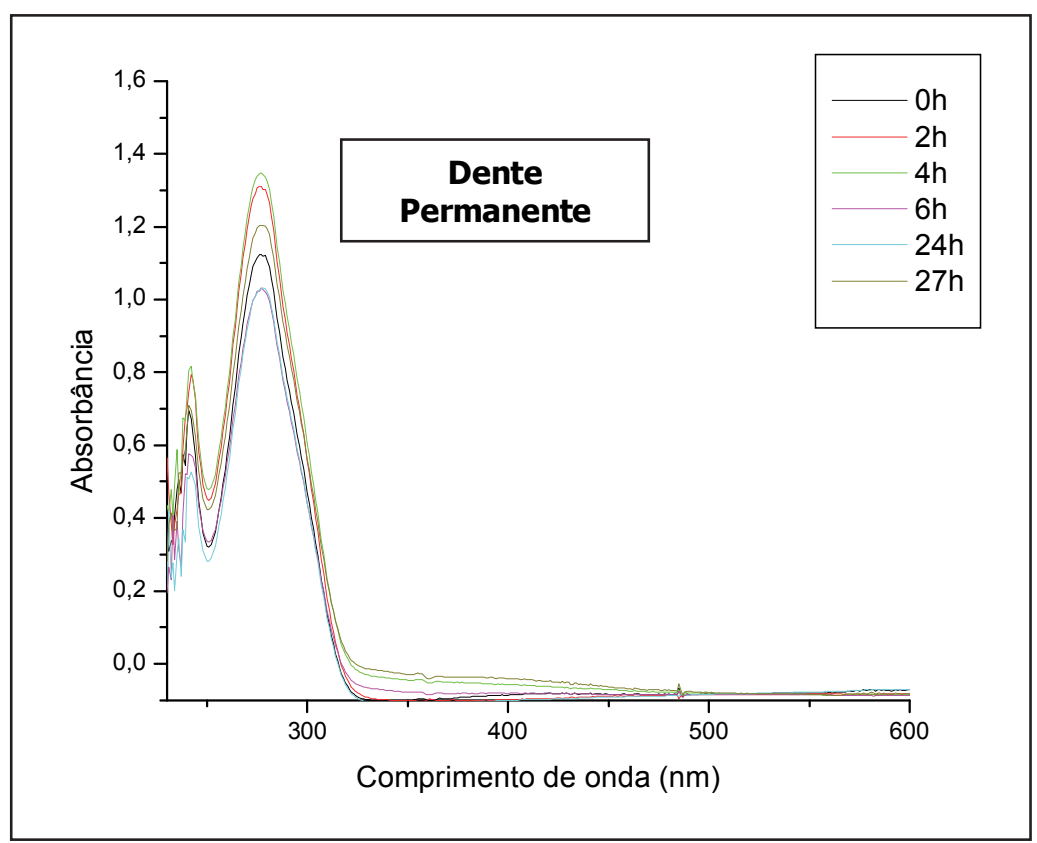

Figura 28. Estudo da estabilidade do sistema de liberação de EGCG na presença de permanente, no período de 27 horas, por meio de espectroscopia de UV/Vis. Concentração da EGCG= $1,09 \times 10^{-4} \mathrm{~mol} / \mathrm{L} ; \lambda=278 \mathrm{~nm}$; absorbância< 1 u.a.

No estudo de fluorescência da EGCG apresenta o espectro de emissão em 377 nm, com o espectro de excitação em 329 nm (Figura 29).

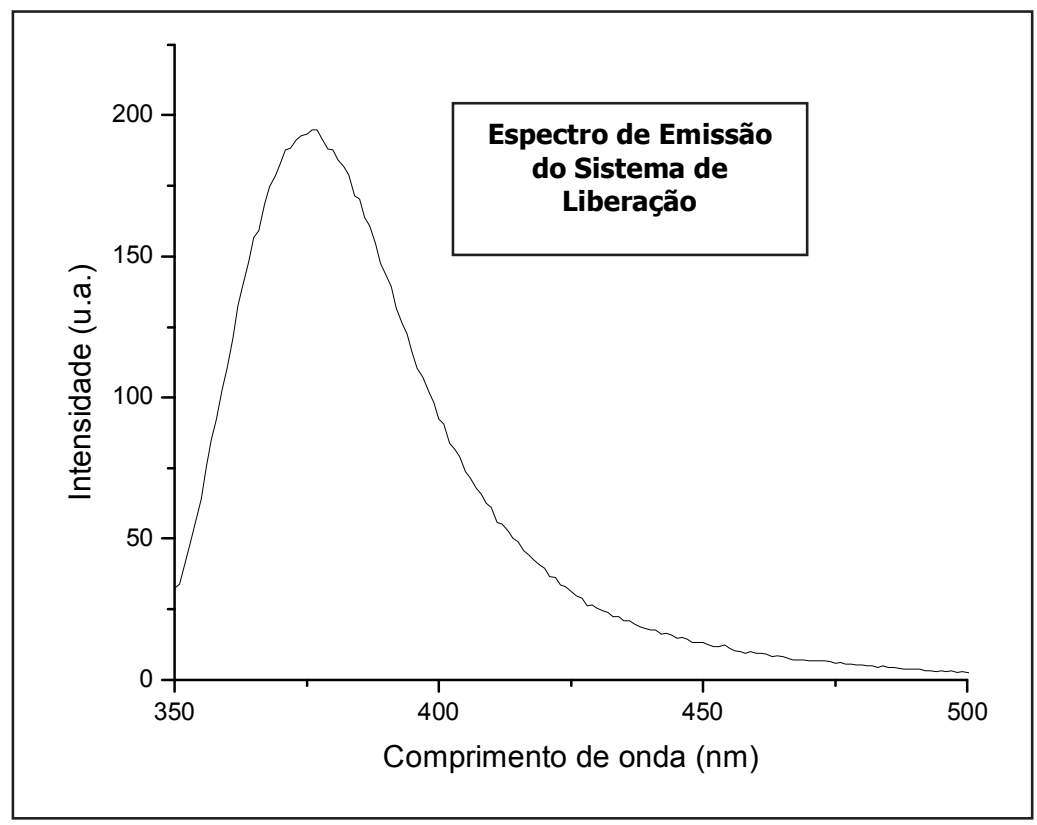

Figura 29. Espectro de emissão do sistema de liberação de EGCG, por meio de espectroscopia de fluorescência. Concentração da $\mathrm{EGCG}=8,6 \times 10^{-5} \mathrm{~mol} / \mathrm{L} ; \lambda$ em $=377 \mathrm{~nm} ; \lambda$ exc $=329 \mathrm{~nm}$; fendas 5, $10 \mathrm{~nm}$; absorbância< 1u.a. 
Estabilidade de Cor

Os valores absolutos (média e desvio padrão) de L*, a* e b* do estudo de alteração de cor após aplicação intracanal de EGCG (veiculada em água) e do sistema de liberação de EGCG estão apresentados nas Figuras 30 a 33. Não se verificou diferença estatística significativa nos valores absolutos de $L^{*}, a^{*}$ e $b^{*}$ dos elementos dentais em nenhum dos períodos avaliados $(p<0,05)$.

Os valores (média e desvio padrão) de $\Delta \mathrm{L}, \Delta \mathrm{a}, \Delta \mathrm{b}$ e $\Delta \mathrm{E}$, nos períodos de 21,42 e 56 dias estão apresentados na Tabela 2. De acordo com os valores de $\Delta \mathrm{E}$, os grupos que apresentaram valores inferiores a 3,3 (limite clinicamente aceitável), foram o sistema de liberação de EGCG em dentes permanentes, em todos os períodos avaliados, e a EGCG em dentes decíduos e permanentes, no período de 21 dias. 


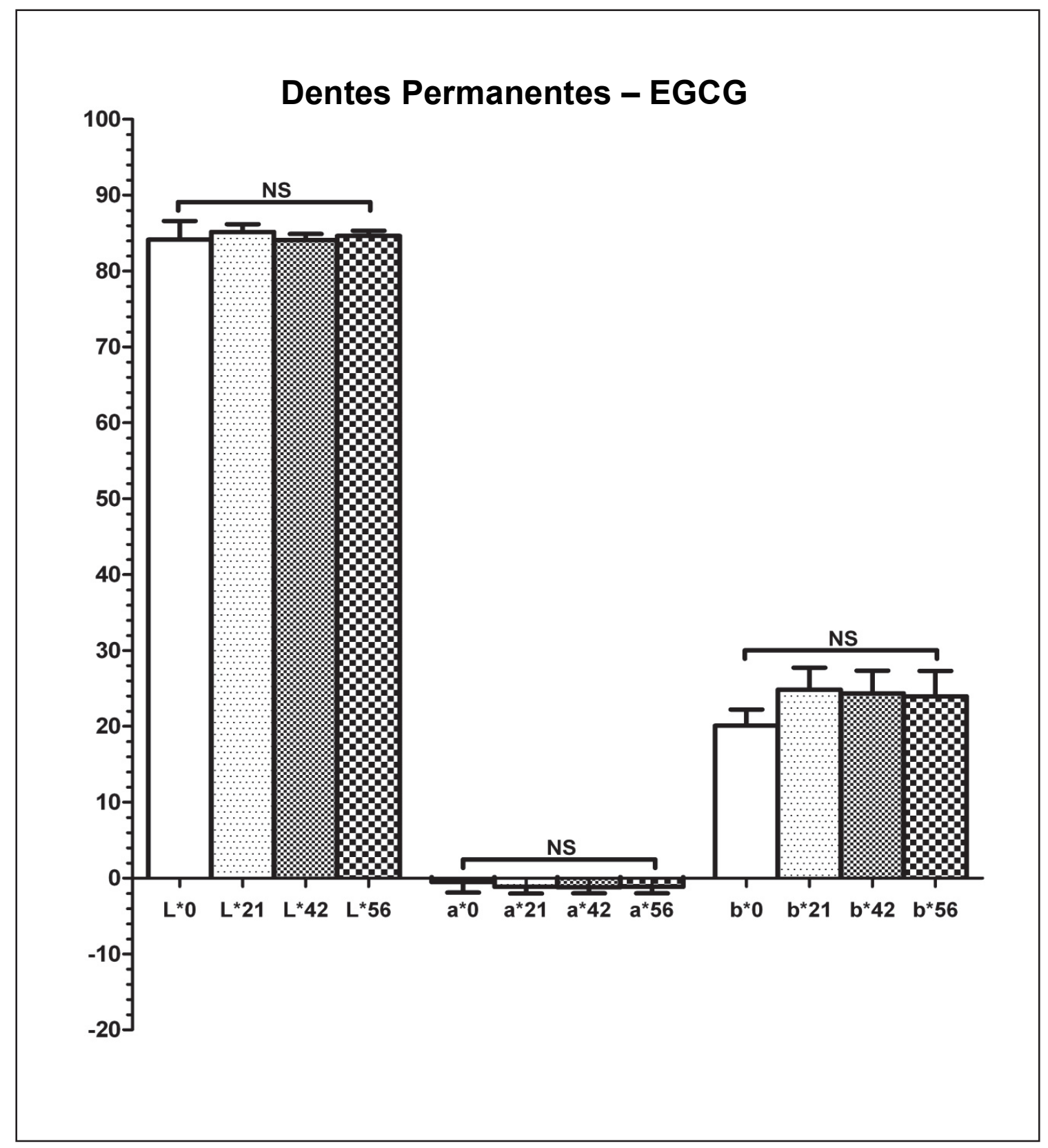

\begin{tabular}{|c|c|c|c|c|c|c|c|c|c|c|c|c|}
\hline & \multicolumn{3}{|c|}{ Inicial } & \multicolumn{3}{|c|}{21 dias } & \multicolumn{3}{|c|}{42 dias } & \multicolumn{3}{|c|}{56 dias } \\
\hline & $\mathbf{L} *$ & a* & b* & L* & a* & b* & L* & a* & b* & L* & a* & b* \\
\hline Média & 84,14 & $-0,54$ & 20,07 & 85,14 & $-1,16$ & 24,84 & 84,06 & $-1,20$ & 24,36 & 84,62 & $-1,16$ & 23,96 \\
\hline DP & 5,49 & 3,06 & 3,74 & 2,28 & 1,96 & 6,49 & 1,86 & 1,79 & 6,66 & 1,54 & 1,88 & 7,44 \\
\hline
\end{tabular}

Figura 30. Média e desvio padrão (DP) dos valores de $L^{*}, a^{*}$ e b* dos dentes permanentes após aplicação intracanal de EGCG por 21, 42 e 56 dias. NS: diferença estatística não significante 


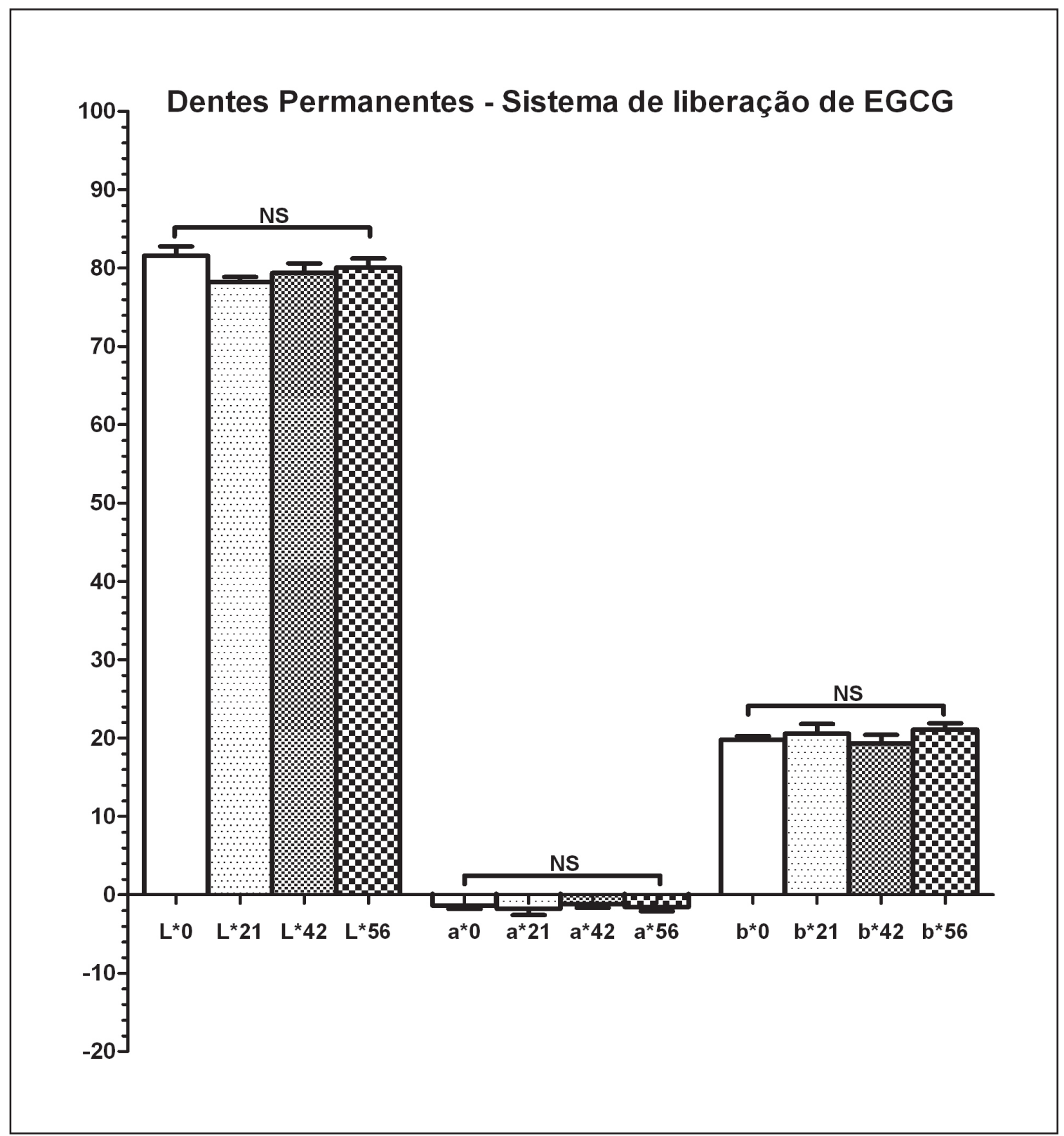

\begin{tabular}{|c|c|c|c|c|c|c|c|c|c|c|c|c|}
\hline & \multicolumn{3}{|c|}{ Inicial } & \multicolumn{3}{|c|}{21 dias } & \multicolumn{3}{|c|}{42 dias } & \multicolumn{3}{|c|}{56 dias } \\
\hline & L* & a* & b* & L* & a* & b* & L* & a* & b* & L* & a* & b* \\
\hline Média & 81,56 & $-1,38$ & 19,78 & 78,22 & $-1,76$ & 20,58 & 79,38 & $-1,18$ & 19,28 & 80,08 & $-1,57$ & 21,10 \\
\hline DP & 2,65 & 0,97 & 1,04 & 1,41 & 1,44 & 2,69 & 2,70 & 1,13 & 2,52 & 2,55 & 1,05 & 1,73 \\
\hline
\end{tabular}

Figura 31. Média e desvio padrão (DP) dos valores de $L^{*}$, a* e b* dos dentes permanentes após aplicação intracanaldo sistema de liberação de EGCG por 21, 42 e 56 dias. NS: diferença estatística não significante 


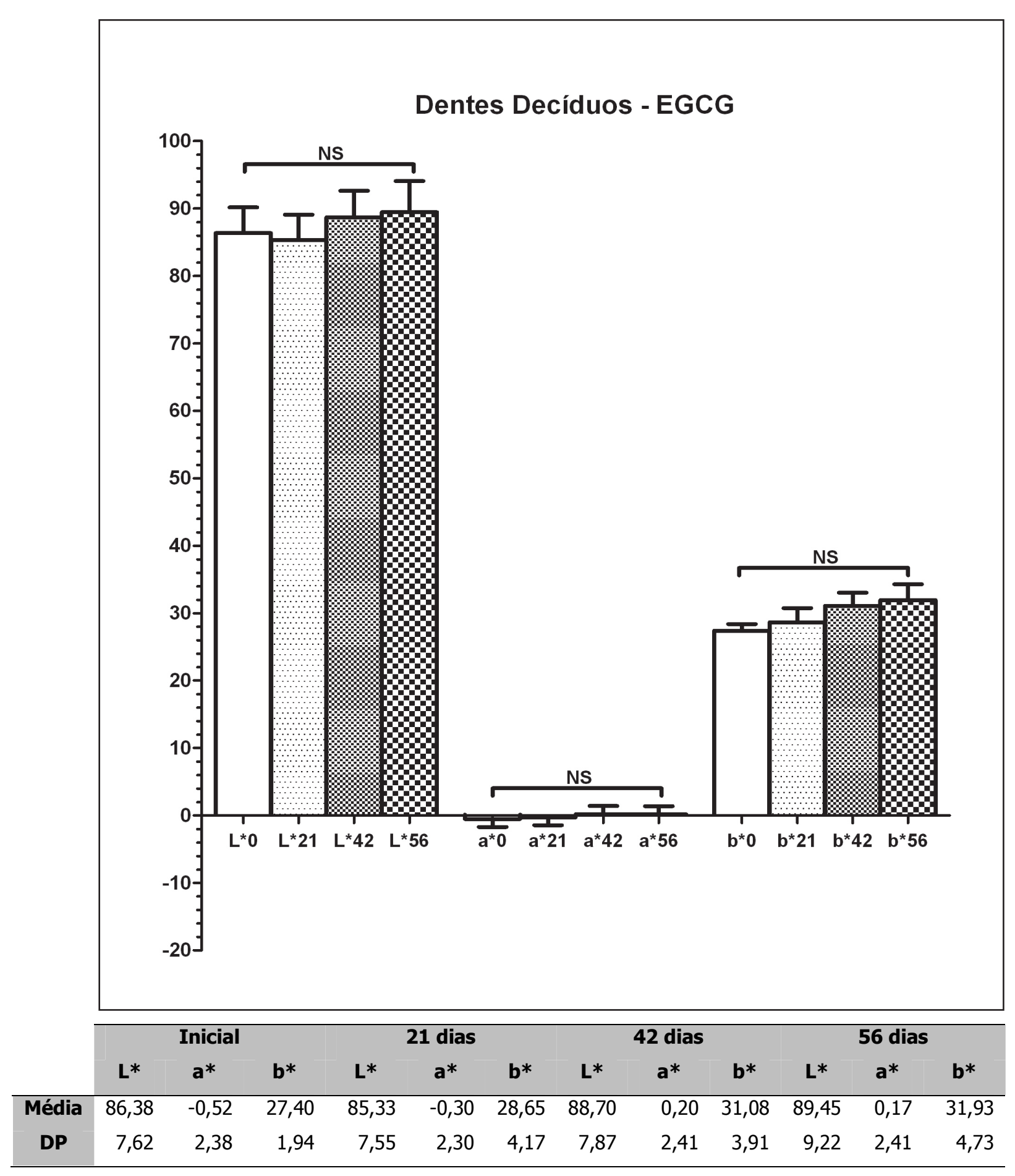

Figura 32. Média e desvio padrão (DP) dos valores de $L^{*}$, a* e b* dos dentes decíduos após aplicação intracanal de EGCG por 21, 42 e 56 dias. NS: diferença estatística não significante 


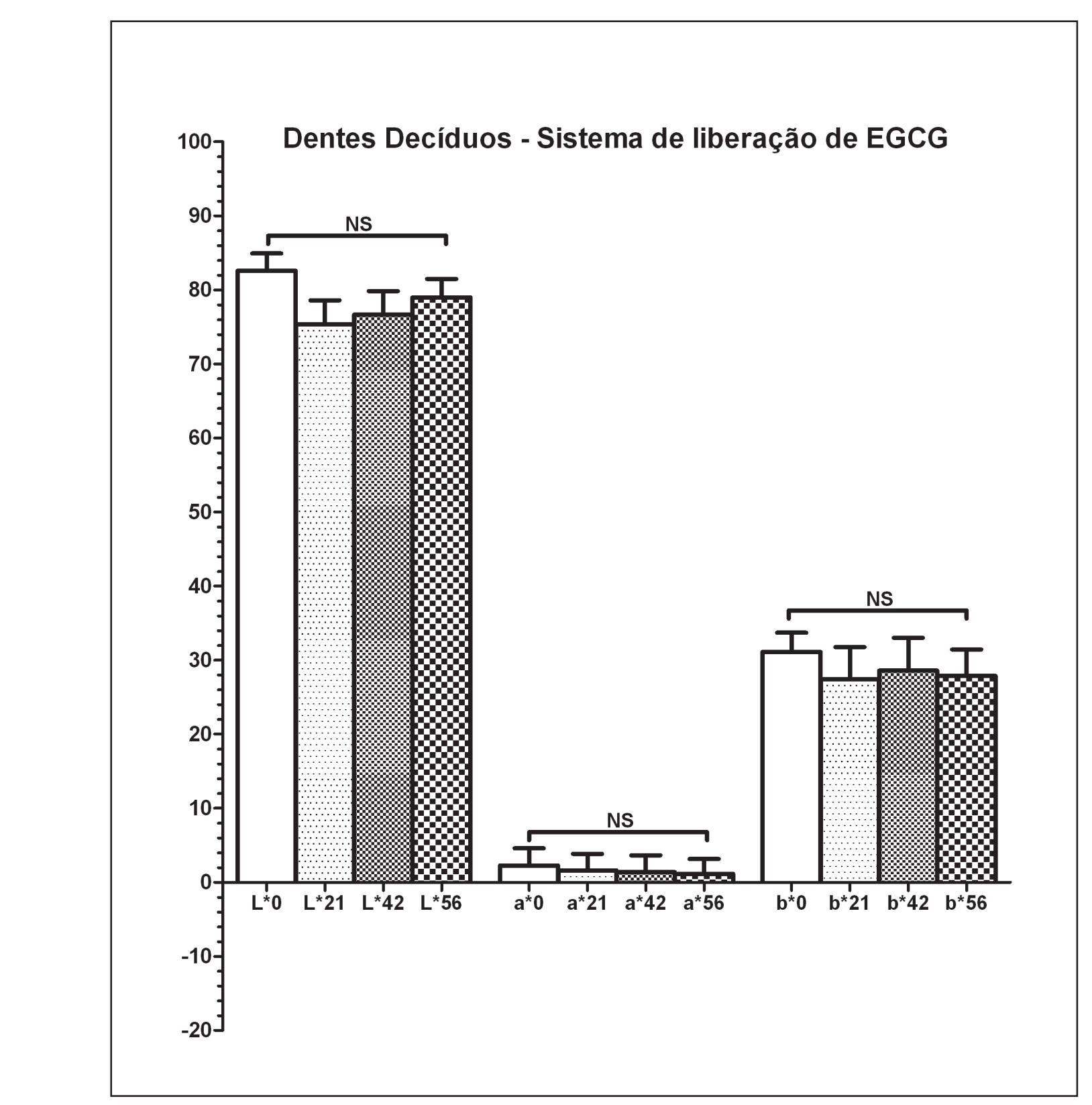

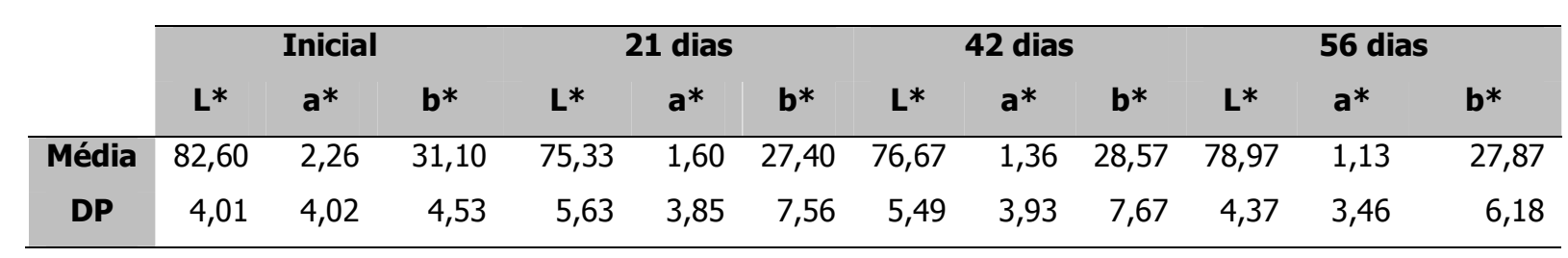

Figura 33. Média e desvio padrão (DP) dos valores de $L^{*}$, a* e b* dos dentes decíduos após aplicação intracanal do sistema de liberação de EGCG por 21, 42 e 56 dias. NS: diferença estatística não significante 
Tabela 2. Média (Desvio Padrão) dos valores de $\Delta \mathrm{L}, \Delta \mathrm{a}, \Delta \mathrm{b}$ e $\Delta \mathrm{E}$, da coroa dos dentes permanentes e decíduos, tratados com EGCG (EGCG/ $\left.\mathrm{H}_{2} \mathrm{O}\right)$ ou com o sistema de liberação de EGCG (EGCG/PEG) durante 21,42 e 56 dias.

\begin{tabular}{|c|c|c|c|c|}
\hline & & 21 dias & 42 dias & 56 dias \\
\hline & \multicolumn{4}{|c|}{$\Delta \mathbf{L}$} \\
\hline \multirow[t]{2}{*}{ Dentes Decíduos } & $\mathrm{EGCG} / \mathrm{H}_{2} \mathrm{O}$ & $-1.05(0.07)$ & $2.32(0.24)$ & $3.07(1.60)$ \\
\hline & EGCG/PEG & $-7.27(1.61)$ & $-5.93(1.47)$ & $-3.63(0.35)$ \\
\hline \multirow{3}{*}{ Dentes Permanentes } & $\mathrm{EGCG} / \mathrm{H}_{2} \mathrm{O}$ & $1.00(3.21)$ & $0.08(3.63)$ & $0.48(3.95)$ \\
\hline & EGCG/PEG & $-3.34(1.23)$ & $-2.18(0.04)$ & $-1.48(0.09)$ \\
\hline & \multicolumn{4}{|c|}{$\Delta \mathbf{a}$} \\
\hline \multirow[t]{2}{*}{ Dentes Decíduos } & $\mathrm{EGCG} / \mathrm{H}_{2} \mathrm{O}$ & $0.22(0.08)$ & $-0.32(0.03)$ & $-0.35(0.03)$ \\
\hline & EGCG/PEG & $-0.66(-0.16)$ & $-0.9(0.08)$ & $-1.13(0.55)$ \\
\hline \multirow{2}{*}{ Dentes Permanentes } & $\mathrm{EGCG} / \mathrm{H}_{2} \mathrm{O}$ & $-0.62(1.09)$ & $-0.66(3.69)$ & $-0.62(1.18)$ \\
\hline & EGCG/PEG & $-0.38(0.47)$ & $0.20(0.16)$ & $-0.19(0.08)$ \\
\hline \multirow{3}{*}{ Dentes Decíduos } & \multicolumn{4}{|c|}{$\mathbf{\Delta b}$} \\
\hline & $\mathrm{EGCG} / \mathrm{H}_{2} \mathrm{O}$ & $1.25(2.23)$ & 3.68 (1.97) & $4.53(2.76)$ \\
\hline & EGCG/PEG & $-3.7(3.03)$ & $-2.53(3.13)$ & $-3.23(1.65)$ \\
\hline \multirow{2}{*}{ Dentes Permanentes } & $\mathrm{EGCG} / \mathrm{H}_{2} \mathrm{O}$ & $4.77(2.74)$ & $4.29(2.92)$ & 3.89 (3.69) \\
\hline & EGCG/PEG & $0.80(1.65)$ & $-0.50(0.08)$ & $1.32(0.68)$ \\
\hline \multirow{3}{*}{ Dentes Decíduos } & \multicolumn{4}{|c|}{$\Delta \mathbf{E}$} \\
\hline & $\mathrm{EGCG} / \mathrm{H}_{2} \mathrm{O}$ & $1.26(0.10)$ & $4.36(1.98)$ & $5.48(3.19)$ \\
\hline & EGCG/PEG & $7.29(1.61)$ & $6.50(3.45)$ & $4.98(1.77)$ \\
\hline \multirow[t]{2}{*}{ Dentes Permanentes } & $\mathrm{EGCG} / \mathrm{H}_{2} \mathrm{O}$ & $1.17(3.39)$ & $4.34(5.94)$ & $3.96(5.53)$ \\
\hline & EGCG/PEG & $0.88(1.31)$ & $2.24(0.18)$ & $1.99(0.69)$ \\
\hline
\end{tabular}




\section{$D_{\text {iscussão }}$}





\section{DisCUSSÃO}

O estudo e utilização de substâncias naturais com finalidade terapêutica constitui medida de grande impacto econômico e social, principalmente em saúde pública. Em todo o mundo, uma grande variedade de plantas medicinais vem sendo utilizadas há milhares de anos para o tratamento de doenças. No entanto, muitas vezes o isolamento da substância responsável pelos efeitos terapêuticos da planta (princípio ativo) e seu mecanismo de ação não são conhecidos. A identificação e caracterização do princípio ativo dos extratos naturais é muito importante para avaliar seus verdadeiros benefícios ou potenciais riscos à saúde humana (Reto et al., 2007). A EGCG, derivado bioativo do chá-verde recentemente isolado e purificado, apresenta comprovada ação antimicrobiana (Yang et al., 2010), anti-inflamatória, inibidora de reabsorção e inativadora de LPS bacteriano (Yun et al., 2004) e estimuladora de regeneração óssea (Rodrigues et al., 2011) em diferentes condições patológicas. No entanto, sua utilização como medicação entre sessões durante a terapia endodôntica não havia sido proposta.

Na literatura endodôntica, apenas um estudo relatou que o uso sistêmico da EGCG em ratos, por meio de injeções intraperitoneais, resultou em acentuada redução na extensão e severidade de lesões periapicais associadas a dentes portadores de necrose pulpar (Lee et al., 2009). No entanto, tal medida sugere o uso da EGCG de forma sistêmica para o tratamento de uma doença que apresenta etiopatogenia local. Sabe-se o tratamento de dentes portadores de necrose pulpar e lesão periapical visível radiograficamente é essencialmente tópico, envolvendo a desinfecção do sistema de canais radiculares e região periapical, que abrigam os microrganismos responsáveis pelo aparecimento e manutenção da doença (Kakehashi et al., 1965; Tronstad, 1992). Por esse motivo nosso objetivo foi desenvolver uma formulação tópica à base de EGCG que proporcionasse a desinfecção do sistema de canais radiculares e reparação de tecidos apicais e periapicais destes dentes utilizando um medicamento natural. Até o momento não existe um tratamento ideal ou uma medicação que resulte em $100 \%$ de sucesso clínico, radiográfico, microbiológico e histológico. Para esta finalidade sugerimos que a EGCG fosse aplicada na sua forma biológica ativa, o que tornou inicialmente necessária a caracterização de suas propriedades fotofísicas e fotoquímicas em diferentes meios e condições locais.

Atualmente, o método mais utilizado para caracterização físico-química de substâncias com finalidade farmacológica é a espectroscopia de absorção, que pode ser realizada em luz UV-VIS ou fluorescência. A espectroscopia na faixa de luz UV-VIS é utilizada 
na caracterização reações químicas e bioquímicas, bem como na descrição de mecanismos e cinéticas de reações biológicas complexas em pesquisas de novos agentes farmacológicos (Galo e Colombo, 2009). As vantagens de aplicação dessa metodologia, que foi utilizada no presente estudo, incluem o baixo custo operacional, reduzido tempo de análise (inferior a 1 minuto) e o fato de ser uma técnica espectroscópica quantitativa, de fácil interpretação. A metodologia consiste na aplicação de um feixe de luz, de comprimento de onda e intensidade conhecidos, que permite a quantificação da absorção de luz (absorbância) da amostra. No presente estudo a técnica espectrofotometria em luz UV/Vis mostrou que EGCG em solução aquosa neutra $\left(8,6 \times 10^{-5} \mathrm{~mol} / \mathrm{L}\right)$ apresentou absorbância de $274 \mathrm{~nm}$, muito semelhante ao preconizado pelo fabricante $(275 \mathrm{~nm}$ ) e ao obtido em estudos anteriores (272 a 274nm) (Tang et al., 2004; Zheng et al., 2006; Zhao et al., 2012). Esse padrão de absorbância apresentou estabilidade ao longo do tempo, por até 27 horas, e não foi alterado em meio ácido. A estabilidade da EGCG em meio ácido, é de grande importância e favorece seu possível uso intracanal no tratamento das lesões periapicais, pois nesse ambiente estão presentes produtos e subprodutos tóxicos provenientes das bactérias Gram-negativas, que torna esse meio ácido, com baixo nível de $\mathrm{pH}$, favorável à reabsorção dos tecidos mineralizados (Nair, 2004).

A espectroscopia de fluorescência, metodologia também utilizada no presente estudo, foi desenvolvida como alternativa à luz UV/Vis, para quantificar fármacos em medicamentos. Esta técnica apresenta maior sensibilidade e precisão, sendo amplamente aplicada em substâncias que requerem baixos limites de detecção. A sensibilidade inerente a esta técnica é consideravelmente maior em comparação à espectrofotometria em luz UV/visível, apresentando limites de detecção de até três ordens de grandeza menores. Contudo, apesar de todas as vantagens oferecidas pelos métodos fluorescentes, somente algumas substâncias exibem fluorescência nativa, como consequência dos processos de desativação que ocorrem em uma molécula (Sotomayor et al., 2008). Desta forma, o espectrofluorímetro pode facilmente dosar baixos teores de quaisquer hidrocarbonetos aromáticos, conhecendose seus comprimentos de onda de excitação (obtidos por meio de espectroscopia na região do ultravioleta) e a partir daí constrói-se uma curva de calibração. Nossos resultados mostraram a EGCG apresentou propriedades fluorescentes e espectro de emissão em 393 nm, também semelhante ao encontrado por outro estudo $393 \mathrm{~nm}$ (Miyake et al., 2011), diferente de um estudo anterior onde encontrou-se o espectro de emissão da EGCG foi de 343 nm (Maiti et al., 2006). Considerando que variações no meio, ácido ou básico, podem interferir na intensidade da fluorescência, também efetuamos essa análise e verificamos que as propriedades fluorescentes da EGCG também não foram alteradas em função do tempo 
ou do meio. No presente não foi possível determinar o valor exato do pKa da EGCG, sugerindo-se que o ponto de desprotonação da substância possa estar presente em um pH inferior ao utilizado.

Após a caracterização físico-química da EGCG em água, buscamos o desenvolvimento de uma formulação que apresentasse condições de uso clínico, podendo ser levada no interior dos canais radiculares e mantida por períodos prolongados. A água, apesar de ser considerado um solvente universal e ser indicada pelo fabricante da EGCG, não apresenta características físicas favoráveis para utilização como medicação intracanal, pois é rapidamente solubilizada e reabsorvida pelo organismo (Ballal et al., 2010), o que manteria o canal radicular vazio na maioria do período entre as sessões de tratamento. Assim, foi testada a associação da EGCG com um veículo viscoso, o PEG 400. A opção pela utilização do PEG 400, um polímero flexível, levou em consideração o fato do mesmo ser biocompatível e apresentar um sistema lipossomal de liberação de droga, permitindo que esta seja liberada de forma lenta e por um período tempo prolongado (Klibanov et al., 1990; Allen t al., 1991; Torchilin, 2005). Ainda, este veículo é também utilizado no curativo de demora mais consagrado na literatura e utilizado na prática clínica por nosso grupo de pesquisa, uma pasta à base de base de hidróxido de cálcio (Calen, S.S. White Artigos Dentários Ltda, Rio de Janeiro, RJ - Brasil). A tecnologia de liberação controlada de substâncias para uso terapêutico oferece inúmeras vantagens quando comparados a sistemas de aplicação convencionais, tais como: maior eficácia terapêutica, com liberação progressiva e controlada do fármaco, diminuição significativa da toxicidade e maior tempo de permanência na circulação, além de proteção contra mecanismos de instabilidade e decomposição do fármaco (inativação prematura), administração segura, sem reações inflamatórias locais, diminuição do número de doses devido à liberação progressiva e possibilidade de direcionamento a alvos específicos (Mufamandi et al., 2011). De acordo com nossos resultados, o PEG 400, utilizado como veículo viscoso, não causou alteração no comportamento espectral da EGCG em luz UV/Vis ou em fluorescência. Além de manter as propriedades físico-químicas da EGCG, o PEG 400 preservou sua integridade e estabilidade na presença de cálcio, o que não ocorreu quando a mesma foi manipulada em água.

Alguns estudos na literatura sugerem que a EGCG possa ter ação quelante em íons de metais de transição (Wu et al., 2009; Yin et al., 2009; Miyake et al., 2011; Soler et al., 2012). Isso pode justificar o comportamento alterado do espectro de absorção da EGCG, quando a mesma for manipulada em água na presença de meio básico $\left(\mathrm{Ca}(\mathrm{OH})_{2}\right)$ e neutro $\left(\mathrm{CaCl}_{2}\right)$, visto que o íon cálcio $\left(\mathrm{Ca}^{+}\right)$, principal componente, é um metal. A EGCG em solução aquosa de hidróxido de cálcio e cloreto de cálcio apresentou uma complexação com o íon 
$\mathrm{Ca}^{+}$, sendo verificada pelo escurecimento da solução, sugerindo a ação quelante da EGCG com o íon. Este resultado é corroborado por um estudo recente onde o transporte de $\mathrm{Ca}^{+}$ celular foi reduzido proporcionalmente ao aumento de concentração da EGCG (Soler et al., 2012). Outros estudos anteriores têm mostrado que a EGCG pode produzir alterações na homeostase de $\mathrm{Ca}_{2}{ }^{+}$intracelular, quer em células excitáveis ou não excitáveis (Wu et al., 2009; Yin et al., 2009). Essa ação quelante também pôde ser verificada em outros metais como ferro $\left(\mathrm{Fe}_{2}^{+}\right)$, cobre $\left(\mathrm{Cu}_{2}^{+}\right)$e zinco $\left(\mathrm{Zn}_{2}{ }^{+}\right)$, sobre a atividade hepatoprotetora da EGCG contra hepatotoxina induzida por lesão celular. Os resultados sugerem que há uma complexação da EGCG com o $\mathrm{Zn}_{2}{ }^{+}$, a qual foi confirmada pelo método de UV-Vis (Kagaya et al., 2002), o mesmo método utilizado no presente estudo, para verificar a complexação da EGCG com o $\mathrm{Ca}^{+}$.

Em razão de ter sido verificada possível ação quelante da EGCG em solução aquosa e na presença de cálcio, precedemos estudos de imersão de dentes. Sabe-se que o íon cálcio, na forma de fosfato de cálcio, constitui a $99 \%$ do peso seco do esmalte dentário (Fejerskov e Kidd, 2007). O comportamento alterado da EGCG (diminuição da absorbância) em solução aquosa também foi verificado no estudo de imersão dos dentes decíduos e permanentes, onde verificou-se o escurecimento da solução e de regiões dos dentes onde havia presença de remanescentes de colágeno. Uma vez que a EGCG em solução aquosa e na presença de cálcio sofre degradação acentuada da estrutura molecular no tempo máximo de avaliação, que foi de 27 horas de acompanhamento, sua utilização como curativo de demora poderia estaria comprometida. Ainda, considerando a possível ação quelante de cálcio da EGCG, não se sabe o quão prejudicial poderia ser à estrutura dental, um contato prolongado da EGCG em solução aquosa com o dente na forma de curativo. Por outro lado, o PEG 400, impediu a ação quelante da EGCG quando em contato com os elementos dentais, sendo verificado bom comportamento espectral da substância não havendo escurecimento da solução, nem das estruturas dentais e também não havendo alteração da absorbância. Esses resultados sugerem que a formulação proposta para aplicação da EGCG, com PEG 400, atue como um protetor da estrutura molecular da EGCG, impedindo sua degradação e assim prolongando sua efetividade por meio da liberação prolongada da droga.

Atualmente, o aumento das exigências estéticas dos pacientes torna importante a avaliação de possíveis mudanças de cor do dente em decorrência de tratamentos odontológicos (Moreira et al., 2012). Sabe-se que a alteração de cor dental pode ser decorrente do curativo antimicrobiano utilizado no tratamento endodôntico (Plotino et al., 2009), incluindo a aplicação tópica do hidróxido de cálcio (Kim et al., 2000; Kim et al., 2000; Tinaz et al., 2008), curativo mais utilizado atualmente. Embora a EGCG veiculada em PEG 
apresente propriedades físico-químicas ideais para possível uso como medicação intracanal durante o tratamento endodôntico, deve-se considerar que a mesma é derivada do chá verde, uma bebida com potencial de causar alteração de cor dental (Attin et al., 2003). Por esse motivo o presente estudo avaliou o possível efeito da aplicação tópica intracanal de EGCG na cor da coroa dental, em períodos de 7, 21 e 56 dias, considerando estes os possíveis períodos clínicos em que os dentes decíduos e permanentes podem permanecer com curativo de demora entre sessões, previamente à obturação dos canais radiculares.

O espectrofotômetro também vem sendo utilizado tem por vários autores para avaliar alteração de cor dental em materiais restauradores (Attin et al., 2003; Pires-de-Souza et al., 2011; Moreira et al., 2012; Sabatini et al., 2012) e foi a metodologia escolhida no presente estudo porque sua análise quantitativa exclui os possíveis erros de subjetividade na avaliação de cor (Paul et al., 2002; Moreira et al., 2013). Sabe-se que percepção de cor por meio de avaliação visual é subjetiva e varia de pessoa para pessoa. Essa subjetividade é resultado de muitos fatores, como a posição do objeto observado e do observador com relação à iluminação; a cor da luz utilizada para a iluminação; metamerismo, fadiga e envelhecimento do objeto; bem como a fisiologia e o estado emocional do observador (Yannikakis, et al., 1998). A avaliação de cor foi feita pelo sistema CIELAB, com análise dos valores absolutos de $L^{*}, a^{*}$ e $b^{*}$. Também aplicamos uma fórmula para a avaliação do $\Delta \mathrm{E}$, que vêm sendo utilizada para avaliar alteração de cor em materiais odontológicos (Pires-deSouza et al., 2011; Moreira et al., 2012; Sabatini et al., 2012). O $\Delta \mathrm{E}$ tem sido avaliado com aceitação clínica de cor dental quando inferior a 3.3 (Sabatini et al., 2012; Pires-de-Souza et al., 2011). Quando o $\Delta \mathrm{E}<1$ a alteração de cor não é detectada pelo olho humano, $1 \leq \Delta \mathrm{E} \leq$ 3.3 a alteração de cor é detectada pelo olho humano mas é clinicamente aceitável e $\Delta \mathrm{E} \geq$ 3.3 a alteração de cor é detectada pelo olho humano e clinicamente inaceitável (Inokoshi et al., 1996; Kim et al., 2006). Em contraste, alguns autores consideram como inaceitável valores de $\Delta \mathrm{E}^{*} \geq 2$ (O'Brien et al., 1990) ou $\Delta \mathrm{E}^{*} \geq 3.7$ (Kim e Lee, 2009). Embora tenhamos considerado valores inaceitáveis acima de 3.3, estes também estavam acima de 3.7, o que não alteraria nossos resultados.

De acordo com os valores absolutos encontrados nas coordenadas $L^{*}$, a* e b*, não verificamos alteração de cor dental significativa após o uso da EGCG. No entanto, o valor de $\Delta \mathrm{E}$ foi superior a 3.3 em quase todos os grupos exceto para o sistema de liberação de EGCG em dentes permanentes e EGCG em dentes decíduos e permanentes após 21 dias. Esses resultados sugerem que o PEG 400 possa ser o melhor veículo se utilizado como curativo antimicrobiano em períodos prolongados, reduzindo possíveis alterações de cor provavelmente oriunda da complexação com cálcio dental em função do tempo, uma vez 
que este íon está presente em maior quantidade em dentes decíduos. Embora tenhamos encontrado esses resultados após a aplicação da fórmula para obtenção do $\Delta \mathrm{E}$, optamos pela apresentação das conclusões tendo como base os valores absolutos e independentes das coordenadas $L^{*}, a^{*}$ e $b^{*}$, de acordo com o CIELAB. A avaliação da alteração de cor das coordenadas $L^{*}, a^{*}$ e $b^{*}$, independentes, também vêm sendo realizada por outros autores (Shi et al., 2012). Esta opção se deu ao fato das possíveis falhas metodológicas decorrentes da aplicação dessa fórmula; estudo recente sobre confiabilidade metodológica do sistema CIELAB, revelou que as coordenadas $a^{*}$ e $b^{*}$ podem ser correlacionadas, pois estão localizadas no mesmo plano volumétrico tridimensional, enquanto a coordenada $L^{*}$, sofre variação independente de $a^{*}$ e $b^{*}$ (Knosel et al., 2012). Assim, nossos resultados de cor e luz foram avaliados na análise estatística considerando valores absolutos de $L^{*}, a^{*}$ e $b^{*}$.

Sugere-se ainda que, embora alguns valores de $\Delta \mathrm{E}$ tenham sido encontrados acima de 3.3, essa variação pode não ser decorrente da alteração de cor do dente, mas sim do cimento de ionômero de vidro, material aplicado na face palatina dos dentes para o selamento coronário provisório dos mesmos durante o período de aplicação do curativo de demora. Sabe-se que o cimento de ionômero de vidro é sensível e pode sofrer alteração de cor com o decorrer do tempo (Davis et al., 1995, Lim et al., 2001) e na presença de água. Sugere-se que a água proveniente do curativo intracanal possa ter alterado as propriedades de cimento de ionômero de vidro. A utilização do PEG impediu a ação hidrofílica do curativo e não alterou a cor dental. No entanto, na clínica essa situação seria evitada, pois para a obturação definitiva dos canais radiculares de dentes decíduos e permanentes, o selamento provisório com cimento de ionômero de vidro é removido e o dente é restaurado definitivamente com uma resina composta fotopolimerizável, da cor do dente. No presente estudo não efetuamos a obturação dos canais radiculares e restauração com resina composta fotopolimerizável para não criar fatores de variação.

Embora a aplicação de EGCG não tenha causado alteração de cor significativa na coroa dental após sua aplicação intracanal, utilizamos dentes hígidos para sua avaliação. Assim, estudos futuros são necessários para avaliar o possível efeito da EGCG sobre dentes portadores de lesões de cárie ou de restaurações dentais, incluindo a avaliação de outros meios de aplicação da EGCG, como em soluções para bochecho ou dentifrícios.

Dentro das limitações do presente estudo, a associação da EGCG com PEG 400 apresentou resultados promissores para sua possível utilização como medicação intracanal. No entanto, deve-se considerar que essa foi a primeira formulação desenvolvida por nosso grupo de pesquisa e que estudos futuros devem ser realizados para a avaliação de outras propriedades, incluindo a definição de sua concentração ideal, visando manter 
biocompatibilidade com o máximo de ação antimicrobiana. Ainda, os recentes avanços trazidos pela nanotecnologia, que se refere à tecnologia utilizada para manipular estruturas pequenas e torná-las mais reativas, têm proporcionado o desenvolvimento de novos fármacos para tratamento de diferentes doenças (Adrian et al., 2011, Kwong et al., 2011; Yoncheva; MomeKov, 2011). Assim, também sugere-se o futuro desenvolvimento de outras formulações, seja em associação com outros veículos ou utilizando os benefícios da nanotecnologia. 



Conclusão 



Conclusão

Com base nas metodologias e nos resultados obtidos no presente estudo pode-se concluir que a EGCG apresenta fluorescência, estabilidade em função do tempo e em meio ácido, enquanto em meio básico e na presença de elementos dentais seu comportamento espectral é alterado. O sistema desenvolvido para liberação controlada da EGCG não alterou suas propriedades físico-químicas, apresentou estabilidade em função do tempo e manteve seu comportamento espectral na presença dos elementos dentais. Ainda a aplicação intracanal deste sistema não causou alteração de cor na coroa dos dentes. 



\section{Referências}





\section{REFERÊNCIAS}

1. Adrian JE, Wolf A, Steinbach A, Rössler J, Süss R. Targeted Delivery to Neuroblastoma of Novel siRNA-anti-GD2-liposomes Prepared by Dual Asymmetric Centrifugation and Sterol-Based Post-Insertion Method. Pharm Res. 2011;28(9):2261-72.

2. Allen TM, Austin GA, Chonn A, Lin L, Lee KC. Uptake of liposomes by cultured mouse bone marrow macrophages: influence of liposome composition and size. Biochim Biophys Acta. 1991; 1061(1):56-64.

3. Andolfatto $C$, da Silva GF, Cornélio AL, Guerreiro-Tanomaru JM, Tanomaru-Filho $M$, Faria G, Bonetti-Filho I, Cerri PS. Biocompatibility of intracanal medications based on calcium hydroxide. ISRN Dent. 2012.

4. Anghileri LJ; Thouvenot, P. Natural polyphenolsiron interaction: its biological importance. Bio Trace Elem Res. 2000;73:251-8.

5. Attin T, Manolakis A, Buchalla W, Hannig C. Influence of tea on intrinsic colour of previously bleached enamel. J Oral Rehabil. 2003;30:488-94.

6. Ballal NV, Shavi GV, Kumar R, Kundabala M, Bhat KS. In vitro sustained release of calcium ions and $\mathrm{pH}$ maintenance from different vehicles containing calcium hydroxide. J Endod. 2010;36(5):862-6.

7. Basu A, Lucas E. Mechanisms and effects of green tea on cardiovascular health. Nutr Rev. 2007;65:361-5.

8. Blanco AR, Mule SLT, Babini G, Garbisa S, Enea V, Rusciano D. (-)Epigallocatechin-3gallate inhibits gelatinase activity of some bacterial isolates from ocular infection, and limits their invasion through gelatine. Biochim Biophys Acta. 2003;1620(1-3):273-81.

9. Cai Y, Kurita-Ochiai T, Hashizume T, Yamamoto M. Green tea epigalocatechin-3-gallate attenuates Porphyrmonas gingivalis - induced atherosclerosis. FEMS Immunol Med Microbiol. 2013;67:76-83.

10. Choi JH, Rhee IK, Park KY, Park KY, Kim JK, Rhee SJ. Action of green tea catechin on bone metabolic disorder in chronic cadmium-poisoned rats. Life Scienses. 2003;73:1479-89.

11. Chung JH, Han JH, Hwang EJ, Seo JY, Cho KH, Kim KH, Youn JI, Eun HC. Dual mechanisms of green tea extract (EGCG)-induced cell survival in human epidermal keratinocytes. FASEB J. 2003;17(13):1913-5.

12. Chung JY, Park JO, Phyu H, Dong Z, Yang CS. Mechanisms of inhibition of the Ras-MAP kinase signaling pathway in $30.7 \mathrm{~b}$ Ras 12 cells by tea polyphenols (-)-epigallocatechin3-gallate and the aflavin-3,3'-digallate. FASEB J. 2001;15(11):2022-4.

13. Cook, N. C.; Samman, S. Flavonoids-Chemistry, metabolism, cardioprotective effects, and dietary sources. J Nutrit Biochemistry.1996;7(2):66-76. 
14. Cui Y, Oh YJ, Lim J, Youn M, Lee I, Pak HK, Park W, Jo W, Park S. AFM study of the differential inhibitory effects of the green tea polyphenol-epigallocatechin-3-gallate (EGCG) against Gram-positive and Gram-negative bacteria. Food Microbiol. 2012;29(1):80-7.

15. Davis BA, Friedl $\mathrm{KH}$, Powers JM. Color stability of hybrid ionomers after accelerated aging. J Prosthodont. 1995;4:111-5.

16. De Rossi A, Silva LA, Leonardo MR, Rocha LB, Rossi MA. Effect of rotary or manual instrumentation, with or without a calcium hydroxide/ $1 \%$ chlorhexidine intracanal dressing, on the healing of experimentally induced chronic periapical lesions. Oral Surg Oral Med Oral Pathol Oral Radiol Endod. 2005;99(5):628-36.

17. Dreger H, Lorenz M, Kehrer A, Baumann G, Stangl K, Stangl V. Characteristics of catechin- and theaflavin-mediated cardioprotection. Exp Biol Med (Maywood). 2008;233(4):427-33.

18. Fejerskov O, Kidd E. Cárie Dentária a Doença e Seu Tratamento Clínico. São Paulo: Ed. Santos; 2007. p:49-69.

19. Ferreira PDF. Ausência do receptor Toll-like 2 ocasionou a formação de lesões periapicais mais extensas e com maior número de osteoclastos em camundongos. 2011. Dissertação de Mestrado - Faculdade de Odontologia de Ribeirão Preto, Universidade de São Paulo, Ribeirão Preto, Brasil.

20. Galo AL, Colombo MF. Espectrofotometria de longo caminho óptico em espectrofotômetro de duplo-feixe convencional: uma alternativa simples para investigações de amostras com densidade óptica muito baixa. Quim. Nova. 2009;32(2), 488-92.

21. Hamilton-Miller JM. Anti-cariogenic properties of tea (Camellia sinensis). J Med Microbiol. 2001;50(4):299-302.

22. Hegarty VM, May HM, Khaw KT. Tea drinking and bone mineral density in older women. Am J Clin Nutr. 2000;71(4):1003-7.

23. Hirasawa $\mathrm{M}$, Takada $\mathrm{K}$, Otake $\mathrm{S}$. Inhibition of acid production in dental plaque bacteria by green tea catechins. Caries Res. 2006;40:265-270.

24. Hodgson JM, Croft KD. Tea flavonoids and cardiovascular health. Mol Aspects Med. 2010;31(6):495-502.

25. Hwang JY, Choi SC, Park JH, Kang SW. The use of green tea extract as a storage medium for the avulsed tooth. J Endod. 2011;37:962-7.

26. Ikigai $H$, Nakae $T$, Hara $Y$, Shimamura $T$. Bactericidal catechins damage the lipid bilayer. Biochim Biophys Acta. 1993;1147(1):132-6.

27. Inokoshi S, Burrow MF, Kataumi M, Yamada T, Takatsu T. Opacity and color changes of tooth-colored restorative materials. Oper Dent. 1996;21:73-80. 
28. Itoh T, Tabuchi M, Mizuguchi N, Imano M, Tsubaki M, Nishida S, Hashimoto S, Matsuo $K$, Nakayama T, Ito A, Munakata $H$, Satou T. Neuroprotective effect of (-)epigallocatechin-3-gallate in rats when administered pre- or post-traumatic brain injury. J Neural Transm. 2013;120(5):767-83.

29. Ján K, Daniel K. [Microbial decontamination of the root canals of devitalized teeth]. [Article in Czech] Epidemiol Mikrobiol Imunol. 2012;61(4):87-97.

30. Jenabian N, Moghadamnia AA, Karami E, Mir A PB. The effect of Camellia Sinensis (green tea) mouthwash on plaque-induced gingivitis: a single-blinded randomized controlled clinical trial. Daru. 2012;20:39.

31. Jung IH, Lee DE, Yun JH, Cho AR, Kim CS, You YJ, Kim SJ, Choi SH. Anti-inflammatory effect of (-)-epigallocatechin-3-gallate on Porphyromonas gingivalis lipopolysaccharidestimulated fibroblasts and stem cells derived from human periodontal ligament. J Periodontal Implant Sci. 2012;42:185-95.

32. Jung IH, Yun JH, Cho AR, Kim CS, Chung WG, Choi SH. Effect of (-)-epigallocatechin-3gallate on maintaining the periodontal ligament cell viability of avulsed teeth: a preliminary study. J Periodontal Implant Sci. 2011;41:10-6.

33. Kagaya N, Kawase M, Maeda H, Tagawa $Y$, Nagashima H, Ohmori H, Yagi K. Enhancing effect of zinc on hepatoprotectivity of epigallocatechin gallate in isolated rat hepatocytes. Biol Pharm Bull. 2002;25(9):1156-60.

34. Kakehashi S, Stanley HR, Fitzgerald RJ. The effects of surgical exposures of dental pulps in germ-free and conventional laboratory rats. Oral Surg Oral Med Oral Pathol. $1965 ; 20: 340-9$.

35. Kandaswamy D, Venkateshbabu N. Root canal irrigants. J Conserv Dent. 2010;13(4):256-64.

36. Kang HG, Jenabi JM, Liu XF, Reynolds CP, Triche TJ, Sorensen PH. Inhibition of the insulin-like growth factor I receptor by epigallocatechin gallate blocks proliferation and induces the death of Ewing tumor cells. Mol Cancer Ther. 2010;9(5):1396-407.

37. Kanis JA, Johnell O, Oden A, Jonsson B, De Laet C, Dawson A. Prediction of fracture from low bone mineral density measurements overestimates risk. Bone. 2000;26(4):387-91.

38. Keraliya RA, Patel C, Patel P, Keraliya V, Soni TG, Patel RC, Patel MM. Osmotic drug delivery system as a part of modified release dosage form. ISRN Pharm. 2012.

39. Khan N, Mukhtar H. Tea and health: Studies in humans. Curr Pharm Des. 2013.

40. Kim BJ, Lee YK. Influence of the shade designation on the color difference between the same shade-designated resin composites by the brand. Dental Materials 2009;25:1148-54.

41. Kim JH, Lee YK, Powers JM. Influenca of a series of organic and chemical substances on the translucency of resin composites. J Biomed Mater Res B Appl Biomater. 2006;77B:21-7. 
42. Kim ST, Abbott PV, McGinley P. The effect of Ledermix paste on discolouration of immature teeth. Int Endod J. 2000;33:233-7.

43. Klibanov AL, Maruyama K, Torchilin VP, Huang L. Amphipathic polyethyleneglycols effectively prolong the circulation time of liposomes. FEBS Lett. 1990;268(1):235-7.

44. Knösel $M$, Reus $M$, Rosenberger $A$, Ziebolz D. A novel method for testing the veridicality of dentel colour assessments. Eur J Orthod. 2012;34(1):19-24.

45. Kokubo Y, Iso H, Saito I, Yamagishi K, Yatsuya H, Ishihara J, Inoue M, Tsugane S. The Impact of Green Tea and Coffee Consumption on the Reduced Risk of Stroke Incidence in Japanese Population: The Japan Public Health Center-Based Study Cohort. Stroke. 2013;44(5):1369-74.

46. Kovac J, Kovac D. Effect of irrigating solutions in endodontic therapy. Bratisl Lek Listy. 2011;112(7):410-5.

47. Krastl G, Allgayer N, Lenherr P, Filippi A, Taneja P, Weiger R. Tooth discoloration induced by endodontic materials: a literature review. Dent Traumatol. 2013;29(1):2-7.

48. Küchler IL, Silva FAM. Método potenciométrico para determinação de cobre em cachaça. Quím Nova. 1999 22(3).

49. Kwong B, Liu H, Irvine DJ. Induction of potent anti-tumor responses while eliminating systemic side effects via liposome-anchored combinatorial immunotherapy. Biomaterials. 2011;32(22):5134-47.

50. Lee $\mathrm{YL}$, Hong $\mathrm{CY}$, Kok SH, Hou KL, Lin YT, Chen MH, Wang CC, Lin SK. An extract of green tea, epigallocatechin-3-gallate, reduces periapical lesions by inhibiting cysteinerich 61 expression in osteoblasts. J Endod. 2009;35(2):206-11.

51. Lee $\mathrm{YL}$, Lin SK, Hong CY, Wang JS, Yang H, Lai EH, Chen MH, Kok SH. Major histocompatibility complex class II transactivator inhibits cysteine-rich 61 expression in osteoblastic cells and its implication in the pathogenesis of periapical lesions. J Endod. 2010;36(6):1021-5.

52. Leonardo MR, Hernandez ME, Silva LA, Tanomaru-Filho M. Effect of a calcium hydroxide-based root canal dressing on periapical repair in dogs: a histological study. Oral Surg Oral Med Oral Pathol Oral Radiol Endod. 2006;102(5):680-5.

53. Leonardo MR, Leonardo RT. Tratamento de canais radiculares: Avanços tecnológicos de uma endodontia minimamente invasiva e reparadora. São Paulo: Artes Médicas; 2012.

54. Leonardo MR, Silveira FF, Silva LA, Tanomaru Filho M, Utrilla LS. Calcium hydroxide root canal dressing. Histopathological evaluation of periapical repair at different time periods. Braz Dent J. 2002;13(1):17-22.

55. Lim BS, Moon HJ, Baek KW, Hahn SH, Kim CW. Color stability of glass-ionomers and polyacid-modified resin-based composites in various environmental solutions. Am J Dent. 2001;14:241-6. 
56. Lin SK, Chang HH, Chen YJ, Wang CC, Galson DL, Hong CY, Kok SH. Epigallocatechin3-gallate diminishes CCL2 expression in human osteoblastic cells via up-regulation of phosphatidylinositol 3-Kinase/Akt/Raf-1 interaction: a potential therapeutic benefit for arthritis. Arthritis Rheum. 2008;58(10):3145-56.

57. Magalhães AC, Wiegand A, Rios D, Hannas A, Attin T, Buzalaf MA. Chlorhexidine and green tea extract reduce dentin erosion and abrasion in situ. J Dent. 2009;37:994-8.

58. Maiti TK, Ghosh KS, Dasgupta S. Interaction of (-)-epigallocatechin-3-gallate with human serum albumin: fluorescence, fourier transform infrared, circular dichroism, and docking studies. Proteins. 2006;64(2):355-62.

59. Maruyama T, Tomofuji T, Endo Y, Irie K, Azuma T, Ekuni D, Tamaki N, Yamamoto T, Morita M. Supplementation of green tea catechins in dentifrices suppresses gingival oxidative stress and periodontal inflammation. Arch Oral Biol. 2011;56:48-53.

60. Meincke DK, Prado M, Gomes BP, Della Bona A, Sousa EL. Effect of endodontic sealers on tooth colour. J Dent. 2012.

61. Miyake T, Yasukawa K, Inouye K. Analysis of the mechanism of inhibition of human matrix metalloproteinase 7 (MMP-7) activity by green tea catechins. Biosci Biotechnol Biochem. 2011;75(8):1564-9.

62. Moreira AD, Mattos CT, de Araújo MV, Ruellas AC, Sant'anna EF. Chromatic analysis of teeth exposed to different mouthrinses. J Dent. 2012.

63. Mufamadi MS, Pillay V, Choonara YE, Du Toit LC, Modi G, Naidoo D, Ndesendo VM. A review on composite liposomal technologies for specialized drug delivery. J Drug Deliv. 2011.

64. Mukhtar H, Ahmad N. Green tea in chemoprevention of cancer. Toxicol Sci. 1999;52(2 Suppl):111-7.

65. Murad C, Fariniuk LF, Fidel S, Fidel RA, Sassone LM. Bacterial leakage in root canals filled with calcium hydroxide paste associated with different vehicles. Braz Dent J. 2008;19(3):232-7.

66. Nagle DG, Ferreira D, Zhou YD. Epigallocatechin-3-gallate (EGCG): chemical and biomedical perspectives. Phytochemistry. 2006;67(17):1849-55.

67. Nair PN, Sjögren U, Figdor D, Sundqvist G. Persistent periapical radiolucencies of rootfilled human teeth, failed endodontic treatments, and periapical scars. Oral Surg Oral Med Oral Pathol Oral Radiol Endod. 1999;87(5):617-27.

68. Nair PN, Sjögren U, Krey G, Kahnberg KE, Sundqvist G. Intraradicular bacteria and fungi in root-filled, asymptomatic human teeth with therapy-resistant periapical lesions: a long-term light and electron microscopic follow-up study. J Endod. 1990;16(12):5808.

69. Nair PN. Pathogenesis of apical periodontitis and the causes of endodontic failures. Crit Rev Oral Biol Med. 2004;15(6):348-81. 
70. Nakamura H, Ukai T, Yoshimura A, Kozuka Y, Yoshioka H, Yoshinaga Y, Abe Y, Hara Y. Green tea catechin inhibits lipopolysaccharide-induced bone resorption in vivo. J Periodontal Res. 2010;45(1):23-30.

71. O'Brien WJ, Groh CL, Boenke KM. A new, small-color-difference equation for dental shades. J Dent Res. 1990;69:1762-4.

72. Oka Y, Iwai S, Amano H, Irie Y, Yatomi K, Ryu K, Yamada S, Inagaki K, Oguchi K. Tea polyphenols inhibit rat osteoclast formation and differentiation. J Pharmacol Sci. 2012;118(1):55-64.

73. Özok AR, Persoon IF, Huse SM, Keijser BJ, Wesselink PR, Crielaard W, Zaura E. Ecology of the microbiome of the infected root canal system: a comparison between apical and coronal root segments. Int Endod J. 2012;45(6):530-41.

74. Paul S, Peter A, Pietrobon N, Hämmerle $\mathrm{CH}$. Visual and spectrophotometric shade analysis of human teeth. J Dent Res. 2002;81(8):578-82.

75. Pianetti S, Guo S, Kavanagh KT, Sonenshein GE. Green tea polyphenol epigallocatechin-3 gallate inhibits Her-2/neu signaling, proliferation, and transformed phenotype of breast cancer cells. Cancer Res. 2002;62(3):652-5.

76. Pires-de-Souza FCP, Garcia LFR, Roselino LMR, Naves LZ. Color stability of siloranebased composites submitted to accelerated artificial ageing-An in situ study. J Dent 2011;39(Suppl1):18-24.

77. Plotino G, Buono L, Grande NM, Pameijer CH, Somma F. Nonvital tooth bleaching: a review of the literature and clinical procedures. J Endod. 2009;34:394-407.

78. Prabhakar J, Senthilkumar M, Priya MS, Mahalakshmi K, Sehgal PK, Sukumaran VG. Evaluation of antimicrobial efficacy of herbal alternatives (Triphala and green tea polyphenols), MTAD, and 5\% sodium hypochlorite against Enterococcus faecalis biofilm formed on tooth substrate: an in vitro study. J Endod. 2010;36(1):83-6.

79. Rao SD, Pagidas K. Epigallocatechin-3-gallate, a natural polyphenol, inhibits cell proliferation and induces apoptosis in human ovarian cancer cells. Anticancer Res. 2010;30(7):2519-23.

80. Reto M, Figueira ME, Filipe HM, Almeida CM. Chemical composition of green tea (Camellia sinensis) infusions commercialized in Portugal. Plant Foods Hum Nutr. 2007;62(4):139-44.

81. Roccaro AS, Blanco AR, Giuliano F, Rusciano D, Enea V. Epigallocatechin-gallate enhances the activity of tetracycline in staphylococci by inhibiting its efflux from bacterial cells. Antimicrob Agents Chemother. 2004;48(6):1968-73.

82. Rodriguez $R$, Kondo $H$, Nyan $M$, Hao J, Miyahara $T$, Ohya K, Kasugai. Implantation of green tea catechin a-tricalcium phosphate combination enhances bone repair in rat skull defects. J Biomed Mater Res B Appl Biomater. 2011;98B(2). 
83. Sabatini $C$, Campillo $M$, Aref J. Color stability of ten resin-based restorative materials. J Esthet Restor Dent. 2012;24:185-99.

84. Schmitz W; Saito AY; Estevão D; Saridakis HO. O chá verde e suas ações como quimioprotetor. Semina: Ciências Biológicas e da Saúde. 2005;26(2):119-130.

85. Senger AEV, Schwanke CHA, Gottlieb MGV. Chá verde (Camellia sinensis) e suas propriedades funcionais nas doenças crônicas não transmissíveis. Scientia Medica (Porto Alegre) 2010;20(4):292-300.

86. Shi XC, Ma H, Zhou JL, Li W. The effect of cold-light-activated bleaching treatment on enamel surfaces in vitro. Int J Oral Sci 2013;4:208-13.

87. Silva LA, Nelson-Filho P, da Silva RA, Flores DS, Heilborn C, Johnson JD, Cohenca N. Revascularization and periapical repair after endodontic treatment using apical negative pressure irrigation versus conventional irrigation plus triantibiotic intracanal dressing in dogs' teeth with apical periodontitis. Oral Surg Oral Med Oral Pathol Oral Radiol Endod. 2010;109(5):779-87.

88. Siqueira JF Jr, Guimarães-Pinto T, Rôças IN. Effects of chemomechanical preparation with $2.5 \%$ sodium hypochlorite and intracanal medication with calcium hydroxide on cultivable bacteria in infected root canals. J Endod. 2007;33(7):800-5.

89. Siqueira JF Jr, Rôças IN. Optimising single-visit disinfection with supplementary approaches: a quest for predictability. Aust Endod J. 2011;37(3):92-8.

90. Sjögren U, Figdor D, Persson S, Sundqvist G. Influence of infection at the time of root filling on the outcome of endodontic treatment of teeth with apical periodontitis. Int Endod J. 1997;30(5):297-306.

91. Soler $\mathrm{F}$, Asensio MC, Fernández-Belda $\mathrm{F}$. Inhibition of the intracellular $\mathrm{Ca}(2+)$ transporter SERCA (Sarco-Endoplasmic Reticulum $\mathrm{Ca}(2+)$-ATPase) by the natural polyphenol epigallocatechin-3-gallate. J Bioenerg Biomembr. 2012;44(5):597-605.

92. Sood N, Nagpal S, Nanda S, Bhardwaj A, Mehta A. An overview on stimuli responsive hydrogels as drug delivery system. J Control Release. 2013

93. Sotomayor MDPT, Dias ILT, Lanza MRV, Moreira AB, Kubota LT. Aplicação e avanços da espectroscopia de luminescência em análises farmacêuticas. Quim. Nova. 2008;31(7),1755-74.

94. Stapleton PD, Taylor PW. Methicillin resistance in Staphylococcus aureus: mechanisms and modulation. Sci Prog. 2002;85(Pt 1):57-72.

95. Subramanian P, Eswara U, Maheshwar Reddy KR. Effect of different types of tea on Streptococcus mutans: an in vitro study. Indian Journal of Dental Research: official publication of Indian Society for Dental Research 2012;23:43-8.

96. Tang DS, Shen SR, Chen $\mathrm{X}$, Zhang $\mathrm{YY}, \mathrm{Xu} \mathrm{CY}$. Interaction of catechins with aluminum in vitro. J Zhejiang Univ Sci. 2004;5(6):668-75. 
97. Téo TB, Takahashi MK, Gonzaga CC, Lopes MGK. Avaliação, após clareamento, da alteração de cor de dentes bovinos imersos em soluções com elevado potencial de pigmentação. Ver Sul-Bras Odontol. 2010; 7(4):401-5.

98. Tinaz AC, Kivanc BH, Gorgul G. Staining potential of calcium hydroxide and monochlorophenol following removal of $\mathrm{AH} 26$ root canal sealer. J Contemp Dent Pract. 2008;9:56-63.

99. Torchilin VP. Recent advances with liposomes as pharmaceutical carriers. Nat Rev Drug Discov. 2005;4(2):145-60.

100. Trevisanato SI, Kim YI. Tea and health. Nutr Rev. 2000;58(1):1-10.

101. Tronstad L. Recent development in endodontic research. Scand J Dent Res. 1992;100(1):52-9.

102. Vestergaard $P$, Hermann AP, Gram J, Jensen LB, Eiken $P$, Abrahamsen B, Brot $C$, Kolthoff N, Sørensen OH, Beck Nielsen H, Pors Nielsen S, Charles P, Mosekilde L. Evaluation of methods for prediction of bone mineral density by clinical and biochemical variables in perimenopausal women. Maturitas. 2001;40(3):211-20.

103. Victorino FR, Bramante CM, Zapata RO, Casaroto AR, Garcia RB, de Moraes IG, Hidalgo MM. Removal efficiency of propolis paste dressing from the root canal. J Appl Oral Sci. 2010;18(6):621-4.

104. Wu P-P, Kuo S-C, Huang W-W, Yang J-S, Lai K-C, Chen H-J, Lin K-L, ChiuY-J, Huang LJ, Chung J-G (-)-Epigallocatechin gallate induced apoptosis in human adrenal cancer $\mathrm{NCI}-\mathrm{H} 295$ cells through caspase-dependent and caspase -independent pathway. Anticancer Res. 2009; 29:1435-42.

105. Yang CS, Wang X. Green tea and cancer prevention. Nutr Cancer. 2010;62(7):931-7.

106. Yang GY, Liao J, Kim K, Yurkow EJ, Yang CS. Inhibition of growth and induction of apoptosis in human cancer cell lines by tea polyphenols. Carcinogenesis. $1998 ; 19(4): 611-6$.

107. Yannikakis SA, Zissis AJ, Polyzois GL, Caroni C. Color stability of provisional resin restorative materials. J Prosthet Dent. 1998;80:533-9.

108. Yin S-T, Tang $M-L$, Deng $H-M$, Xing $T-R$, Chen J-T, Wang $H-L$, Ruan D-Y. Epigallocatechin-3-gallate induced primary cultures of rat hippocampal neurons death linked to calcium overload and oxidative stress. Naunyn-Schmied Arch Pharmacol. 2009 379:551-64.

109. Yoda Y, Hu ZQ, Zhao WH, Shimamura T. Different susceptibilities of Staphylococcus and Gram-negative rods to epigallocatechin gallate. J Infect Chemother. 2004;10(1):55-8.

110. Yoncheva K, Momekov G. Antiangiogenic anticancer strategy based on nanoparticulate systems. Expert Opin Drug Deliv. 2011;8(8):1041-56. 
111. Yun JH, Kim CS, Cho KS, Chai JK, Kim CK, Choi SH. (-)-Epigallocatechin gallate induces apoptosis, via caspase activation, in osteoclasts differentiated from RAW 264.7 cells. J Periodontal Res. 2007;42(3):212-8.

112. Zhao Y, Chen L, Yakubov G, Aminiafshar T, Han L, Lian G. Experimental and theoretical studies on the binding of epigallocatechin gallate to purified porcine gastric mucin. J Phys Chem B. 2012;116(43):13010-6.

113. Zheng $X$, Chen A, Hoshi T, Anzai J, Li G. Electrochemical studies of (-)-epigallocatechin gallate and its interaction with DNA. Anal Bioanal Chem. 2006;386(6):1913-9. 



\section{Anexos}



Anexo A

\section{UNIVERSIDADE DE SÃO PAULO \\ FACULDADE DE ODONTOLOGIA DE RIBEIRÃO PRETO \\ Comissăo de Pesquisa}

Of. $\mathrm{CPq} 322 / 2012$

Ribeirão Preto, 13 de setembro de 2012.

Ref. proc. $n^{\circ} \underline{2011.1 .1450 .58 .4}$

Prezado(a) Orientador(a),

Informamos que a Comissão de Pesquisa, em sua 179a Sessão, realizada em 13 de setembro de 2012, aprovou o relatório Final do Projeto de Pesquisa intitulado "Estudo das propriedades físico-químicas da EGCG-3 e da alteração de cor causada após sua aplicação em dentes deciduos e permanentes", desenvolvido pelo(a) acadêmico(a) Bruna Santos Honorio Tonin, referente à bolsa do Programa de Iniciação Cientifica - Institucional (2011-2012).

$\mathrm{Na}$ oportunidade, lembramos da obrigatoriedade de entregar a cópia do certificado de participação no SIICUSP - Simpósio Internacional de Iniciação Científica da Universidade de São Paulo, na Secretaria da Comissão de Pesquisa da FORP/USP, até 30 de novembro de 2012.

Atenciosamente,

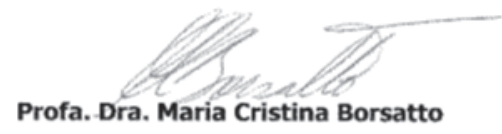

Presidente da Comissão de Pesquisa

Ilmo(a). Sr(a)

Prof(a). Dr(a). Andiara De Rossi

Departamento de Clínica Infantil, Odontologia Preventiva e Social

desta Faculdade 


\section{ANeXo B}

\section{Product|nformation}

\section{(-)-EPIGALLOCATECHIN GALLATE}

Sigma Prod. No. E4143

Store at $2-8^{\circ} \mathrm{C}$

CAS NUMBER: $989-51-5$

SYNONYM: (2R,3R)-2-(3,4,5-Trihydroxyphenyl)3,4-dihydro-1(2H)-benzopyran-3,5,7-triol 3-(3,4,5trihydroxybenzoate); (-)-Epigallocatechin 3-Ogallate; $\mathrm{EGCG}^{1}$

\section{PHYSICAL DESCRIPTION:}

Appearance: powder

Molecular formula: $\mathrm{C}_{22} \mathrm{H}_{18} \mathrm{O}_{11}$

Molecular weight: 458.4

Melting point: $218^{\circ} \mathrm{C}^{1}$

$E^{M}(275 \mathrm{~nm})=11,500$ (ethanol $)^{1}$

Optical rotation: $-185^{\circ} \pm 2^{\circ}$ (ethanol)

STORAGE / STABILITY AS SUPPLIED:<smiles>O=C(O[C@H]1Cc2c(O)cc(O)cc2O[C@@H]1c1cc(O)c(O)c(O)c1)c1cc(O)c(O)c(O)c1</smiles>

\section{SOLUBILITY:}

This is soluble in water at least to $5 \mathrm{mg} / \mathrm{mL}$, giving a clear faint yellow solution. The stability of a solution of this product in water at a concentration of $0.3 \mathrm{mg} / \mathrm{mL}$ was tested. A sample left for 2.5 hours at room temperature was found to have significantly decreased in purity (from $99.6 \%$ to $81.7 \%$, by HPLC). A sample left for 2 hours at $4^{\circ} \mathrm{C}$ was found to have decreased only slightly (from $99.5 \%$ to $99.3 \%$ ).

\section{GENERAL NOTES:}

Epigallocatechin gallate (EGCG) is a polyphenolic compound found in green tea leaves. Studies with EGCG indicate it has antitumor promoting activity. ${ }^{1,2}$

\section{METHOD OF PREPARATION:}

It is isolated by extracting the tea leaves with hot water, back-extracted with ethyl acetate. The EGCG is chromatographically isolated from the organic phase. ${ }^{3}$ 


\section{(-)-EPIGALLOCATECHIN GALLATE}

Sigma Prod. No. E4143

\section{HPLC SYSTEM: ${ }^{4}$}

Column: YMC ODS-A $15 \mathrm{~cm} \times 4.6 \mathrm{~mm}$ ID Particle size $5 \mu \mathrm{m}$

Mobile phase:acetonitrile:ethyl acetate:0.05\% $\mathrm{H}_{3} \mathrm{PO}_{4}(12: 2: 86)$

Flow rate: $1.0 \mathrm{~mL} / \mathrm{min}$

Solvent: Product dissolved at $0.3 \mathrm{mg} / \mathrm{mL}$ in water, $20 \mu \mathrm{L}$ injected

Detection at $280 \mathrm{~nm}$

Retention time for major peak $\approx 12$ minutes

Determination of this compound in plasma and urine by HPLC has been reported. ${ }^{5}$

\section{REFERENCES:}

1. Merck Index, 12th ed., \#3568 (1996).

2. Yamane, T. et al., Cancer Res., 55, 2081 (1995).

3. Supplier information.

4. Sigma quality control.

5. Lee, M.-J. et al., Cancer Epidemiol. Biomark. Prev., 4, 393 (1995).

Sigma warrants that its products conform to the information contained in this and other SigmaAldrich publications. Purchaser must determine the suitability of the product(s) for their particular use. Additional terms and conditions may apply. Please see reverse side of the invoice or packing slip. 